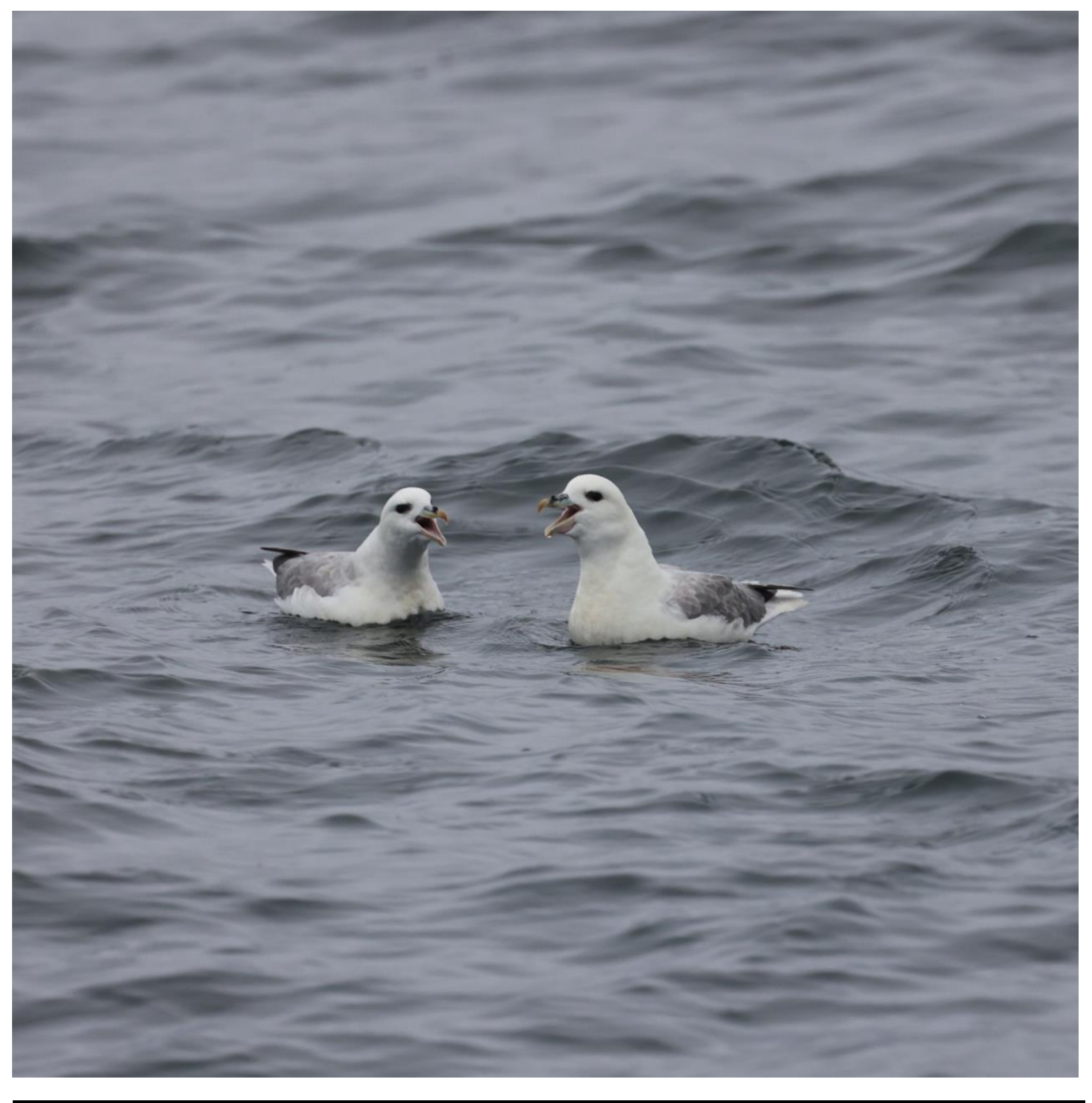

\title{
Fulmar Litter Threshold Value Monitoring in the Netherlands - Update 2020
}

Den Helder, September 2021

Authors: Susanne Kühn, André Meijboom, Oliver Bittner \& Jan Andries van Franeker 


\section{Keywords:}

OSPAR-EcoQO; MSFD-GES; Fulmar Threshold Value (FTV); KRM-GMT; Fulmarus glacialis; monitoring; marine litter; plastic ingestion

$\begin{array}{lll}\text { Wageningen } & \text { Offerte nr: } & 20.43 .17 \\ \text { Marine } & \text { project nr: } & 4315100164 \\ \text { Research } & \text { project name: } & \text { Fulmar-EcoQO-NL2020-26 } \\ \text { references: } & \text { contact: } & \text { Dr. Susanne Kühn, Wageningen Marine Research } \\ & & \text { Ankerpark 27, 1781 AG Den Helder, The Netherlands } \\ & & \text { E: susanne.kuehn@wur.nl T: +31317 } 480459\end{array}$

Client Ministry of Infrastructure and Water Management

references: RWS Water, Traffic and Living Environment (RWS-WVL)) RWS-CIV, PO Box 2232, 3500 GE Utrecht, The Netherlands

contact: Ing. Mervyn Roos [E: mervyn.roos@rws.nl T: +31 612218134$]$

RWS bestelnr: 4500306134 / RWS zaaknr: 31165910

Opdrachtbrief: RWS-2021/565 dated 14 Jan 2021

Title at RWS: $\quad$ "Monitoring plastics in magen van Noordse stormvogels"

This report can be downloaded for free from https://doi.org/10.18174/553736

Wageningen Marine Research provides no printed copies of reports

Wageningen Marine Research is ISO 9001:2015 certified.

Photo cover: Northern Fulmars in conversation, Isafjardardjup, Iceland If not stated differently, all photos in this document were made by the authors.

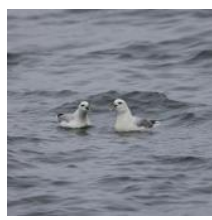

\section{(C) Wageningen Marine Research}

Wageningen Marine Research, instituut binnen de rechtspersoon Stichting Wageningen Research, hierbij vertegenwoordigd door Drs.ir. M.T. van Manen, directeur bedrijfsvoering

KvK nr. 09098104 WMR BTW nr. NL 8113.83.696.B16. Code BIC/SWIFT address: RABONL2U IBAN code: NL 73 RABO 0373599285
Wageningen Marine Research aanvaardt geen aansprakelijkheid voor gevolgschade, noch voor schade welke voortvloeit uit toepassingen van de resultaten van werkzaamheden of andere gegevens verkregen van Wageningen Marine Research. Opdrachtgever vrijwaart Wageningen Marine Research van aanspraken van derden in verband met deze toepassing. Alle rechten voorbehouden. Niets uit deze uitgave mag weergegeven en/of gepubliceerd worden, gefotokopieerd of op enige andere manier gebruikt worden zonder schriftelijke toestemming van de uitgever of auteur.

\section{A_4_3_1 V31 (2021)}




\section{Contents}

$1 \quad$ Introduction

2 The Fulmar as an ecological monitor of marine litter

$3 \quad$ Materials and Methods

$4 \quad$ Results \& Discussion

4.1 The year 2020

4.2 Current levels for the Netherlands (2016-2020) 29

4.3 Trends 38

4.3.1 Long-term trends 38

4.3.2 Recent trends $\quad 39$

4.4 Dutch data in terms of the OSPAR Fulmar-TV metric $\quad 44$

4.5 Modelling future Fulmar-TV Performance. 46

$\begin{array}{llr}5 & \text { Concluding remarks } & 50\end{array}$

$6 \quad$ Acknowledgements $\quad 51$

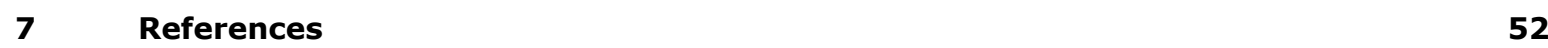

$8 \quad$ Main acronyms - abbreviations $\quad 60$

9 Quality Assurance $\quad 62$

$\begin{array}{llr}10 & \text { Justification } & 63\end{array}$ 


\section{SUMMARY}

\section{Fulmar Litter Threshold Value monitoring in the Netherlands - Update 2020}

Marine debris has serious economic and ecological consequences. Economic impacts are most severe for coastal communities, tourism, shipping and fisheries. Marine wildlife suffers from entanglement and ingestion of debris, with micro-particles potentially affecting marine food chains up to the level of human consumers. In the North Sea, marine litter problems were firmly recognized in 2002 when surrounding states assigned to OSPAR the task to include marine plastic litter in its system of Ecological Quality Objectives (EcoQOs) (North Sea Ministerial Conference 2002). At that time, in the Netherlands, marine litter was already monitored by the abundance of plastic debris in stomachs of a seabird species, the Northern Fulmar (Fulmarus glacialis). In 2020 the fulmar EcoQO was formally replaced by OSPAR and is now called Fulmar Threshold Value (Fulmar-TV). See the info box for more background information.

\section{Info Box}

\section{From Fulmar EcoQO to Fulmar Threshold Value}

The regular reader of these annual reports will have noticed some changes in terminology. This update of fulmar litter monitoring does not longer refer to the OSPAR Ecological Quality Objectives (ECOQO) but to the OSPAR/EU-MSFD Fulmar Threshold Value (Fulmar-TV). The background of this change lays in policy developments within the European Union. The Dutch monitoring approach using beached fulmars was developed for international implementation by OSPAR* as one of its ECoQOs for the North Sea (OSPAR 2008, 2009, 2010a,b; Van Franeker et al. 2011). This approach is now also implemented as an indicator for 'Good Environmental Status (GES)' in the Marine Strategy Framework Directive (MSFD*) (EC 2008, 2010, 2017; Galgani et al. 2010; MSFD-TSML 2011, 2013). International guidelines on the monitoring methods and data presentation have been published (OSPAR 2015a,b) and were implemented in 'Intermediate Assessments' (OSPAR 2017, 2019). (* acronyms further explained in Chapter 8).

The European MSFD aims for Good Environmental Status by the year 2020 and defines this for marine litter as the situation in which "properties and quantities of marine litter do not cause harm to the coastal and marine environment". The concept of 'no harm' is difficult to quantify (Rochman et al. 2016; Werner et al. 2016). Therefore it was agreed on, that an alternative concept may be sufficient, where the threshold should be close to pollution levels in nearly-pristine areas. Such threshold value for plastics in fulmars has been proposed and is closely related to the OSPAR ECOQO, but has an improved data and statistical basis (Van Franeker et al. 2021):

'Over a period of at least five consecutive years, no more than $10 \%$ of northern fulmars (Fulmarus glacialis) in samples of at least 100 birds may exceed the level of $0.1 \mathrm{~g}$ of plastic particles in the stomach.'

Standard procedures for dissection and stomach analyses have been documented in a manual, reports, scientific literature and formal OSPAR guidelines. Although the 'OSPAR Coordinated Environmental Monitoring Program' (CEMP) and assessment guidelines (OSPAR 2015a,b) have been designed to provide detailed data analyses and statistics, the focus of this summary report is on the most policy relevant aspect: that is the proportion of fulmars exceeding a threshold level of $0.1 \mathrm{gram}$ of plastic in the stomachs. The Fulmar Threshold Value (Fulmar-TV or FTV) in the above definition is thus that the FTV\% will be reduced to under $10 \%$ (Van Franeker et al. 2021).

The scientifically derived Fulmar-TV, as proposed by Van Franeker et al. (2021) has been formally accepted in OSPAR as a replacement of the earlier ECOQO (OSPAR 2020). The formal acceptance of the same Fulmar-TV by the EU MSFD is expected soon. In line with these new developments we were asked by RWS to change the terms used in this report from EcoQO to Fulmar-TV.

Fulmars are purely offshore foragers that ingest all sorts of litter from the sea surface and normally do not regurgitate poorly degradable diet components like plastics. Initial size of ingested debris is usually in the range of three to five millimetres to centimetres, but may be considerably larger for flexible items as for instance threadlike or sheetlike materials (Bravo Rebolledo 2012). Items must 
gradually wear down in the muscular stomach to a size small enough to pass into the intestines. During this process, plastics accumulate in the stomach to a level that integrates litter levels encountered in their foraging area for a period of probably up to a few weeks (van Franeker and Law 2015). The monitoring system uses fulmars found dead on beaches, often slowly starved but also accidentally killed e.g. as in fisheries bycatch. In a pilot study, it has been shown that the amount of plastic in stomachs of slowly starved beached birds was not statistically different from that of healthy birds killed in instantaneous accidents in the same area (van Franeker and Meijboom 2002).

\section{The $\mathbf{2 0 2 0}$ update of monitoring data for the Netherlands}

This report adds new data for year 2020 to the earlier report (Van Franeker \& Kühn, 2020). A total of 18 fulmar corpses were collected, of which 15 contained stomachs. Annual numbers of beached birds may vary considerably for unknown reasons. For our monitoring purposes, we do not use birds that have spent more than 3 days alive under human care, because particles break and wear down in the muscular stomach and disappear through the intestines (Van Franeker \& Law 2015) and are not replaced by new plastics from the marine environment. In 2020, we did receive some fulmars from rehabilitation centres, but only one had survived more than three days in care, so all but this individual could be used. This means 14 stomachs were available for the 2020 data calculations. No additional fulmars from previous years were analysed. Potential late deliveries can slightly alter earlier published data. The desired annual sample size is \pm 40 birds or more (Van Franeker \& Meijboom 2002). Smaller annual samples, like in 2020 , are not a problem for the monitoring system but may delay the detection of significant trends.

The OSPAR long-term target requires an FTV\% under 10\% for at least 5 consecutive years. Therefore data are also pooled in 5-year periods, as 'current period' in Table $i$. Over the most recent 5 years (2016-2020), in a sample of 139 birds, 39\% of stomachs contained more than $0.1 \mathrm{~g}$ plastic (FTV\%). Although this is (together with the previous period 2015-19) the best FTV-performance in the Dutch monitoring program, it clearly is still far off the OSPAR Fulmar-TV. In this sample, $93 \%$ of fulmars contained some plastic, with an average over all birds of 22.5 plastic particles per stomach, weighing $0.21 \mathrm{gram}$.

The 2020 sample does not continue the decreasing trend seen in the last few years. Although the percentage of birds with plastics remains the same, the average fulmar had 31 plastic particles weighing $0.42 \mathrm{~g}$, and 6 out of 14 birds exceeded the $0.1 \mathrm{~g}$ level (43\%). These figures exceed those of 44 birds in 2019, when the average number of plastic pieces was 11 and the average mass was 0.09 gram per bird. Because of the small size of our 2020 sample it remains unclear if this is an unusual year.

This report includes data on chemical stomach contents, specifically paraffin-like substances for the first time. In $2020,21 \%$ of the analysed fulmars contained some paraffin-like substances, on average weighing $0.041 \mathrm{gram}$.

Table i. Data summary for study year added to the existing monitoring series. The table presents actual year or period of sampling with sample size in brackets, and then the percentage of birds that exceeds $0.1 \mathrm{~g}$ of plastic mass in the stomach (FTV\%), followed by details for the proportion of birds with any plastic particles (Frequency of Occurrence; \%FO) the average number of particles ( $n$ ) and the associated average mass of plastic per bird in gram $(g)$.

\begin{tabular}{|c|c|c|c|c|c|}
\hline year & (sample size) & FTV\% & $\% \mathrm{FO}$ & average $\mathbf{n}$ & average \\
\hline $\begin{array}{c}2020 \\
\text { period }\end{array}$ & (14) & $43 \%$ & $93 \%$ & 30.9 & 0.42 \\
\hline 2016_20 & (139) & $39 \%$ & $93 \%$ & 22.5 & 0.21 \\
\hline
\end{tabular}




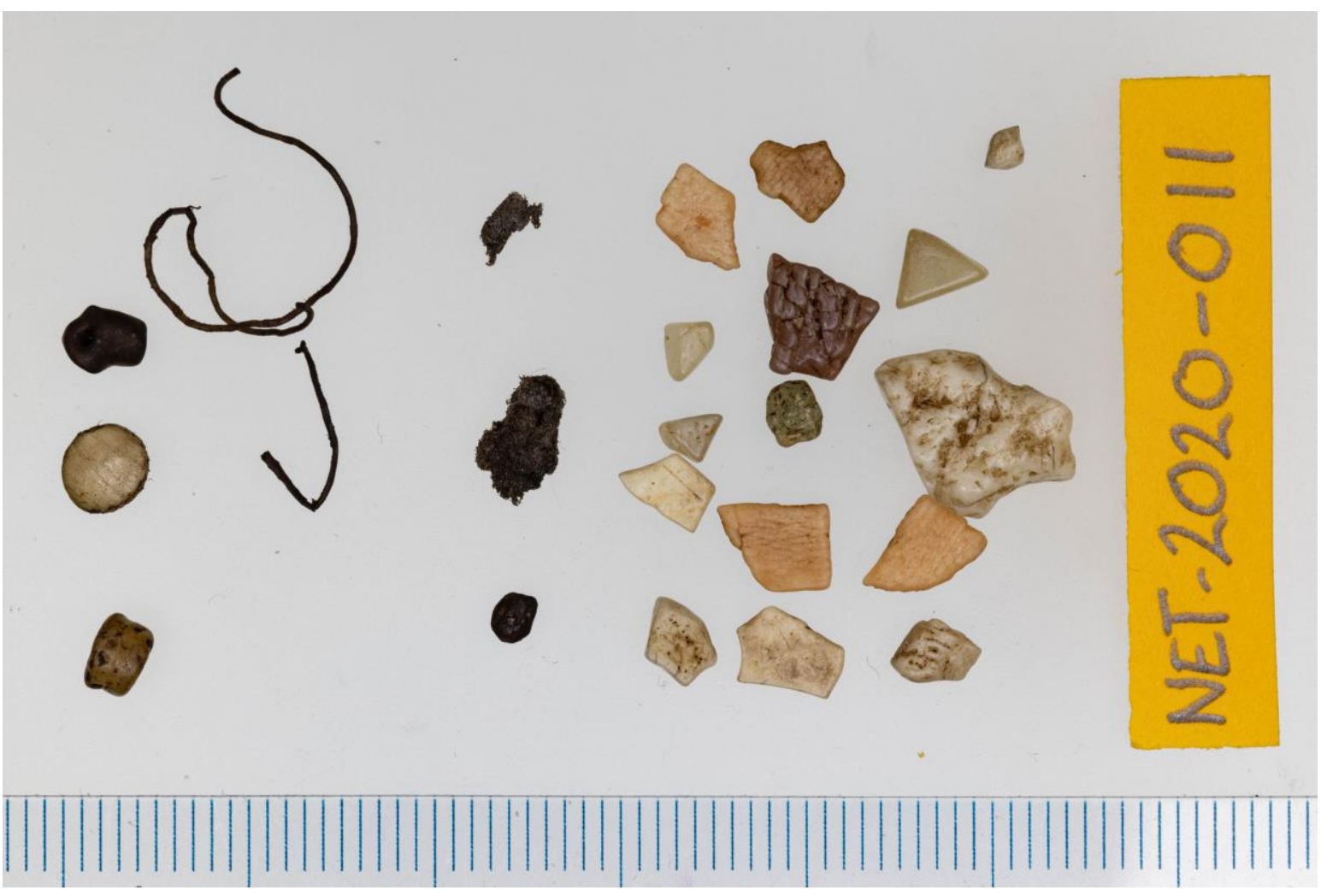

Photo 1. A representative fulmar stomach content for the year 2020. On average, fulmars from the Dutch coast in 2020 contain about 31 plastic particles weighing $0.42 \mathrm{~g}$ (Table i). The stomach content on the photo (NET-2020-011) is then a fairly representative example. With 23 plastic particles it has a lower number of particles but a representative plastic mass of $0.4455 \mathrm{~g}$. This bird was an emaciated (starved) juvenile male, collected on Schiermonnikoog and stored at Faunavisie Wildcare before dissection. The stomach contained three pellets (left), two threads (centre left), three black pieces of foam (centre) and 15 fragments (right).

\section{Trend and prediction}

In order to provide policy makers with simple straightforward information, this summary report focuses on a new predictive model to estimate when in future the Fulmar-TV may be reached if the current trend persists. This model simply uses the existing annual figures for sample size plus the number of birds within that sample exceeding the $0.1 \mathrm{~g}$ threshold. These data are analysed in a General Linearized Model (GLM) which uses a logistic approach to binomial data (bird yes or no above threshold) resulting in a trend within the observed data, which if statistically significant can be extrapolated to the future. OSPAR guidelines request trend analyses of ingested plastic mass to be conducted over a recent 10-year period, but that applies to a large number of individual bird data over those years. The new GLM calculation has only one data-point per year, and longer time series are recommended. In relation to international comparisons we focus on the period starting 2002, the year when international fulmar monitoring was started in the EU Interreg IIB project 'Save the North Sea' (Save the North Sea, 2004).

GLM analysis over the 19-year period 2002-2020 for the Netherlands indicated a highly significant improvement in Fulmar-TV performance (FTV\% decreased significantly at $\mathrm{p}<0.001 ;$ Fig. $i$ ). When the calculated trend is projected into the future, results suggest that the OSPAR Long-term target may be reached in year 2049. 


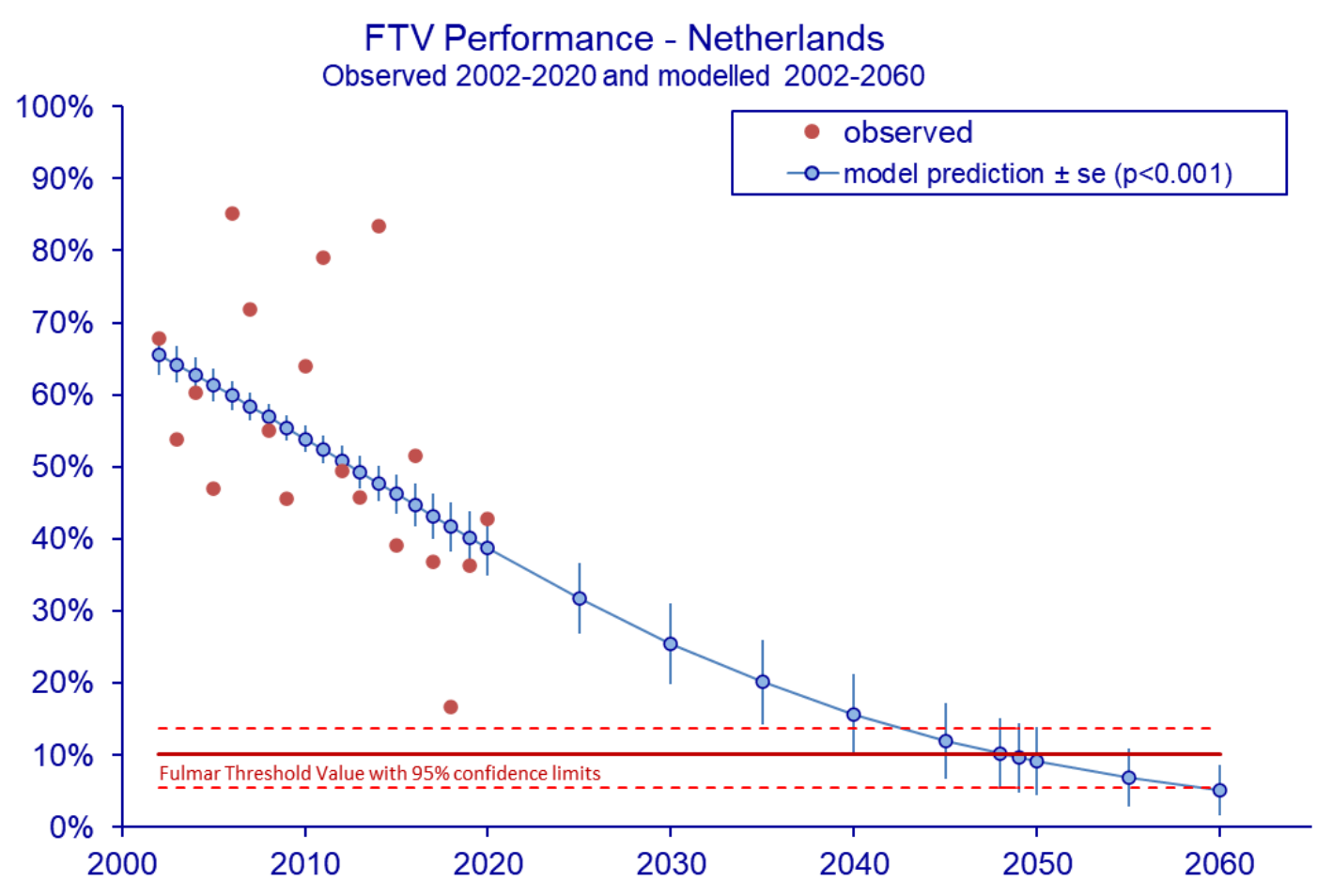

Figure i. GLM model analyses of annual Fulmar-TV Performance using 19 years of fulmar data (2002-2020). Observed data are the red circles in the graphs. When the model is significant, the predicted annual values and standard errors (vertical lines) are shown by blue closed circles and solid lines, connected by a trendline. When the model from observed data is not significant, predicted values and standard error lines are dashed, and no trendline is shown.

It has to be emphasized that the predictive trendline does not imply that no further action is needed. The model predicts the future development if we continue, at the same rate as we have done so far, to take and maintain new policy measures and if we continue to create further changes in awareness and behaviour. No extra effort means that the trendline will level off and that the Fulmar-TV will not be reached. Intensifying further measures and efforts could mean that the target might be reached earlier than predicted by the current model.

Existing OSPAR guidelines (2015a,b) prescribe the tests for trends over time as analyses over the most recent 10 years, using linear regression analyses of log transformed values of individual plastic mass against year of collection. Those tests (see Table 4C) do show negative correlations between plastics and the year of observation (2011-2020; 298 birds: $p=0.018$ ). Over the 2002-2020 period as used in the GLM procedure, the test is significant ( 790 birds: $p=0.002$ ). So both approaches indicate a statistically significant gradual decrease in plastics ingested by fulmars.

A non-statistical way to illustrate and double-check the trends in plastic ingestion over time is by comparison of separate age classes. Monitoring results are mostly presented for birds of all ages together, but the pilot study for the fulmar monitoring project (Van Franeker \& Meijboom 2002) showed that younger birds on average carry a higher load of ingested plastic than adult birds. As long as age composition shows no substantial persistent change, age groups may be combined. The difference between age groups should also be reflected in the respective EcoQO data. Fig. ii illustrates EcoQ Performance for separate adult and non-adult age groups. This is done by means of running 5year data-points because annual figures are often too variable (see the red data-points for observed data in Fig. i), and certainly so when sample size is reduced by splitting into subgroups. Data for the 1980s have been grouped into a single data-point. The graph clearly illustrates similarity in trends for the separate age groups both in a longer-term and in several shorter-term variations. This supports the validity of GLM modelling using annual data. Data from running 5-year averages cannot be used for statistical trend analysis as those figures entail repeated use of the same individuals. 


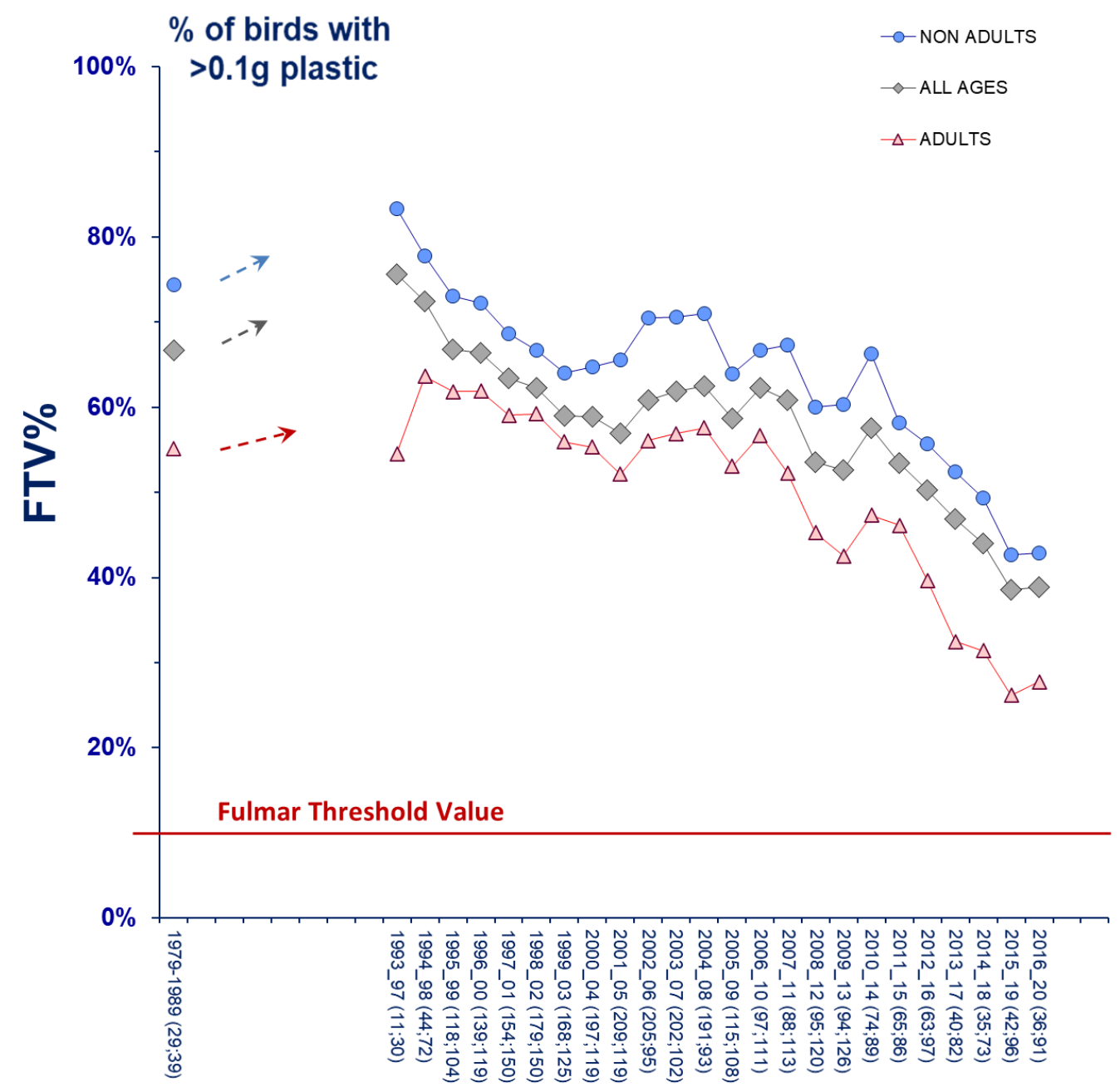

5-year period (sample size adult; non-adult)

Figure ii. Visualisation of Fulmar-TV performance of different age classes of beached fulmars from the Netherlands 1979-2020. Trendlines for all birds combined (grey diamonds, including birds of unknown age), for adult birds (red triangles) and for non-adults (blue circles). This graphic visualization is based on a single data-point for the 1980s and overlapping running 5-year averages in later periods. Periods with less than 10 birds in the sample during the late 1980s and early 1990s are not shown in the graph. This visualization in itself does not represent a statistical trend analysis.

It is difficult to pinpoint specific events that may have triggered increases in ingested plastics from the 1980 s into the 1990s, and subsequent decreases. Different trends for industrial plastics and consumer waste complicate the issue. Since the start of the Save the North Sea project in 2002 and up to 2014, no significant trends were detected in the ingested mass of plastics over 10-year time series.

However, starting with 10-year period 2006-2015 an in absolute terms moderate, but statistically significant decrease in ingested plastic mass was observed. This slow change has persisted over later decades, usually close to or statistically significant for both plastic types or their combination (Table 4D). Ongoing significant reduction may be considered an intermediate aim in terms of the European MSFD and GES by the year 2020, but will be hard to show at a significant level within 10-year periods. The 2011-2020 period showed significant reduction in ingested mass of industrial plastic, user plastic and their combined total, however the reduction is less prominent than in previous years.

\section{MAIN POINTS}


1. North Sea governments aim at a long-term OSPAR Ecological Quality Objective (EcoQO) in which for at least 5 consecutive years, the proportion of fulmars with more than 0.1 gram of plastic in the stomach remains under $10 \%$. The EU Marine Strategy Framework Directive (MSFD) has set the same figure as its final threshold, with intermediate targets to be defined. The proportion of birds having more than $0.1 \mathrm{~g}$ plastic in the stomach is referred to as EcoQ-performance or EcoQ\%.

2. Over the 5-year period 2016-2020, EcoQ Performance among 139 fulmars beached in the Netherlands was $39 \%$. In this period, $93 \%$ of fulmars had ingested some plastic, with an average over all birds of 22.5 particles per stomach, weighing $0.21 \mathrm{gram}$.

3. For the first time, data on chemicals in fulmar stomachs are reported within this Fulmar EcoQO report series. In $2020,21 \%$ of the analysed fulmars contained some paraffin-like substances, on average weighing $0.041 \mathrm{gram}$. Over the 5-year period 2016-2020 19\% of the birds had ingested such substance, with an average mass of $0.882 \mathrm{gram}$.

4. Although still far from the OSPAR long-term target, the current 5-year dataset is again the best on record since the start of the monitoring program.

5. Trend analyses over the years 2002-2020 indicate a significant decrease in annual EcoQ\% suggesting that the EcoQO may be reached in the year 2049, which is similar to the previous prediction (2048).

6. It is not possible to pinpoint single clear causes for the observed changes. Gradual improvement since the early 2000 s may be linked to media attention for oceanic garbage patches and plastic soup. Increased awareness among all stakeholders may slowly lead to gradually improved policy measures and implementation by marine industries and general public.

7. The model prediction is not based on a status-quo, but on the current rate of change, which is assumed to reflect intensified policy measures and improved awareness and behaviour. This implies that the predicted future change will require further policy measures and further changes in stakeholder awareness and behaviour. Without extra effort, it is unlikely that the EcoQO target could be reached in the predicted time period.

\section{CONCLUSION}

Stomach contents of fulmars beached in the Netherlands indicate that the marine litter situation off the Dutch coast is gradually improving, but still far off the Fulmar-TV. Within 10-year evaluation periods the trend is not consistently significant, but considered over the longer period since 2002 it is. At the current rate of the trend, the Fulmar-TV may be reached around the year 2049.

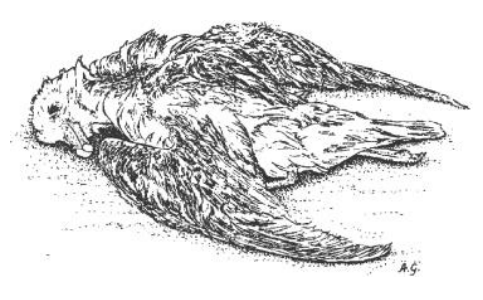




\section{Info box:}

\section{Changing of the guard}

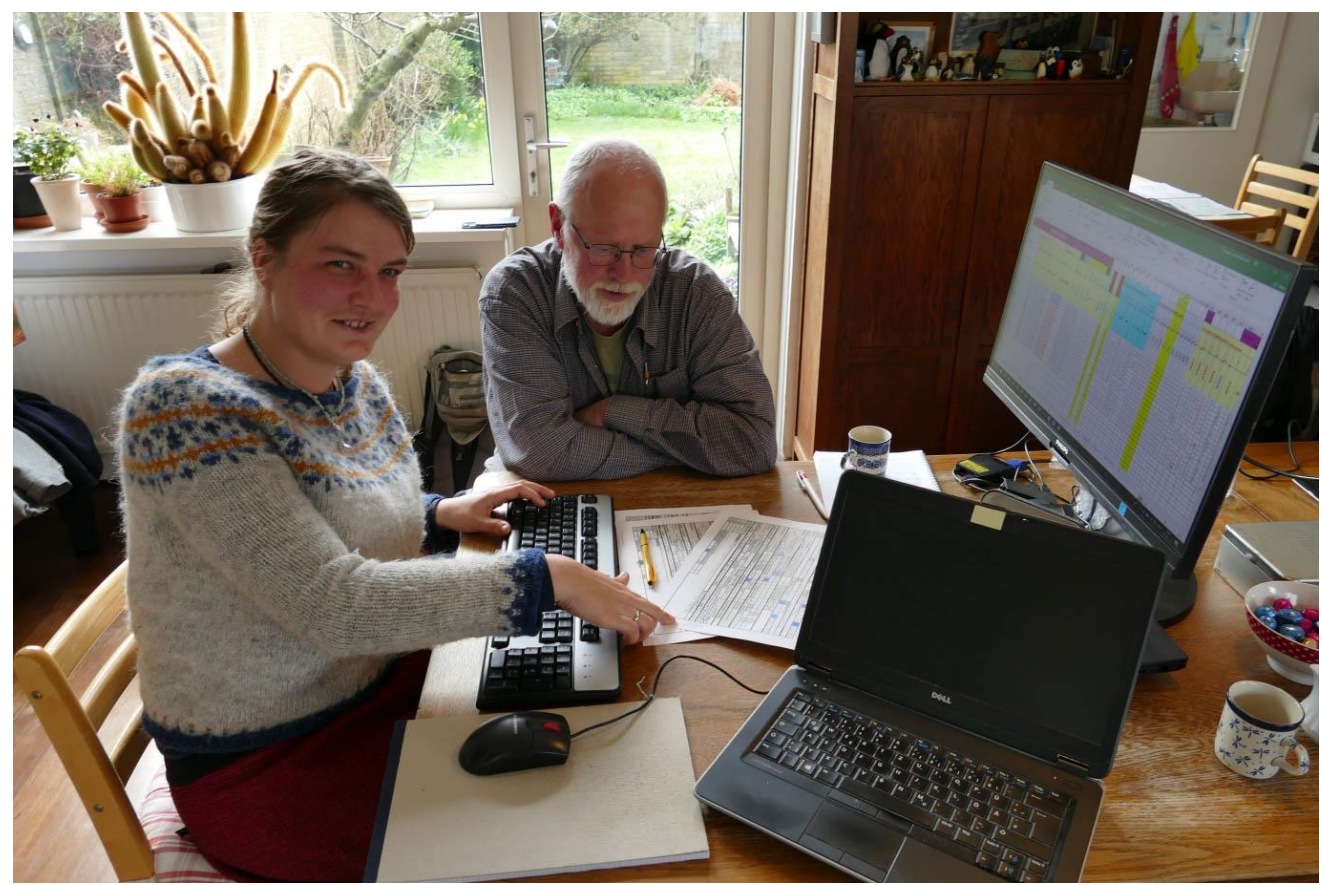

Photo 2. Teaching data input, Texel 22 March 2020 (Photo by Nils Guse).

As of the first of January 2021, Jan Andries van Franeker has retired. With heart and soul, he has dedicated his research to Antarctic ecosystems and the problems of marine plastic litter. His job started in February 1986 at the Dutch Institute for Nature Management (RIN) on Texel and was continued under later institutional names IBN, ALTERRA, IMARES and finally Wageningen Marine Research in Den Helder. His responsibilities in marine litter studies have been transferred to Susanne Kühn. Susanne did her bachelor study on Coastal and Marine Management in Leeuwarden (Netherlands) which included an internship at the German research institute FTZ. Here she met her first fulmars at sea, when joining several seabird surveys on the North Sea. Her second internship led her to Iceland. Here, under partial guidance from Jan she studied the ingestion of plastic litter by Icelandic fulmars. After this initial project, Susanne remained involved in studies on plastic ingestion not just in fulmars, but also in other marine biota, such as other seabirds, whales and fish. In 2016, Susanne started a PhD in Jan's team at Wageningen Marine Research and Wageningen University. Susanne successfully defended her thesis in October 2020, titled 'Message in a belly - Plastic pathways in Fulmars' (Kühn 2020). In 2020, Susanne started as a Researcher at Wageningen Marine Research, taking over the marine litter projects, in which she hopes to work together with retired Jan for many years to come. 


\section{Introduction}

Marine litter, in particular plastic waste, represents an environmental problem in the North Sea and elsewhere, with considerable economic and ecological consequences. In 2005, a large study along the full $30 \mathrm{~km}$ coast length of the island of Texel revealed that each day, on each $\mathrm{km}$ of beach, 7 to $8 \mathrm{~kg}$ of debris washed ashore (Van Franeker 2005). Roughly half of the debris was wood, the other half was synthetic materials, with minor contributions from other materials such as glass and metals. On Texel, the main source of the debris, estimated at up to $90 \%$ of mass, was related to activities at sea, i.e. shipping, fisheries, aquaculture and offshore industries.

The economic consequences of marine litter affect many stakeholders. Coastal municipalities are confronted with excessive costs for beach clean-ups. Tourism suffers damage because visitors avoid polluted beaches especially when health-risks are involved. Fisheries are confronted with a substantial bycatch of marine litter, which causes loss of time, damage to gear, and tainted catch. Shipping suffers financial damage and -more importantly- safety-risks from fouled propellers or blocked waterintakes. Marine litter blowing inland can even seriously affect farming practices. The overall economic damage from marine litter is difficult to estimate, but a detailed study in the Shetlands with additional surveys elsewhere indicate that even local costs may run into millions of Euros (Hall 2000; Lozano \& Mouat 2009; Mouat et al. 2010; Newman et al. 2015).

The ecological consequences of marine litter are most obvious in the suffering and death of marine birds, turtles or mammals entangled in debris. Entangled whales are front-page news and attract a lot of public attention. However, only a small proportion of entanglement mortality becomes visible among beached animals. Even less apparent are the consequences from the ingestion of plastics and other types of litter. Ingestion is extremely common among a wide range of marine species including many seabirds, marine mammals and turtles (Laist 1987, 1997; Derraik 2002; Kühn et al. 2015; Kühn \& Van Franeker 2020). It can cause direct mortality but the major impact most likely occurs through reduced fitness of many individuals. 


\section{Info box \\ The $0.1 \mathrm{~g}$ plastic threshold and the $90 \%$ proportion rule in the Fulmar EcoQO target definition and the EU Fulmar-TV: history and application}

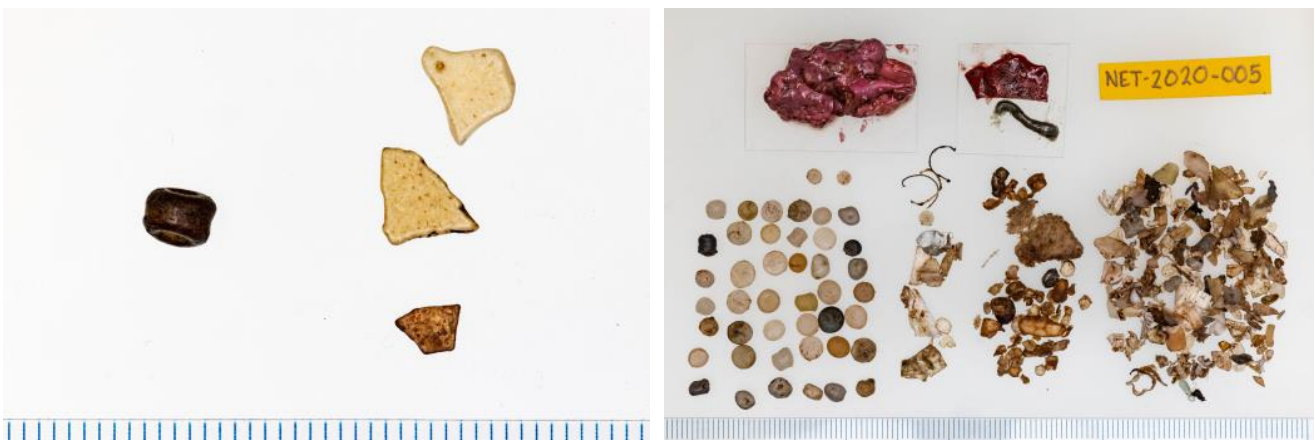

Photo 3. Near threshold value and extreme examples of plastics in fulmar stomachs from

2020. Fulmar NET-2020-015 (left photo) was collected by Carl Zuhorn on Vlieland had 4 plastic particles weighing 0.0932 gram (1 industrial pellet at left and 3 user plastics), so slightly below the threshold. The stomach of fulmar NET-2020-005 (right photo) was found by Yerko Hankmann on Texel and was the most extreme stomach in 2020 in terms of plastic number and mass. It contained 273 plastic particles weighing $4.2881 \mathrm{gram}$, so extremely high above the $0.1 \mathrm{~g}$ threshold. The plastics in this stomach consist of 44 pellets, (left), 9 sheets, 3 threads, 51 foam particles and 163 fragments (right). On top of the picture there are two balloon pieces and one rubber band. The Fulmar-TV implies that no more than 90\% of the birds must contain the amount of plastic or as on the left photo. The remaining $10 \%$ may exceed the limit of 0.1 gram without upper mass limit. The $10 \%$ threshold helps to correct for such outliers and reduce their influence on the total data set.

In the Fulmar EcoQO target definition, the threshold level ( $0.1 \mathrm{~g}$ of plastic) and the proportion of individuals that should be under this threshold (90\%) have a historical background. In early phases of discussions to install an ECOQO on marine litter in the North Sea, working groups in ICES (International Council for the Exploration of the Sea) and in OSPAR followed the concept already used in the ECoQO on oiled seabirds. This ECoQO for marine oil pollution used the common guillemot (Uria aalge) as its monitored species, and the accepted target for ecological quality was that the proportion of oiled specimens among beached individuals should be reduced to under $10 \%$.

In a similar approach, it was proposed that the amount of plastics in seabirds should remain under 10 particles in at least $90 \%$ of stomachs of beached specimens. As in the guillemot EcoQO there was no ecological or health background to the target. The general concept was that such pollutants do not belong in the natural environment at all, and will always cause some level of harm. The only reason to not set the target at zero oil or zero plastics (or zero harm) was that even under maximum precautionary behaviour, some accidental losses should be accounted for in policy targets. The target of $90 \%$ of fulmars having less than $0.1 \mathrm{~g}$ was an arbitrary ambitious level in a period when over $60 \%$ of birds exceeded that level.

It was only later that this arbitrary target could be shown to be realistic and achievable as fulmars in the relatively unpolluted areas of the high Canadian Arctic were found to have plastic levels in the stomach close to the long-term OSPAR target. Detailed evaluation of the Canadian data showed, that $10.06 \%$ of the 179 studied individuals exceeded the $0.1 \mathrm{~g}$ target, virtually the same proportion as the earlier OSPAR ECOQO, arbitrarily set at 10\% (Van Franeker et al. 2021).

Together with the 5-year averages (thus increased sample sizes) and geometric means, the EcoQO and now the similar Fulmar-TV target can compensate for outliers that may influence the overall picture or set some bias in trend or significance calculations. Some extreme outliers however may impact the data series, as can be seen in Figure $2 B$ of this report, where a single bird with 278 industrial pellets caused an increase for several 5-year periods.

Sub-lethal effects on animal populations remain largely invisible. In spite of spectacular examples of mortality caused by entanglement in, or ingestion of marine litter, the real impact on marine wildlife 
therefore remains difficult to estimate (Browne et al. 2015; Rochman et al. 2016; Werner et al. 2016). Plastics gradually break down to microscopically small particles, but these may pose an even more serious problem (Thompson et al. 2004). Leaching of toxic additives from ingested plastics to seabirds has been shown by Tanaka et al. (2013, 2015, 2019, 2020); Yamashita et al. (2018); and Kühn et al. (2020a). Microplastics can also adsorb and concentrate organic pollutants from the surrounding water, but experimental results and model predictions are not all in agreement concerning release of such chemicals into marine organisms or associated negative effects (Browne et al. 2013; Endo et al. 2005, 2013; Koelmans et al. 2013a,b, 2014, 2016; Moore 2008; Teuten et al. 2007, 2009; Rochman et al. 2013, 2014a,b; Tanaka et al. 2013; Thompson et al. 2009; Cole et al. 2015; CBD 2016; Beaman \& Bergeron 2016; Peda et al. 2016; Hermabessiere et al. 2017; Ribeiro et al. 2017). Thus, in addition to the toxic substances incorporated into plastics in the manufacturing process, plastics may concentrate pollutants from the environment and act as a pathway adding to their accumulation in marine organisms. Evidently, this same mechanism operates at all levels of organisms and sizes of ingested plastic material, from small zooplankton filter-feeders to large marine birds and mammals. However, it is especially the ingestion of microplastics by small filter-feeders that has emphasized the potential scale and urgency of the problem of marine plastic litter, as it may ultimately affect human food quality and safety as well (Hauser et al. 2015; Hunt et al. 2016). Concerns have also been expressed for the even smaller particles, those in the nano-size range $(<1 \mu \mathrm{m})$, which might penetrate into tissues and cells with potential chemical and mechanical damage to e.g. DNA but are extremely difficult to quantify in non-experimental situations (Koelmans et al. 2015; Booth et al. 2016; Gigault et al. 2016; Liu et al. 2016; Jahnke et al. 2017; Mintenig et al. 2018).

Recognizing the negative impacts from marine debris, a variety of international policy measures has attempted to reduce the input of litter. Examples of these are the London Dumping Convention 1972; Bathing Water Directive 1976; MARPOL 73/78 Annex V 1988; Special Area status North Sea MARPOL Annex V 1991; and the OSPAR Convention 1992. In the absence of significant improvements, political measures have been intensified by for example the EU-Directive 2000/59/EC on Port Reception Facilities (EC 2000; EU 2019), the Declaration from the North Sea Ministerial Conference (2002) in Bergen, and recently in a revision of MARPOL Annex V (MEPC 2011) and the European Marine Strategy Framework Directive (MSFD) 2008/56/EC (EC 2008; EC 2010; EC 2017).

Policy initiatives have recognized the need to use quantifiable and measurable aims. Therefore, the North Sea Ministers in the 2002 Bergen Declaration decided to introduce a system of Ecological Quality Objectives for the North Sea (EcoQOs) (North Sea Ministerial Conference 2002). For example, the oil pollution situation in the North Sea is measured by the rate of oil-fouling among beached Guillemots (Uria aalge) with an EcoQO target of less than $10 \%$ of beached Guillemots having oil on the plumage (OSPAR 2005). Similarly, as proposed by ICES Working Group on Seabird Ecology (ICES-WGSE 2003), OSPAR decided to use the abundance of plastic in stomachs of seabirds, in casu the Northern Fulmar (Fulmarus glacialis) to measure quality objectives for marine litter (OSPAR 2008, 2009, 2010a, 2010b, $2015 a, b)$. The fulmar EcoQO monitoring has been included as an indicator for marine litter in the approach for Good Environmental Status (GES) in the European Marine Strategy Framework Directive (EC 2010; MSFD GES Technical Subgroup on Marine Litter 2011).

Internationally, as of 2002, the Dutch fulmar research was expanded to all countries around the North Sea as a project under the Save the North Sea (SNS) program. Main initiators of the SNS campaign were the Keep Sweden Tidy Foundation and KIMO (see Chapter 8). SNS was co-funded by EU Interreg IIIB over period 2002-2004 and aimed to reduce littering in the North Sea area by increasing stakeholder awareness. The fulmar acted as the symbol of the SNS campaign. The SNS fulmar study was published by Van Franeker et al. (2005). Findings strongly supported the important role of shipping (incl. fisheries) in the marine litter issue. For further publications of the SNS fulmar study see e.g. Save the North Sea (2004), Van Franeker (2004), Edwards (2005), Guse et al. (2005, 2020) and Olsen (2005). After completion of the European SNS project, the international work was continued through CSR awards from the NYK Group Europe Ltd and support from Chevron Upstream Europe. These funds contributed to further North Sea EcoQO wide updates in reports (Van Franeker \& the SNS Fulmar Study Group 2013), including peer-reviewed scientific publications on the EcoQO methods with data up to 2007 (Van Franeker et al. 2011) and 2012 (Van Franeker \& Law 2015). These awards were used also to promote fulmar work in other areas of the world such as Ireland (Acampora et al. 2016), the Faroe Islands (Van Franeker 2012), Iceland (Kühn \& Van Franeker 2012; Snaethorsson 2018, 2019, 2021), Svalbard (Trevail et al. 2015), Atlantic Canada (Bond et al. 2014), the Canadian Arctic (Mallory et al. 2006; Mallory 2008; Provencher et al. 2009; Poon et al. 2017; Avery-Gomm et al. 2018; Baak et al. 2020) and the Pacific (Nevins et al. 2011; Avery-Gomm et al. 2012; Donnelly et al. 2014; Terepocki et al. 2017) and to explore the potential use of other marine species for ingestion monitoring as intended in the European MSFD (Bravo Rebolledo et al. 2013; Foekema et al. 2013; 
Matiddi et al. 2017; van Franeker et al. 2018; Kühn et al. 2020b). The most recent international overview of the monitoring of plastics in stomach contents of fulmars in the North Sea area includes data up to 2016 (Intermediate Assessment, OSPAR 2019). A third intermediate assessment using data up to 2018 has been prepared and will likely be published by OSPAR in 2021. The detailed history of the development of the OSPAR ECOQO and its successor the EU MSFD Fulmar Threshold Value can be found in earlier reports (e.g. Van Franeker and Kühn 2020). Currently there is no structural funding dedicated to international coordination and integrated data analysis and reporting.

The current assignment from I\&W, through its section Rijkswaterstaat Water, Traffic and Living Environment RWS-WVL included:

> Update of the Dutch time series on litter in stomachs of fulmars with the data of year 2020.

$>\quad$ Adjustment of this report to the new and informally accepted fulmar threshold value terminology.

Continued co-ordination of the beached fulmar sampling in the Netherlands in 2021.
$\quad$ Addition of the basic raw data to the database of RWS CIV (Centrale Informatievoorziening, Lelystad) and via CIV to third parties like OSPAR.

The following two information needs of the Dutch Ministry of Infrastructure and Water Management are the major driving forces to finance the monitor fulmar data on Dutch coastlines. First, there is an agreement of The Netherlands with OSPAR to (a) deliver fulmar plastics data annually and (b) to lead the OSPAR assessments of fulmar plastics. Second, since the introduction of the EU MSFD in 2008, the Netherlands have a European legal obligation to deliver data for plastics ingested by marine animals (MSFD criterion D10C3; represented for NL by fulmars) to Europe and to assess these data using a threshold value. The fulmar data presented in this report serve both these two major information needs. Obviously, Wageningen Marine Research also has their own scientific information need, which also makes use of these fulmar monitoring data. 


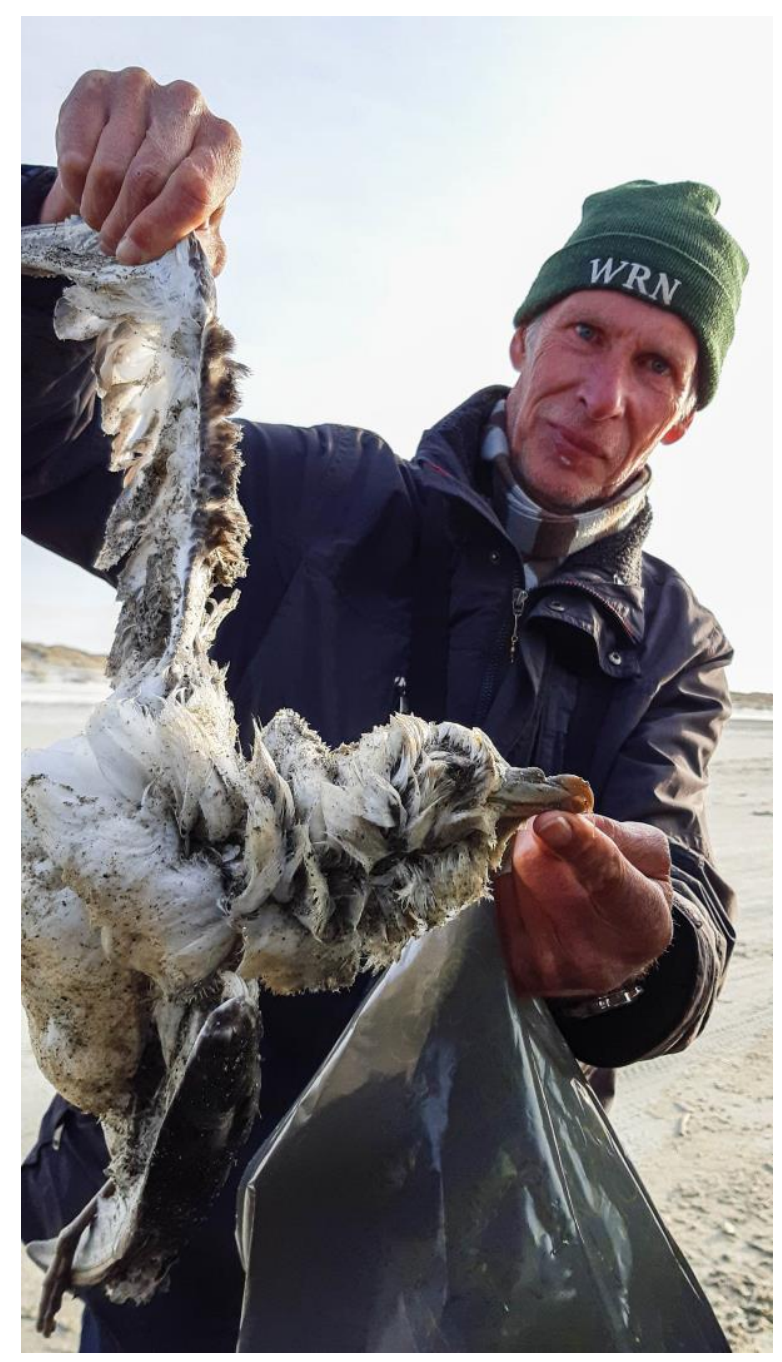

Photo 4. This monitoring work would be impossible without volunteers. Here, one of our longstanding volunteers, Johan Krol, has found a dead northern fulmar on his regular beach visits on Ameland. Without volunteers, our monitoring study of plastics in the marine environment would be impossible and public awareness and policy measures to reduce litter would suffer. Photo provided by J. Krol, 21 April 2021, Ameland. 


\section{The Fulmar as an ecological monitor of marine litter}

The interpretation of monitoring information presented in this report requires a summary of earlier findings as published in earlier reports and peer reviewed literature (Van Franeker et al. 2011; Van Franeker \& Law 2015, Van Franeker et al. 2021).

Since the early days of plastic pollution of our oceans, the Northern Fulmar has been known as a species that readily ingests marine plastic debris (Bourne 1976; Baltz \& Morejohn 1976; Day et al. 1985; Furness 1985; Van Franeker 1985; Moser \& Lee 1992; Robards et al. 1995; Blight \& Burger 1997). Nevertheless, it took until the pilot study of Van Franeker \& Meijboom (2002) to properly investigate the feasibility of using stomach contents of Northern Fulmars to monitor changes in marine litter abundance in an ecological context. Samples of fulmars available for a feasibility study of monitoring in the Netherlands mainly originated from the periods 1982 to 1987 and 1996 to 2000, with smaller numbers of birds from the years in between.

Reasons for selection of the fulmar out of a list of potential seabird species for monitoring are of a practical nature:

> Fulmars are abundant in the North Sea area (and elsewhere) and are regularly found in beached bird surveys, which guarantee supply of an adequate number of bird corpses for research.

$>\quad$ Fulmars are known to consume a wide variety of marine litter items.

$>\quad$ Fulmars avoid inshore areas and forage exclusively at sea (never on land).

> Fulmars do not normally regurgitate indigestible items, but accumulate these in the stomach (digestive processes and mechanical grinding gradually wear down particles to sizes that are passed on to the gut and are excreted).

> Thus, stomach contents of fulmars are representative for the wider offshore environment, averaging pollution levels over a foraging space and time span that avoids bias from local pollution incidents.

> Historical data are available in the form of a Dutch data series since 1982 (one earlier 1979 specimen); and literature is available on other locations and related species worldwide (Van Franeker 1985; Van Franeker \& Bell 1988; Kühn \& van Franeker 2020).

Other North Sea species that ingest litter either do not accumulate plastics (they regurgitate indigestible remains); are coastal only and/or find part of their food on land (e.g. Larus gulls); ingest litter only incidentally (e.g. North Sea alcids) or are too infrequent in beached bird surveys for the required sample size or spatial coverage (e.g. other tubenoses or Kittiwake Rissa tridactyla). 


\section{Info Box}

Illustrating the importance of collecting 'old' corpses

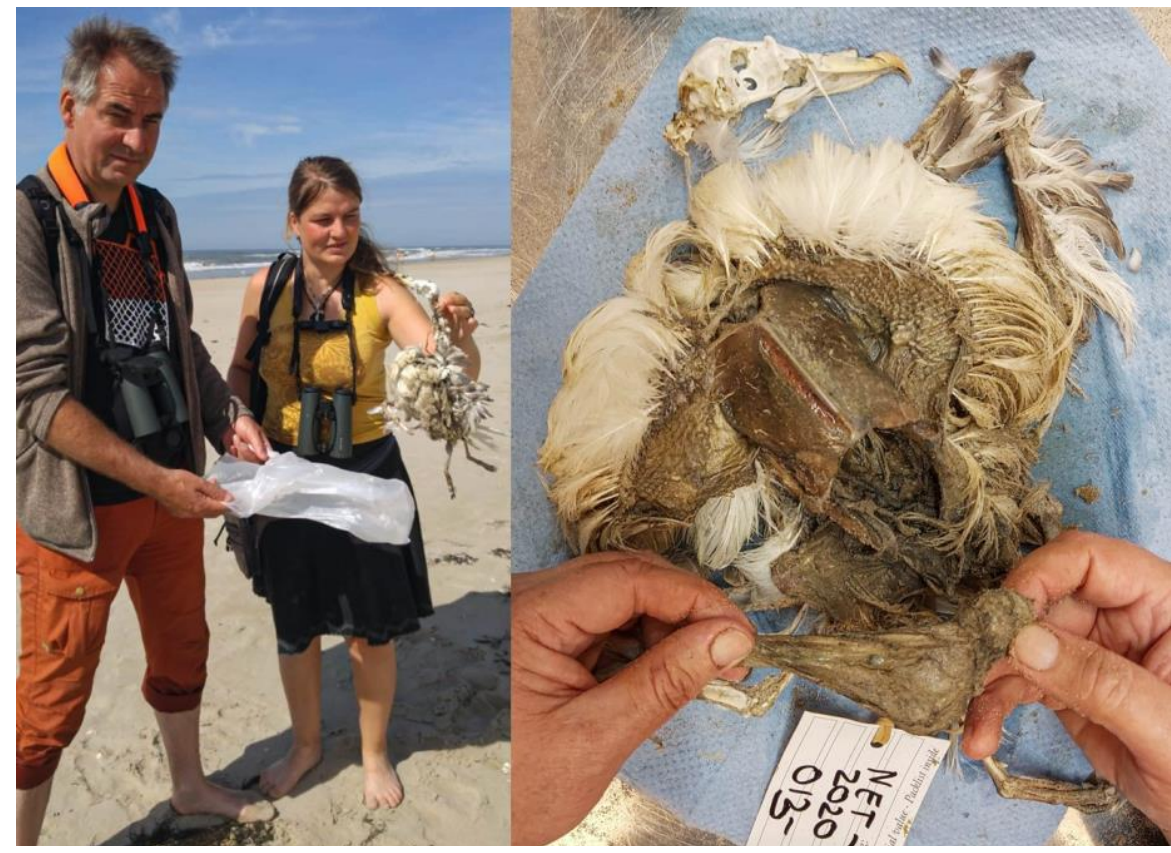

Photo 5 Fulmar NET-2020-013 was found by Stephan Kühn, Christine Fabricius and Susanne Kühn on Texel in mid-summer as a smelly, decaying and partly mummified old corpse. Note the 'clean' skull and neck, and dried legs and wings. In spite of its look, this bird contained a complete stomach that was used in the monitoring program. Fulmar corpses should only be left on the beach if it is completely certain that there is no stomach left, as shown in the picture below. If in doubt, corpses should be collected for us to check.

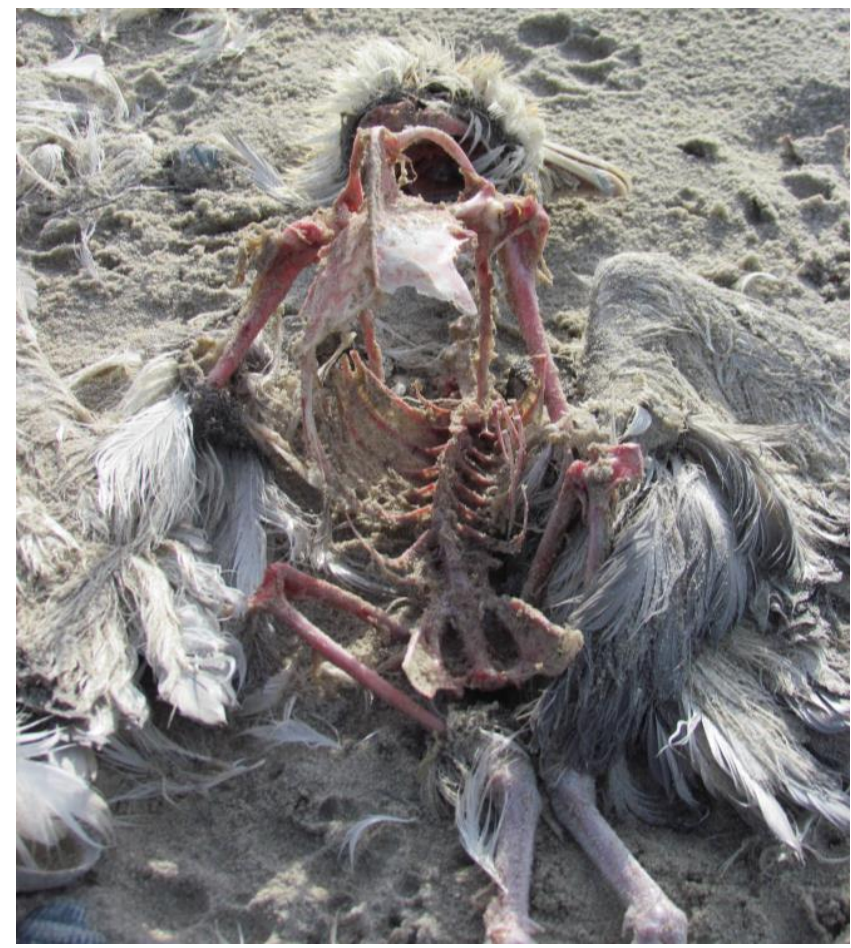

Photo 6 This fulmar was found by Susanne Kühn and Job ten Horn on the beach of Texel on 24 January 2021. This is a very clear case of 'no stomach left', the bird was not collected.

Beached birds may have died for a variety of reasons. For some birds, plastic accumulation in the stomach is evidently the direct cause of death, e.g. by plastic sheets blocking food passage. More often the effects of litter ingestion act at sub-lethal levels, except maybe in cases of ingestion of chemical substances. For other birds, fouling of the plumage with oil or other pollutants (Camphuysen 
2020), collisions with ships or other structures, drowning in nets, extremely poor weather or foodshortage may have been direct or indirect causes of mortality.

At dissection of birds, their sex, age, origin, condition, likely cause of death and a range of other potentially relevant parameters are determined. Standardized dissection procedures for EcoQO monitoring have been described in detail in a manual (Van Franeker 2004), subsequent peer-reviewed publications (Van Franeker et al. 2011; Van Franeker \& Law 2015) and OSPAR Guidelines (OSPAR 2015a,b).

Stomach contents are sorted into main categories of plastics (industrial and user plastics), non-plastic rubbish, pollutants, natural food remains and natural non-food remains. Each of these categories has a number of subcategories of specific items. For each individual bird and litter category, data are recorded on presence or absence ("incidence"), the number of items, and the mass of subcategory (see methods). For efficiency/economy reasons, some of the details described in the manual and earlier reports were discontinued in the current research projects.

The pilot study by Van Franeker and Meijboom (2002) undertook extensive analyses to check whether time-related changes in litter abundance were susceptible to errors caused by bias from variables such as sex, age, origin, condition, cause of death, or season of death. If any of these would substantially affect quantities of ingested litter, changes in sample composition over the years could hamper or bias the detection of time-related trends.

A very important finding of the same pilot study was that no statistical difference was found in litter in the stomach between birds that had slowly starved to death and 'healthy' birds that had died instantly (e.g. because of collision or drowning). This means that our results, which are largely based on beached starved birds, are representative for the 'average' healthy fulmar living in the southern North Sea.

Only age was found to have an effect on average quantities of ingested litter, adults having less plastic in their stomach than younger birds. Possibly, adults loose some of the plastics accumulated in their stomach when they feed chicks or spit stomach-oil during defence of nest-sites. Another factor could be that foraging experience may increase with age. Our understanding of the observed age difference in plastic accumulation is poor. In search of better understanding of such issues, Chevron Upstream Europe has funded a cooperative project with the Faroese Fisheries Laboratory. Using fulmars from the Faroe Islands, we investigate seasonal and age related variations in stomach contents. On the Faroe Islands, fulmars are hunted for consumption and large numbers of samples are easily obtained. Additional samples have been obtained from fisheries by-catch in the area. Stomach contents are analysed for both normal diet (Faroese component in the study; Danielsen et al. 2010) and for accumulated litter (Dutch contribution to the study). General results were published in Van Franeker (2012), but detailed analyses of samples obtained from all months of the year during several years continue to be analysed.

Although age has been shown to affect absolute quantities of litter in stomach contents, changes over time follow the same pattern in adults or non-adults. As long as no directional change in age composition of samples is observed, trends may be analysed for the combined age groups. However, background information for the presentation of results and their interpretations always requires insight in age composition of samples.

Significant long-term trends from 1982 to 2000 were detected in incidence (Frequency of Occurrence $\%$ FO), number of items and mass of industrial plastics, user plastics and suspected chemical pollutants (often paraffin-like substances). Over the 1982-2000 period, only industrial plastics decreased while user plastics significantly increased. When comparing averages in the 1980 s to those in the 1990s, industrial plastics approximately halved from 6.8 granules per bird (77\% incidence; 0.15 $\mathrm{g}$ per bird) to 3.6 granules $(64 \% ; 0.08 \mathrm{~g})$. User plastics almost tripled from 7.8 items per bird $(84 \%$; $0.19 \mathrm{~g}$ ) to 27.6 items $(97 \% ; 0.52 \mathrm{~g})$. Since about 2015 (Van Franeker \& Kühn 2019), the analyses indicate a continuing trend of slow but significant decrease.

Analysis of variability in data and Power Analysis revealed that reliable figures for litter in stomachs in a particular region and specific time period are obtained at a sample size of about 40 birds and that reliable conclusions on change or stability in ingested litter quantities can be made after periods of 4 to 8 years, depending on the category of litter. Lower annual sample sizes are no problem, but will lengthen the periods needed to draw conclusions on regional levels and trends. 
Mass of litter, rather than incidence or number of items, should be considered the most useful unit of measurement in the long-term. Mass is also the most representative unit in terms of ecological impact on organisms. Frequency of occurrence loses its sensitivity as an indicator when virtually all birds are positive (as is the case in fulmars). In regional or time-related analyses, mass of plastics is a more consistent measure than number of items, because the latter appears to vary with changes in plastic characteristics.

The pilot study (Van Franeker and Meijboom 2002) concluded that stomach content analysis of beached fulmars offers a reliable monitoring tool for (changes in) the abundance of marine litter off the Dutch coast. By its focus on small-sized litter in the offshore environment, such monitoring has little overlap with, and high additional value to beach litter surveys of larger waste items. Furthermore, stomach contents of fulmars reflect the potential ecological consequences of litter ingestion on a wide range of marine organisms and create public awareness of the fact that environmental problems from marine litter persist even when larger items are broken down to sizes below the range of normal human perception. As indicated, there is an increasing concern on the dangers from microplastics, but monitoring quantities and effects in these species is more difficult than that of intermediate sized plastics in seabirds.

The same pilot study recommended that Dutch fulmar litter monitoring should focus on mass of plastics (industrial plastic and user) and suspected chemical substance. Each of these represents different sources of pollution, and thus specific policy measures aimed at reduced inputs. Because no funding was obtained to work on suspected chemicals so far, this element had been dropped and plastics have become the main focus. For this report however, additional funding was available to present general data on chemical waste in fulmar stomachs. Data-recording procedures are such that at the raw data-level, various sub-categories of plastics and other rubbish continue to be recorded by number and mass, and can be extracted from databases, should the need and funding arise.

Also in 2002, North Sea Ministers in the Bergen Declaration, decided to start a system of 'Ecological Quality Objectives (EcoQOs) for the North Sea'. One of the EcoQOs to be developed was for the issue of marine litter pollution, using stomach contents of a seabird, the fulmar, to monitor developments, and to set a target for 'ecological quality'. This target is about to be replaced by the similar OSPAR/ EU MSFD Fulmar threshold (Fulmar-TV). The proposed wording of the OSPAR/ EU MSFD Fulmar Threshold Value (Fulmar-TV) is:

"Over a period of at least five consecutive years, no more than $10 \%$ of northern fulmars (Fulmarus glacialis) in samples of at least 100 birds may exceed the level of $0.1 \mathrm{~g}$ of plastic particles in the stomach."

As recommended from the Dutch studies, the mass of plastics forms the basis of the Fulmar-TV monitoring system. Rather than using average plastic mass for the target definition, a combination is used of frequency of occurrence of plastic masses above a certain critical mass level $(10 \% ; 0.1 \mathrm{~g})$. The background of such approach is that a few exceptional outliers can have a strong influence on the calculated average. The wording of the target level basically excludes influence of exceptional outlying values. A similar effect can be obtained by calculating mean values from logarithmically transformed data (Geometric means). The OSPAR Fulmar EcoQO has been published in a background document (OSPAR 2008) and its implementation was included in the OSPAR Quality Status Report (OSPAR $2010 a, b)$. Formal guidelines and assessment methods have been published (OSPAR 2015a,b). OSPAR $(2017,2019)$ published two intermediate assessments of data up to 2016 for all five North Sea areas, indicating continued although less pronounced latitudinal differences as compared to Van Franeker et al. $(2005,2011)$, and a significant downward trend for the combined data. A third 'Intermediate Assessment' analysis data up to 2018 is in preparation.

As indicated in Chapter 1, the international work was continued and expanded after the SNS project. Quality of the methodology has been established by publications in peer-reviewed scientific articles (Ryan et al. 2009; Van Franeker et al. 2011; Van Franeker \& Law 2015). This monitoring is used by researchers in the Atlantic and Canadian Arctic and in the Pacific (Mallory 2008; Provencher et al. 2009; Nevins et al. 2011; Avery-Gomm et al. 2012, 2018; Donnelly-Greenan et al. 2014; Bond et al. 2014; Trevail et al. 2015; Poon et al. 2017; Terepocki et al. 2017; Baak et al. 2020). In principle this monitoring can be implemented throughout the fulmars Atlantic and Pacific breeding ranges (Hatch \& Nettleship 1998) and has been promoted as monitoring species in the Arctic Ocean (AMAP 2021). 


\section{Materials and Methods}

Wageningen Marine Research continues the collection of beached fulmars from Dutch beaches with the assistance of the Dutch Seabird Group (Nederlandse Zeevogelgroep - NZG) through its Working Group on Beached Bird Surveys (Nederlands Stookolieslachtoffer Onderzoek - NSO). Beached fulmars are collected by volunteers along the Dutch coast. These volunteers consist of regular beach-walkers, whereby some of them combine the collection of dead fulmars with the beached bird surveys. These regular beach bird surveys give the opportunity to continuously monitor the amount and species distribution of beached birds and can give early indications of larger bird wrecks (e.g. fulmars). Other beached fulmars are occasionally recorded on waarneming. $\mathrm{nl}$. These birds are then retrieved by volunteers if possible. In addition, several coastal bird rehabilitation centres support the collection program. Sampling effort for the Dutch fulmar study is spread over the full Dutch coastline, but hard to define in detail. In general, most fulmars in our study originate from the more northern part of the Netherlands, with next in line fulmars from the Zeeland area. The lower number of beached fulmars from the more central parts of the Dutch coast may be due to lower observer effort, but also to more rapid disappearance of corpses due to higher numbers of scavenging foxes or cleaning activities on the touristic beaches.

With the Save the North Sea (SNS) project in 2002, IMARES, now Wageningen Marine Research, started and co-ordinated similar sampling projects at a range of locations in all countries around the North Sea. Organizations involved in different countries differ widely, and range from volunteer bird groups to governmental beach cleaning projects. Fig. 1 shows all locations that were involved in the SNS monitoring program, and their regional grouping. Lack of funding has led to a stop of the international coordination, although separate countries, except Sweden, have committed to continued monitoring and submission of basic data to OSPAR, also as a part of their involvement in the European Marine Strategy Framework Directive (MSFD). These data are analysed in intermediate assessments (OSPAR 2017, 2019) and in the most recent publication by Van Franeker et al. (2021).

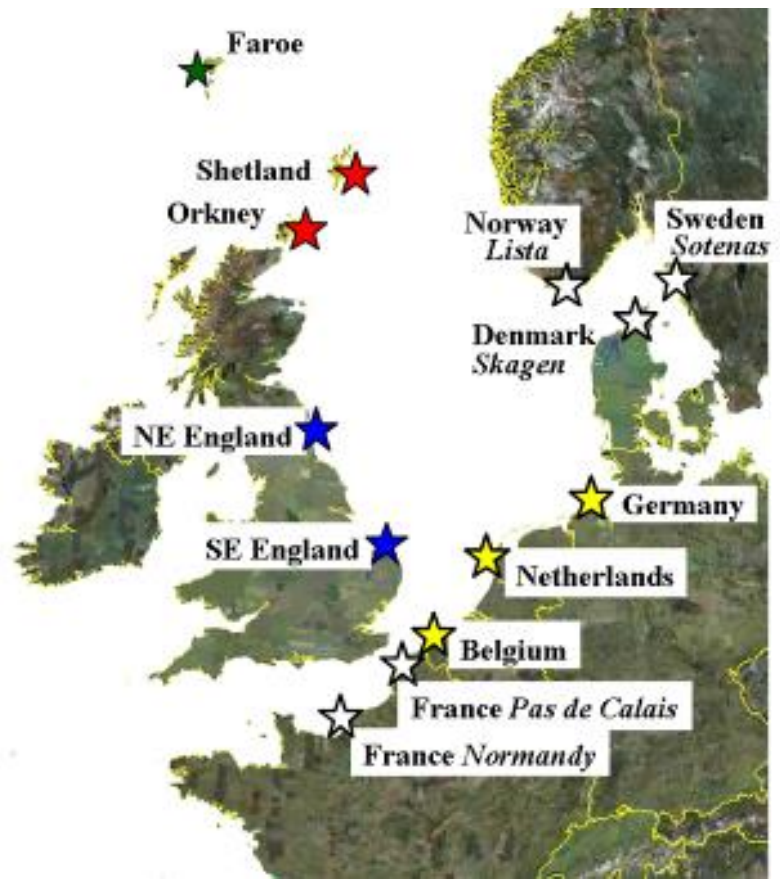

Figure 1. Fulmar-Litter study sites in the Save the North Sea Project (SNS). Colour of symbols indicates original regional grouping into Scottish Islands (red), East England (blue), Channel area (white), Southeastern North Sea (yellow), and Skagerrak area (white). Not all locations are equally active. The Faroe Islands study area (green) is considered as an external reference monitoring site for the North Sea. For further details, see the online supplement of Van Franeker et al. (2011).

Bird corpses are stored frozen until analysis. Standardized dissection methods for fulmar corpses have been published in a dedicated manual (Van Franeker 2004) and are internationally calibrated during annual workshops. Stomach content analyses and methods for data processing and presentation of results were described in full detail in Van Franeker \& Meijboom (2002), further developed in 
consultation with ICES and OSPAR by updates in later reports and OSPAR documents (OSPAR 2008, 2010b). Scientific reliability of the methodology was established by its publication in the peer reviewed scientific literature (van Franeker et al. 2011, 2021; Van Franeker \& Law 2015) with condensed guidelines for future assessments recently published by OSPAR (OSPAR 2015a,b).

For convenience, some of the methodological information is repeated here in a condensed form.

\section{Dissection}

At dissections, a full series of data is recorded that is of use to determine sex, age, breeding status, likely cause of death, origin, condition index and other issues. Age, the only variable found to influence litter quantities in stomach contents (Van Franeker \& Meijboom 2002), is largely determined on the basis of development of sexual organs (size and shape) and presence of Bursa of Fabricius (a gland-like organ positioned near the end of the gut which is involved in immunity systems of young birds. Bursa of Fabricius is well developed in chicks, but disappears within the first year of life or shortly after). Further details are provided in Van Franeker (2004). In the future, an updated version of the manual should be published to improve details and maximize efficiency and standardisation of methods.

\section{Stomach analysis procedure}

After dissection, stomachs of birds are opened for analysis. Stomachs of fulmars have two 'units': initially food is stored and starts to digest in a large glandular stomach (the proventriculus) after which it passes into a small muscular stomach (the gizzard) where harder prey remains can be processed through mechanical grinding. In early phases of the project, data for the two individual stomachs were recorded separately, but for the purpose of reduction in monitoring costs, the contents of proventriculus and gizzard are now combined.

Stomach, contents are carefully rinsed in a sieve with a $1 \mathrm{~mm}$ mesh and then transferred to a petri dish for sorting under a binocular microscope. The $1 \mathrm{~mm}$ mesh is used because smaller meshes become clogged with mucus from the stomach wall and with food-remains. Analyses using smaller meshes were found to be extremely time consuming and particles smaller than $1 \mathrm{~mm}$ seemed rare in the stomachs, and when present contribute little to plastic mass.

If oil or chemical types of pollutants are present, these may be sub-sampled and weighed before rinsing the remainder of stomach content. Although this was a standard component at the start of our studies, requirements for the Dutch "graadmeter" and international EcoQO have a focus on plastic or at best MARPOL Annex $V$ litter types. Thus, for financial efficiency, potential chemical pollutants in the stomachs were no part of the monitoring project: however, starting this report, general data on frequency of occurrence and mass of potential chemical substances are included. If sticky substances hamper further processing of the litter objects, hot water and detergents are used to rinse the material clean as needed for further sorting and counting under a binocular microscope. In 2018, an internally funded project was conducted by Wageningen Marine Research looking at paraffin- or palmoil like substances collected from beaches and fulmar stomachs in the period 1979-2017. In over $20 \%$ of fulmar stomachs, such substances are found without obvious trend over time. Chemical analyses identified both vegetable oils and paraffins in the stomachs. Paraffins dominated the beach samples (Van Franeker et al. 2019).

\section{Categorization of debris in stomach contents}

The following categorization is ideally used for plastics and other rubbish found in the stomachs, with acronyms between parentheses. However, please note that for financial efficiency in OSPAR EcoQO/FTV monitoring, the required dataset has been restricted to just categories 1.1 (Industrial Plastics) and 1.2 (User Plastics) without further subcategories (OSPAR 2015a,b).

\section{PLASTICS (PLA)}

1.1. Industrial plastic pellets (IND) are small, often cylindrically-shaped granules of \pm $4 \mathrm{~mm}$ diameter, but also disc and rectangular shapes occur. Various names are used, such as pellets, beads or granules. They can be considered as "raw" plastic or a half-product in the form of which, plastics are usually first produced (mostly from mineral oil). The raw industrial plastics are then usually transported to manufacturers that melt the granules and mix them with a variety of additives (fillers, stabilizers, colorants, anti-oxidants, softeners, biocides, etc.) that depend on the user product to be made. For the time being, included in this category are a relatively small number of very small, usually transparent spherical granules, also considered to be a raw industrial product.

1.2. User plastics (USE) (all non-industrial remains of plastic objects) may be differentiated in the following subcategories: 
1.2.1. sheetlike user plastics (she), as in plastic bags, foils etc., usually broken up in smaller pieces;

1.2.2. threadlike user plastics (thr) as in (remains of) ropes, nets, nylon line, packaging straps etc. Sometimes 'balls' of threads and fibres form in the gizzard;

1.2.3. foamed user plastics (foam), as in foamed polystyrene cups or packaging or foamed polyurethane in matrasses or construction foams;

1.2.4. fragments (frag) of more or less hard plastic items as used in a huge number of applications (bottles, boxes, toys, tools, equipment housing, toothbrushes, lighters etc.);

1.2.5. other (poth), for example cigarette filters, rubber, elastics etc., so items that are 'plastic-like' or do not fit into a clear category.

2. RUBBISH (RUB) other than plastic:

2.1. paper (pap) which besides normal paper includes silver paper, aluminium foil etc., so various types of non-plastic packaging material;

2.2. kitchenfood (kit) for human food wastes such as fried meat, chips, vegetables, onions etc., probably mostly originating from ships' galley refuse;

2.3. various rubbish (rubvar) is used for e.g. pieces of timber (manufactured wood); paint chips, pieces of metals etc.;

2.4. fish hook (hook) from either sport-fishing or long-lining.

3. POllutants (POL)

For items indicating industrial or chemical waste remains such as slags (the remains of burning ovens, e.g. remains of coal or ore after melting out the metals); tar-lumps (remains of mineral oil); chemical (lumps or 'mud' of paraffin-like materials or sticky substances arbitrarily judged to be unnatural and of chemical origin, see Van Franeker et al. 2019) and feather-lumps (indicating excessive preening by the bird of feathers sticky with oil or chemical pollutants). For this Dutch report, only chemicals (or paraffin-like substances) are considered in more detail. All other pollutants (slag, coal, feather lumps or fish hooks) are not included in this study.

Further optional categories of stomach contents (not included in this study):

4. NATURAL FOOD REMAINS (FOO)

4.1.1. Numbers of specific items may be recorded in separate subcategories (fish otoliths, eye-lenses, squid-jaws, crustacean remains, jelly-type prey remains, scavenged tissues incl. feathers, insects, other).

\section{NATURAL NON-FOOD REMAINS (NFO)}

5.1.1. Numbers of subcategories e.g. plant-remains, seaweed, pumice, stone and other may be recorded. 
Non-plastic or debris categories

To be able to sort out items of categories 1 and 2, all other materials in the stomachs described in categories 3 to 5, have to be cleaned out. However, in these latter categories, further identification, categorization, counting, weighing and data-processing is not essential for the Fulmar-TV. Whether details are recorded depends of the interest of the participating research group and their reasons to collect beached fulmars.

\section{Acronyms}

In addition to the acronyms used for (sub)categories as above, further acronyms may be used to describe datasets. Logarithmic transformed data are initiated by 'In' (natural logarithm); mass data are characterized by capital G (gram) and numerical data by N (number). For example, InGIND refers to the dataset that uses In-transformed data for the mass of industrial plastics in the stomachs; acronym NUSE refers to a dataset based on the number of items of user plastics.

\section{Info box}

\section{Paraffin-like substances}

As of this year (2021), chemical substances such as paraffin-like material are reported in the annual EcoQO reports. So far the restricted budget did not allow the detailed data analysis of these substances within the standard fulmar plastic monitoring work. In 2019, a first pilot study on paraffin-like substances in Dutch fulmars and on Dutch coasts was conducted (Van Franeker et al. 2019). In the entire study period from 1979 until $2017,21 \%$ of the 1101 fulmars contained paraffin-like substances. The chemical analysis of a subsample revealed, that $31 \%$ of the 32 analysed samples were made of paraffin, while $40 \%$ consisted of plant-based fats (e.g. palm oil). Unfortunately this distinction is impossible to make without complex chemical analysis. Therefore, in this context, we refer to paraffin-like substances to keep this uncertainty in

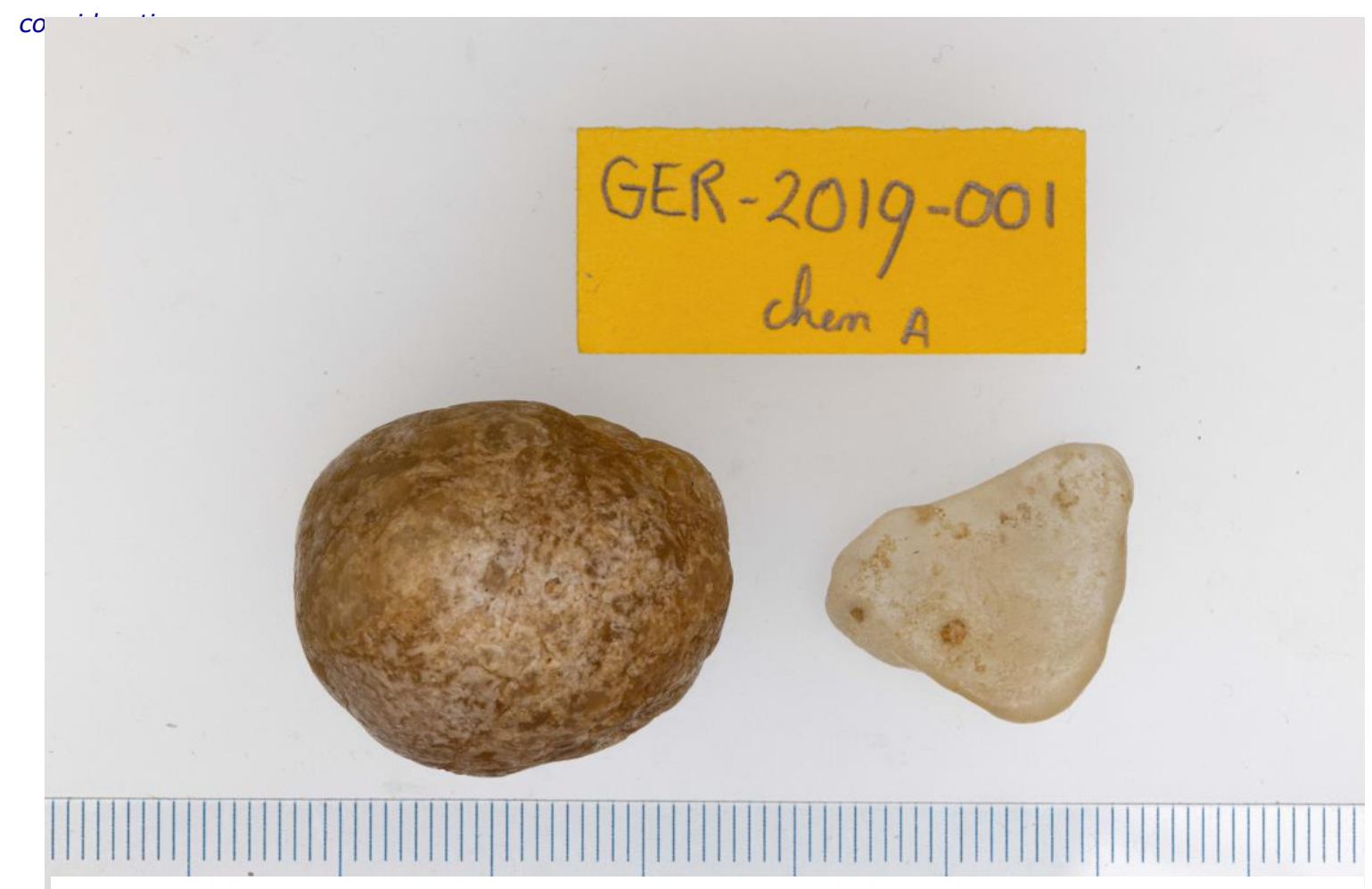

Photo 7. Paraffine ingested by fulmars. In 2019, a fulmar found on the German coast contained two paraffin-like items, several centimetres in size. Paraffine-like substances can vary in shape and appearance, from hard, well-defined fragments (as shown here) to sludgy, soft masses that are impossible to count. The German government has commissioned a similar pilot study to the Dutch one, the final report is in preparation and is expected to be published in 2021. 


\section{Particle counts and category weights}

For the main categories 1 (plastic) and 2 (rubbish) we record for each bird and each (sub)category:

$>$ The number of particles ( $\mathrm{N}=$ count of number of items in each (sub)category)

$>$ mass $(\mathrm{W}=$ weight in grams) using Sartorius electronic weighing scale after at least a two-day period of air drying at laboratory temperatures. For marine litter (categories 1 to 3 above), this is done separately for all subcategories. In the early fulmar study, we also weighed the natural-food and natural-non-food categories as a whole, but this was discontinued in 2006 to reduce costs. Weights are recorded in grams accurate to the $4^{\text {th }}$ decimal (= tenth of milligram).

\section{Data presentation}

On the basis of these records, data can be presented in different formats.

Frequency of Occurrence (\%FO)

The simplest form of data presentation is by proportional presence or absence. This metric is also referred to as Incidence or Prevalence. The \%FO gives the percentage of all investigated stomachs that contained the category of debris discussed. The quantity of debris in a stomach is irrelevant in this respect.

Arithmetic Average

Data for numbers or mass are frequently shown as averages with standard errors calculated for a specific type of debris by location and specified time period. Averages are calculated over all available stomachs in a sample, so including the ones that contained no plastic ('population averages'). Usage of standard error (se) is preferred over standard deviation (sd) because se reflects the reliability of the calculated average by taking into account the sample size where sd mainly considers the spread in the data. Especially when sample sizes are smaller, arithmetic averages may be influenced by short-term or local variations or extreme outliers. An option then is to pool data over a larger area or longer time period. An alternative to reduce influence of outliers is by logarithmic transformation of data.

Geometric Mean

Sample sizes may not be large enough to average out the impact of occasional extreme outliers.

Therefore, data are often additionally presented as geometric means. Geometric mean is calculated as the average of logarithmically transformed data values, which is then back calculated to the normal arithmetic equivalent. Logarithmic transformation reduces the role of the higher values, but consequently the geometric mean is usually considerably lower than the arithmetic average for the same data. In mass data for plastics in the fulmar stomachs, geometric means are only about one third to half of the arithmetic averages. Geometric means are useful for comparative purposes between smaller sample sizes, for example when looking at annual data rather than at 5-year-periods. Logarithmic transformation cannot deal with the value zero, and thus the common approach chosen is to add a small value (e.g. $0.001 \mathrm{~g}$ in mass data) to all data-points, and then subtracting this again when the mean of log values is back-calculated to normal value. This however implies that geometric means become less reliable with an increasing number of zero values in a dataset. The natural logarithm (In) is used to run calculations for geometric means. Starting with the 2016 update, medians are included in some of the more detailed data sections of the report, as a different additional view on the strongly skewed data distributions that have to be handled.

Fulmar Threshold Value Performance (FTV\%)

For early Dutch reports, the analyses focused on trends in average or mean mass data for different categories. However, OSPAR (2010b) words its Ecological Quality Objective for levels of litter (plastic) in stomachs of fulmars (the 'Fulmar-Litter-ECoQO') as:

"There should be less than $10 \%$ of Northern Fulmars (Fulmarus glacialis) having more than 0.1 gram plastic particles in the stomach in samples of 50 to 100 beach-washed fulmars from each of 4 to 5 different areas of the North Sea over a period of at least 5 years".

This definition has been replaced by the new OSPAR Fulmar Threshold Value (Fulmar-TV or FTV) which is similar to the previous OSPAR EcoQO target (OSPAR 2020). The formal approval by the EU MSFD is expected soon. The new Fulmar Threshold Value definition states:

"Over a period of at least five consecutive years, no more than $10 \%$ of northern fulmars (Fulmarus glacialis) in samples of at least 100 birds may exceed the level of $0.1 \mathrm{~g}$ of plastic particles in the stomach."

With RWS it has been agreed that the new terminology is now consistently used within this and the upcoming reports. Thus, the information requested for OSPAR and the Fulmar-TV focuses on the category of 'total plastic' and pooled data for 5-year periods over larger areas, and a simple decision rule for each stomach if the plastics in it weigh more than 0.1 gram or less, including zero.

Fulmar TV compliance or performance is defined as the percentage of birds in a sample that has $0.1 \mathrm{~g}$ or more plastic mass in the stomach (FTV\%). The OSPAR (and later EU MSFD) target is thus to reduce the FTV $\%$ to under $10 \%$. The former EcoQO and now FTV format are a highly simplified form of datapresentation but through that simplicity escapes the problems faced by more sophisticated procedures as a consequence of excessive outliers or a large proportion of zero values in a dataset. In the 
background however, details of various subcategories of litter continue to play an important role for correct interpretation of the FTV metric.

\section{Data pooling}

To avoid that short-term variations cause erratic information on the level of ingested plastics, data are frequently pooled into 5-year periods. Such pooled data for 5-year periods are not derived from the annual averages, but are calculated from all individual birds over the full 5-year period. For data presentation, the Current Situation of plastic ingestion is defined as the figures for \%FO, number or mass abundance, and FTV\% for the most recent 5-year period, not the figures for the recent single year! Time related changes are illustrated in graphs by running 5-year averages, each time shifting one year and thus overlapping for four years. Such graphs are useful to visualize patterns, which in annual data would be obscured by annual variability and smaller sizes. However, they do not represent statistical evidence. The 5-year running averages cannot be used for statistical analyses as the same source data were repeatedly used.

\section{Statistical tests}

Data from dissections and stomach content analysis are recorded in Excel spreadsheets and next stored in an Oracle relational database. GENSTAT $18^{\text {th }}$ Edition was used for statistical tests. As concluded in the pilot study (Van Franeker \& Meijboom 2002) and later reports, statistical trend analysis is conducted using mass-data. Tests for trends over time are based on linear regressions fitting In-transformed plastic mass values for individual birds on the year of collection. Logarithmic transformation is needed because the original data are strongly skewed and need to be normalized for the statistical procedures. The natural logarithm ( $L n)$ is used. Tests for 'long-term' trends use the full dataset; 'recent' trends only use the past ten years of data. This 10-year period was derived from the pilot study (Van Franeker \& Meijboom 2002) which found that in the Dutch situation a series of about eight years was needed to have the potential to detect significant change. To be on the safe side in our approach, this period was arbitrarily increased to a standard period of 10 years for tests of current time related trends.

Starting with the 2017 update report, a new additional approach was developed to directly evaluate the progress towards the OSPAR long-term target in which the EcoQ\% should be reduced to under $10 \%$. The new approach now uses annual figures of the Fulmar-TV Performance (the former EcoQ Performance). Simplified data as percentages above or below a threshold do have the problem that the dataset is reduced to periodic (annual) average performance. In our approach of evaluating trends over a period of the most recent ten years, the statistical procedure then has only ten data-points available for statistical tests and modelling. Simple linear regression cannot be applied to this type of data. The data are considered in a GLM approach (Generalized Linear Modelling), more specifically in a logistic analysis dedicated for binomial distributions (number of birds in the sample and number of birds above threshold) and using logit transformed data. A similar type of analysis is already used in the analyses of oil-rates among seabirds for OSPAR (cf. Camphuysen 2020 and earlier publications on that topic). The statistical trend based on observed data, if significant, can be used to predict FTV Performance in future years. 


\section{Summary of data presentation and analyses:}

\section{$>$ Frequency of Occurrence (\%FO)}

The percentage of birds having plastic in the stomach. Also referred to as Incidence or Prevalence.

\section{$>$ Average \pm se}

Arithmetic population average with standard error (includes zeros).

\section{$>$ Geometric mean}

Population average calculated using data transformation (natural logarithm). In part of tables and graphs, also medians are shown as an alternative estimate for excluding outliers.

\section{$>$ Fulmar-TV performance (FTV\%)}

The $\%$ of birds having more than 0.1 gram of plastic in the stomach.

\section{$>$ Pooled data}

Data pooled over 5-year periods.

\section{$>$ Current level of plastic ingestion}

Average plastic number or mass from pooled data for the most recent 5 years.

\section{$>$ Running average}

Sequential data pooled over 5 years, shifting one year by data-point, are used as a visual illustration of trends over time, but without statistical relevance.

\section{$>$ Statistics}

Statistical analyses are mainly based on the mass of plastic using In transformed data of individual birds. Tests for trends are based on linear regressions of In-transformed plastic mass against year of collection. The new additional approach of analysing trends based on annual figures of FTV Performance by preference uses longer periods should, e.g. covering the period of the Save the North Sea (SNS) project that started in 2002. 


\section{Results \& Discussion}

This chapter follows the original format of our earlier reports, which uses the approach recommended in OSPAR Guidelines (OSPAR 2015a). That approach has its focus on detailed analyses and statistics of the data on mass of plastics found in individual birds, taking into account the details of different plastic categories (industrial versus user plastics) and the differences between adult and non-adult birds. In earlier reports, in a final section, these data were also viewed, but not statistically tested in terms of EcoQ Performance, which is the proportion of birds having more than $0.1 \mathrm{~g}$ of plastic in the stomach. As the FTV\% (former EcoQ\%) is the most relevant for policy makers, starting with the 2017 update (Van Franeker \& Kühn 2018), a statistical analysis of annual FTV\%'s is included, which, if significant, can be used to predict future developments. The original detailed analyses remain essential to properly understand the Fulmar-TV Performance model as a basis for policy decisions. The abstract of the current report now strongly focuses on the most policy relevant FTV Performance; underlying details and analyses are largely restricted to within this Results \& Discussion chapter.

\subsection{The year 2020}

In 2020, the loyal surveyor network managed to collect 18 fulmar corpses, of which 15 had an intact stomach suitable for analysis of the contents. Several birds had been treated in a rehabilitation centre, but one exceeded the maximum care time of 3 days. For our monitoring purposes, we do not use birds that have been alive in rehabilitation for more than 3 days, because during treatment plastic particles break and wear down in the muscular stomach of the bird (Van Franeker \& Law 2015). Therefore a total of 14 fulmars were available for the year 2020. In 2020, no additional 'late-delivered' stomachs of fulmars were analysed. Late additions can cause minor changes to earlier reports. The desired annual sample size in our monitoring program is \pm 40 birds or more (Van Franeker \& Meijboom 2002). Smaller annual samples, as in 2020 , are not really a problem for the monitoring system but may delay the detection of significant trends.

The 2020 sample (Table 1A; Table 2) does not meet the desired annual sample size and showed a higher average number and mass of plastics, as well as a higher Fulmar-TV performance than in previous years. The frequency of occurrence (\%FO) remained stable (93\%; Table 2A). Out of 14 birds, 13 birds did have plastic in the stomach, the average fulmar had 31 plastic particles weighing 0.42 gram, and 6 of 14 birds exceeded the $0.1 \mathrm{~g}$ level (43\%). Out of 14 birds, $21 \%$ ( 3 birds) contained paraffin-like material in their stomachs. In 2019, $27 \%$ of 44 birds contained paraffin-like substances, but annual data seems to be more variable in these substances than in plastics (Van Franeker et al. 2019).

\subsection{Current levels for the Netherlands (2016-2020)}

The OSPAR long-term target requires an FTV\% under $10 \%$ for at least 5 consecutive years. Therefor data are pooled in 5-year periods. Also because of occasional years of low sample size or incidental variability it is advised to focus on the average stomach contents over the most recent 5 years. In the 'current' 5-year period (2016-2020) (Table 1B, Table 3), in a sample of 139 birds, 39\% of stomachs contained more than $0.1 \mathrm{~g}$ plastic (FTV\%). Although this remains the best FTV performance in the Dutch monitoring program, it clearly is still far off the OSPAR long-term target. In the 20162020 sample, 93\% of fulmars contained some plastic, with an average over all birds of 22.5 plastic particles per stomach, weighing 0.21 gram. Industrial plastics were rare compared to consumer debris plastics. While in the period of 2016-2020, $19 \%$ of the birds had paraffin-like substances, the 5-year period 2013-2017 as published by Van Franeker et al. (2019) showed 15\% of 125 birds with paraffinlike substances in their stomachs. An extreme case of a bird from 2013 (NET-2013-004) who had ingested 110 gram of paraffin-like substances caused an increase in the data series where the year 2013 in included (Figure 2C), in some cases extreme outliers can't be smoothed out, even by summarizing data in running 5-year averages. Fulmars ingest different chemical materials from the 
water surface, including paraffin, natural fats (e.g. palm oil) and substances of unknown origin. For a pilot study, a detailed chemical analysis was done to analyse a subsample of these materials ingested by fulmars (van Franeker et al. 2019). Results indicate, that $31 \%$ of the ingested materials consisted of paraffin. The distinction cannot be made without complex and costly analyses. Not much is known over the consequences of the ingestion of either paraffin or natural fatty substances on the organism. Chemicals added during production or cleaning of ship tanks may be harmful and sometimes the pure volume or mass of the substances may block the stomach or diminish its functioning, however evidences for the harmfulness are currently lacking.

Table 3 provides all details for the full study period, but changes over time are best viewed in graphical presentations combined with statistical tests.

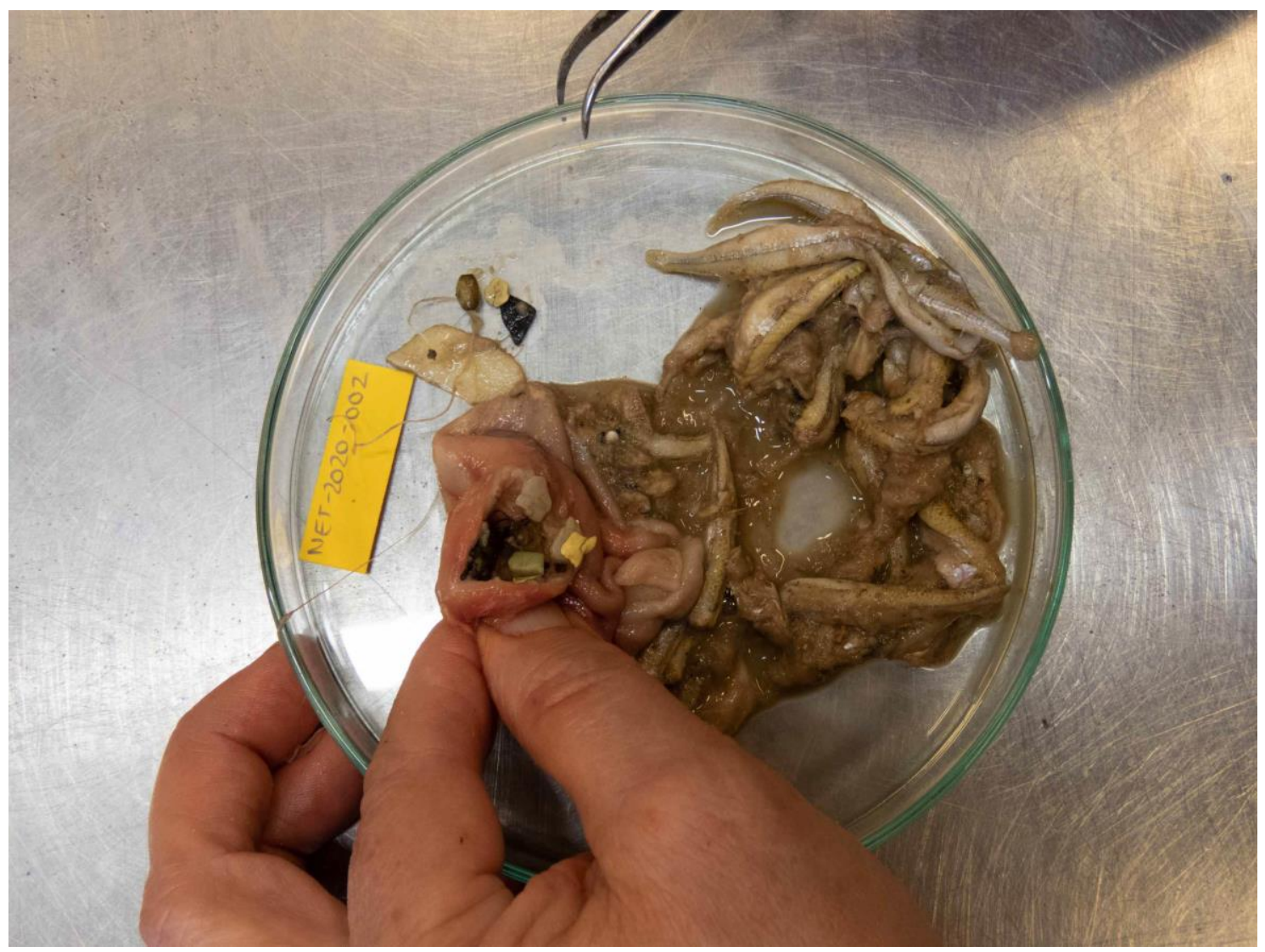

Photo 8. Stomach content of a rehab fulmar. The Fulmar with the collection number NET2020-002 was found alive on the beach. The birds was emaciated and had a damaged bill. It was brought to the Vogelhospital Haarlem, where the stabilization of the bird was tried. After 8 days in rehab the bird died. During the stomach content analysis we found, beside some plastics, also some fish that had been fed to the bird during rehabilitation. This bird, unfortunately, cannot be included to the standard monitoring scheme, as plastic uptake has been disrupted at the moment of rehabilitation and the amount of plastics may therefore be biased. However, birds like this can potentially provide valuable information on plastic retention time and degradation in stomachs. 
Table 1. Summary of sample characteristics and stomach contents of fulmars collected for Dutch marine litter monitoring in a) the year 2020 and b) the current 5-year period 2016-2020.

The top line in each table shows the sample composition in terms of age, sex, origin (colour-phases darker than Double Light (LL) indicate distant Arctic origin), death cause oil, and the average condition-index (which ranges from emaciated condition $=0$ to very good condition=9; Van Franeker 2004). For each litter-

(sub)category the table lists: Incidence, representing the proportion of birds with one or more items of the litter category present; average number of plastic items per bird stomach \pm standard error; average mass of plastic \pm standard error per bird stomach; and the maximum mass observed in a single stomach. The final column shows the geometric mean mass, which is calculated from In-transformed values as used in trendanalyses.

\section{a) Year 2020}

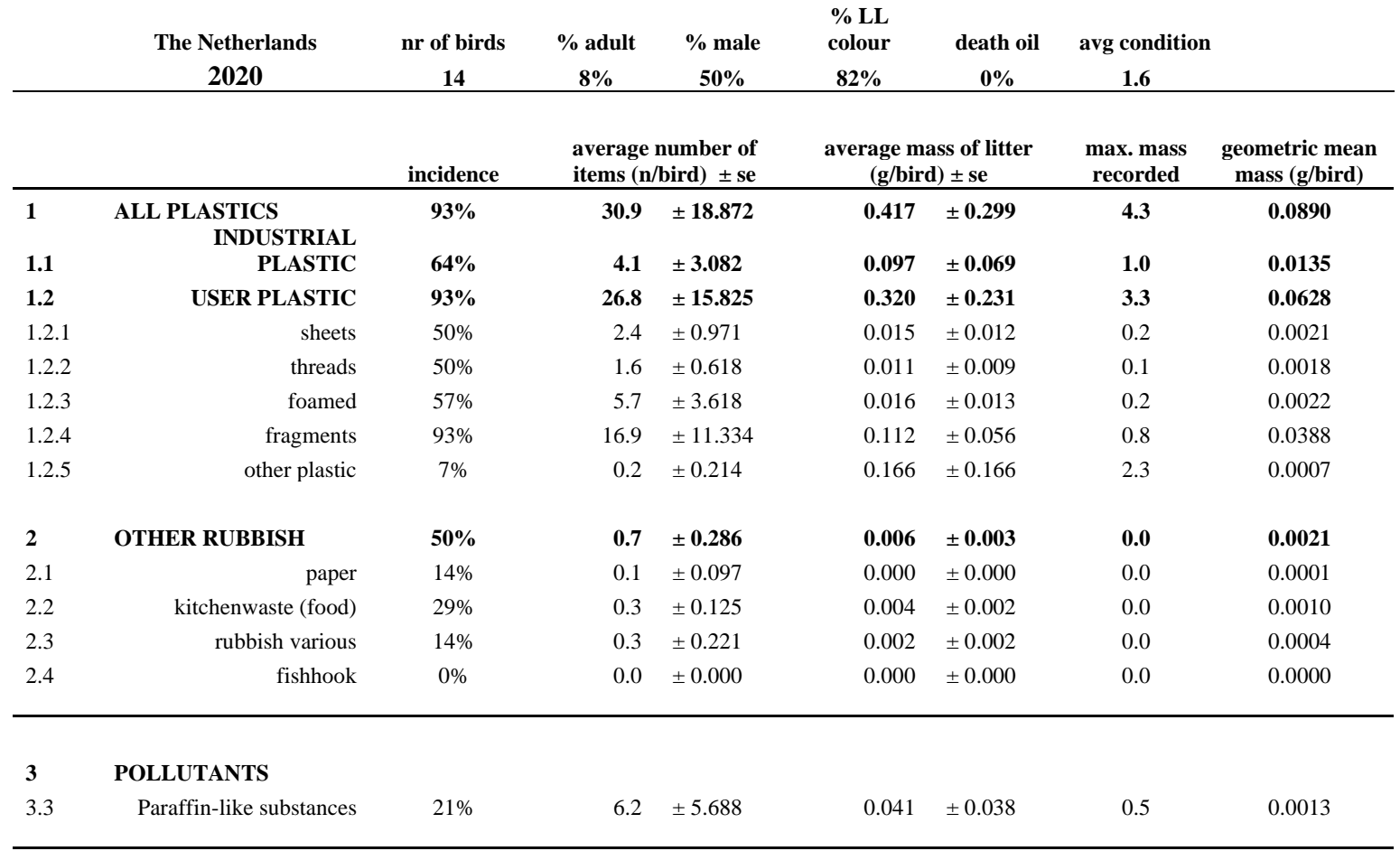

b) 5-year period 2016-2020

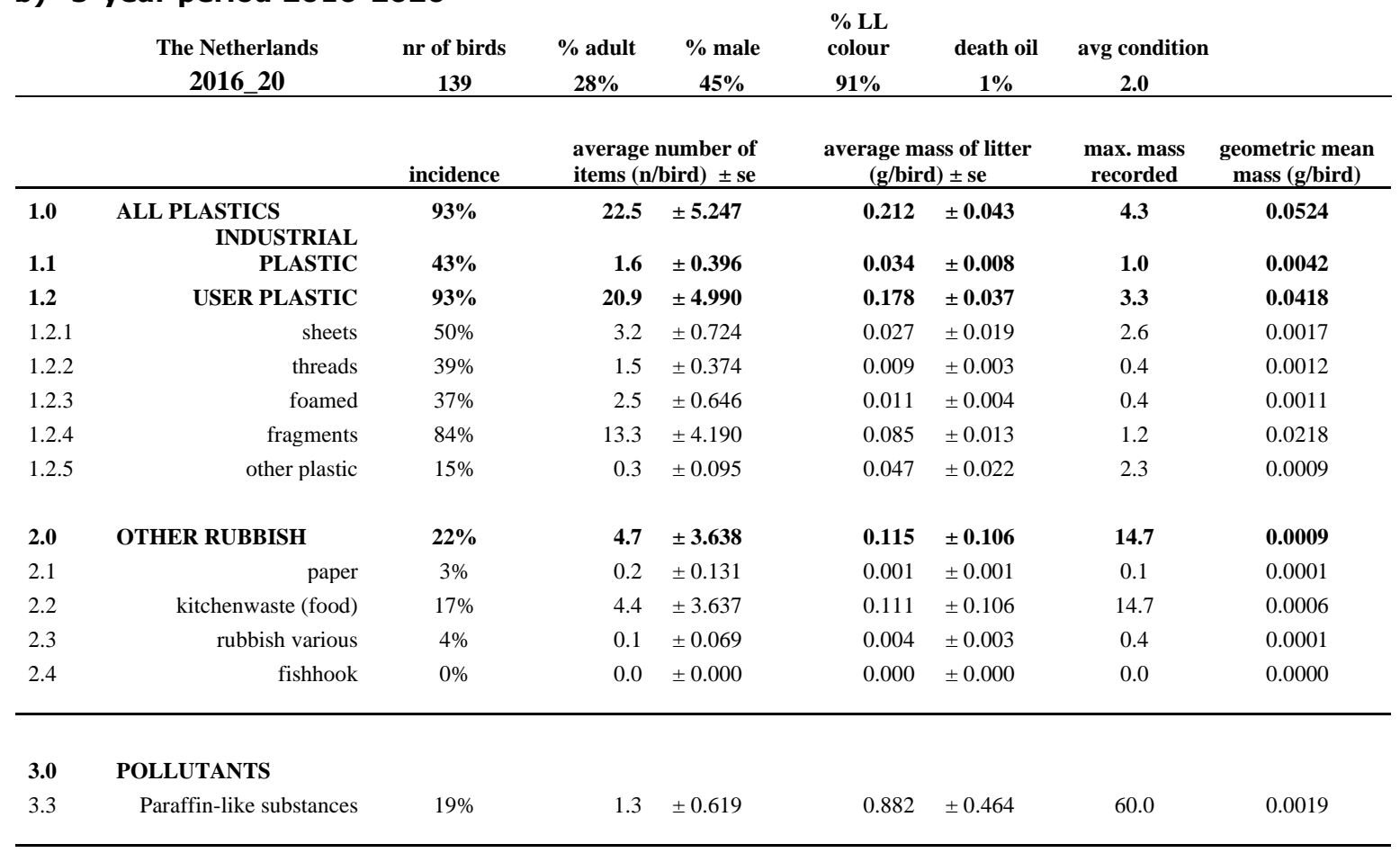


Table 2. Annual details for plastic abundance in fulmars from the Netherlands. A. all plastic categories combined; B. separate data for industrial and user plastic categories. Sample size is given with the proportion of adult birds in brackets. Frequency of Occurrence (\%FO) represents the proportion of birds with one or more items of that litter present. Average number ( $n \pm s e)$ gives the abundance by number of plastic particles per bird with standard error, and average mass ( $g \pm s e$ ) the weight of plastic per bird in grams with standard error. Total plastics mass is also shown in terms of medians and geometric mean mass (for comparative purposes reducing the influence of outliers) and as level of performance in relation to the OSPAR/ EU MSFD Fulmar Threshold Value, viz. the percentage of birds having more than the threshold of 0.1 gram of plastic in the stomach (former EcoQO). Note sample sizes ( $n$ ) to be very low for particular years implying low reliability of the annual averages for such years, not to be used as separate figures (only years with sample size over 10 birds are printed in bold).

Table 2A. 


\section{Netherlands}

\begin{tabular}{|c|c|c|c|c|c|c|c|c|}
\hline YEAR & $\begin{array}{c}\text { sample } \\
n\end{array}$ & $(\% a d)$ & $\%$ FO & $\begin{array}{c}\text { average number } \\
n \pm \text { se }\end{array}$ & $\begin{array}{c}\text { average mass } \\
\mathrm{g} \pm \mathrm{se}\end{array}$ & $\begin{array}{c}\text { median } \\
\text { mass }\end{array}$ & $\begin{array}{l}\text { geometric } \\
\text { mean mass }\end{array}$ & $\begin{array}{c}\text { EcoQ\% } \\
\text { (over 0.1g) }\end{array}$ \\
\hline 1979 & 1 & $(0 \%)$ & $100 \%$ & 5.0 & 0.24 & & & \\
\hline 1980 & 0 & & & & & & & \\
\hline 1981 & 0 & & & & & & & \\
\hline 1982 & 3 & $(0 \%)$ & $100 \%$ & $11.0 \pm 4.0$ & $0.61 \pm 0.34$ & & & \\
\hline 1983 & 19 & $(41 \%)$ & $100 \%$ & $16.0 \pm 2.5$ & $0.49 \pm 0.13$ & 0.302 & 0.284 & $89 \%$ \\
\hline 1984 & 20 & $(40 \%)$ & $90 \%$ & $17.9 \pm 5.5$ & $0.35 \pm 0.13$ & 0.160 & 0.073 & $55 \%$ \\
\hline 1985 & 3 & $(33 \%)$ & $100 \%$ & $10.3 \pm 1.5$ & $0.28 \pm 0.07$ & & & \\
\hline 1986 & 4 & $(25 \%)$ & $75 \%$ & $5.5 \pm 1.8$ & $0.08 \pm 0.05$ & & & \\
\hline 1987 & 17 & $(59 \%)$ & $82 \%$ & $13.6 \pm 4.0$ & $0.19 \pm 0.08$ & 0.112 & 0.056 & $59 \%$ \\
\hline 1988 & 1 & $(0 \%)$ & $100 \%$ & 2.0 & 0.04 & & & \\
\hline 1989 & 2 & $(100 \%)$ & $100 \%$ & $12.5 \pm 9.5$ & $0.43 \pm 0.40$ & & & \\
\hline 1990 & 0 & & & & & & & \\
\hline 1991 & 1 & $(0 \%)$ & $100 \%$ & 11.0 & 0.14 & & & \\
\hline 1992 & 0 & & & & & & & \\
\hline 1993 & 0 & & & & & & & \\
\hline 1994 & 0 & & & & & & & \\
\hline 1995 & 2 & $(50 \%)$ & $100 \%$ & $5.0 \pm 1.0$ & $0.06 \pm 0.02$ & & & \\
\hline 1996 & 8 & $(62 \%)$ & $100 \%$ & $27.4 \pm 13.7$ & $0.26 \pm 0.11$ & & & \\
\hline 1997 & 31 & $(16 \%)$ & $97 \%$ & $35.8 \pm 7.3$ & $0.73 \pm 0.17$ & 0.325 & 0.298 & $84 \%$ \\
\hline 1998 & 75 & $(44 \%)$ & $95 \%$ & $28.6 \pm 5.2$ & $0.94 \pm 0.35$ & 0.186 & 0.156 & $71 \%$ \\
\hline 1999 & 107 & $(70 \%)$ & $98 \%$ & $35.3 \pm 6.2$ & $0.44 \pm 0.11$ & 0.138 & 0.123 & $61 \%$ \\
\hline 2000 & 38 & $(58 \%)$ & $100 \%$ & $22.0 \pm 5.2$ & $0.35 \pm 0.13$ & 0.160 & 0.129 & $61 \%$ \\
\hline 2001 & 55 & $(37 \%)$ & $96 \%$ & $22.7 \pm 4.2$ & $0.24 \pm 0.05$ & 0.094 & 0.088 & $49 \%$ \\
\hline 2002 & 56 & $(54 \%)$ & $98 \%$ & $51.8 \pm 12.5$ & $0.50 \pm 0.20$ & 0.227 & 0.154 & $68 \%$ \\
\hline 2003 & 39 & $(56 \%)$ & $95 \%$ & $28.5 \pm 7.2$ & $0.17 \pm 0.03$ & 0.135 & 0.068 & $54 \%$ \\
\hline 2004 & 131 & $(80 \%)$ & $91 \%$ & $23.4 \pm 3.0$ & $0.27 \pm 0.04$ & 0.140 & 0.081 & $60 \%$ \\
\hline 2005 & 51 & $(68 \%)$ & $98 \%$ & $17.8 \pm 2.8$ & $0.27 \pm 0.06$ & 0.094 & 0.089 & $47 \%$ \\
\hline 2006 & 27 & $(62 \%)$ & $93 \%$ & $33.9 \pm 7.6$ & $0.30 \pm 0.08$ & 0.199 & 0.131 & $85 \%$ \\
\hline 2007 & 64 & $(45 \%)$ & $92 \%$ & $35.9 \pm 5.5$ & $0.37 \pm 0.05$ & 0.298 & 0.137 & $72 \%$ \\
\hline 2008 & 20 & $(58 \%)$ & $95 \%$ & $44.5 \pm 12.3$ & $0.31 \pm 0.10$ & 0.196 & 0.104 & $55 \%$ \\
\hline 2009 & 68 & $(40 \%)$ & $97 \%$ & $19.3 \pm 3.6$ & $0.22 \pm 0.04$ & 0.075 & 0.084 & $46 \%$ \\
\hline 2010 & 36 & $(46 \%)$ & $94 \%$ & $56.4 \pm 16.3$ & $0.46 \pm 0.20$ & 0.127 & 0.112 & $64 \%$ \\
\hline 2011 & 19 & $(37 \%)$ & $100 \%$ & $43.6 \pm 13.1$ & $0.43 \pm 0.19$ & 0.214 & 0.183 & $79 \%$ \\
\hline 2012 & 81 & $(46 \%)$ & $90 \%$ & $20.6 \pm 3.4$ & $0.30 \pm 0.09$ & 0.098 & 0.075 & $49 \%$ \\
\hline 2013 & 24 & $(42 \%)$ & $92 \%$ & $26.8 \pm 8.3$ & $0.18 \pm 0.04$ & 0.083 & 0.067 & $46 \%$ \\
\hline 2014 & 12 & $(64 \%)$ & $100 \%$ & $21.4 \pm 3.9$ & $0.36 \pm 0.14$ & 0.176 & 0.184 & $83 \%$ \\
\hline 2015 & 23 & $(30 \%)$ & $96 \%$ & $12.1 \pm 3.2$ & $0.26 \pm 0.15$ & 0.064 & 0.060 & $39 \%$ \\
\hline 2016 & 31 & $(18 \%)$ & $87 \%$ & $31.7 \pm 12.9$ & $0.29 \pm 0.10$ & 0.133 & 0.059 & $52 \%$ \\
\hline 2017 & 38 & $(31 \%)$ & $92 \%$ & $26.8 \pm 14.1$ & $0.24 \pm 0.07$ & 0.073 & 0.060 & $37 \%$ \\
\hline 2018 & 12 & $(50 \%)$ & $100 \%$ & $15.8 \pm 7.8$ & $0.12 \pm 0.06$ & 0.048 & 0.052 & $17 \%$ \\
\hline 2019 & 44 & $(34 \%)$ & $95 \%$ & $11.4 \pm 2.2$ & $0.09 \pm 0.02$ & 0.059 & 0.036 & $36 \%$ \\
\hline 2020 & 14 & $(8 \%)$ & $93 \%$ & $30.9 \pm 18.9$ & $0.42 \pm 0.30$ & 0.093 & 0.089 & $43 \%$ \\
\hline
\end{tabular}

Total plastics 
Table 2B. (for caption see Table 2A)

\begin{tabular}{|c|c|c|c|c|c|c|c|}
\hline \multicolumn{2}{|c|}{ Netherlands } & \multicolumn{3}{|c|}{ Industrial granules } & \multicolumn{3}{|c|}{ User plastics } \\
\hline YEAR & $\begin{array}{c}\text { sample } \\
n\end{array}$ & $\% \mathrm{FO}$ & $\begin{array}{c}\text { avg number } \\
\mathrm{n} \pm \mathrm{se}\end{array}$ & $\begin{array}{c}\text { avg mass } \\
\mathrm{g} \pm \mathrm{se}\end{array}$ & $\% \mathrm{FO}$ & $\begin{array}{c}\text { avg number } \\
\mathrm{n} \pm \mathrm{se}\end{array}$ & $\begin{array}{c}\text { avg mass } \\
\mathrm{g} \pm \mathrm{se}\end{array}$ \\
\hline 1979 & 1 & $100 \%$ & 2.0 & 0.07 & $100 \%$ & 3.0 & 0.17 \\
\hline 1980 & 0 & & & & & & \\
\hline 1981 & 0 & & & & & & \\
\hline 1982 & 3 & $100 \%$ & $5.0 \pm 2.1$ & $0.11 \pm 0.04$ & $67 \%$ & $6.0 \pm 3.2$ & $0.50 \pm 0.33$ \\
\hline 1983 & 19 & $84 \%$ & $8.8 \pm 2.2$ & $0.19 \pm 0.04$ & $89 \%$ & $7.2 \pm 1.8$ & $0.31 \pm 0.12$ \\
\hline 1984 & 20 & $70 \%$ & $9.6 \pm 2.6$ & $0.19 \pm 0.05$ & $90 \%$ & $8.4 \pm 3.1$ & $0.17 \pm 0.09$ \\
\hline 1985 & 3 & $100 \%$ & $5.3 \pm 1.2$ & $0.14 \pm 0.05$ & $100 \%$ & $5.0 \pm 2.5$ & $0.14 \pm 0.08$ \\
\hline 1986 & 4 & $50 \%$ & $0.8 \pm 0.5$ & $0.02 \pm 0.01$ & $75 \%$ & $4.8 \pm 1.7$ & $0.06 \pm 0.04$ \\
\hline 1987 & 17 & $82 \%$ & $3.9 \pm 1.8$ & $0.11 \pm 0.05$ & $71 \%$ & $9.7 \pm 2.7$ & $0.09 \pm 0.04$ \\
\hline 1988 & 1 & $0 \%$ & 0.0 & 0.00 & $100 \%$ & 2.0 & 0.04 \\
\hline 1989 & 2 & $50 \%$ & $6.5 \pm 6.5$ & $0.17 \pm 0.17$ & $100 \%$ & $6.0 \pm 3.0$ & $0.25 \pm 0.23$ \\
\hline 1990 & 0 & & & & & & \\
\hline 1991 & 1 & $0 \%$ & 0.0 & 0.00 & $100 \%$ & 11.0 & 0.14 \\
\hline 1992 & 0 & & & & & & \\
\hline 1993 & 0 & & & & & & \\
\hline 1994 & 0 & & & & & & \\
\hline 1995 & 2 & $100 \%$ & $1.5 \pm 0.5$ & $0.02 \pm 0.01$ & $100 \%$ & $3.5 \pm 0.5$ & $0.03 \pm 0.01$ \\
\hline 1996 & 8 & $75 \%$ & $2.9 \pm 1.2$ & $0.07 \pm 0.03$ & $100 \%$ & $24.5 \pm 13.7$ & $0.19 \pm 0.10$ \\
\hline 1997 & 31 & $74 \%$ & $5.9 \pm 1.9$ & $0.13 \pm 0.04$ & $97 \%$ & $29.8 \pm 6.8$ & $0.60 \pm 0.17$ \\
\hline 1998 & 75 & $68 \%$ & $3.1 \pm 0.5$ & $0.07 \pm 0.01$ & $93 \%$ & $25.6 \pm 5.2$ & $0.87 \pm 0.35$ \\
\hline 1999 & 107 & $58 \%$ & $3.4 \pm 0.8$ & $0.06 \pm 0.01$ & $97 \%$ & $31.8 \pm 5.7$ & $0.38 \pm 0.11$ \\
\hline 2000 & 38 & $61 \%$ & $3.4 \pm 1.8$ & $0.08 \pm 0.05$ & $100 \%$ & $18.6 \pm 3.7$ & $0.27 \pm 0.09$ \\
\hline 2001 & 55 & $64 \%$ & $2.5 \pm 0.6$ & $0.06 \pm 0.01$ & $96 \%$ & $20.1 \pm 3.8$ & $0.18 \pm 0.05$ \\
\hline 2002 & 56 & $68 \%$ & $4.6 \pm 0.8$ & $0.09 \pm 0.01$ & $96 \%$ & $47.2 \pm 11.9$ & $0.41 \pm 0.19$ \\
\hline 2003 & 39 & $51 \%$ & $2.3 \pm 0.6$ & $0.05 \pm 0.01$ & $92 \%$ & $26.3 \pm 6.9$ & $0.12 \pm 0.03$ \\
\hline 2004 & 131 & $54 \%$ & $2.6 \pm 0.4$ & $0.06 \pm 0.01$ & $91 \%$ & $20.8 \pm 2.8$ & $0.22 \pm 0.04$ \\
\hline 2005 & 51 & $53 \%$ & $2.0 \pm 0.5$ & $0.05 \pm 0.01$ & $96 \%$ & $15.8 \pm 2.7$ & $0.22 \pm 0.06$ \\
\hline 2006 & 27 & $78 \%$ & $3.5 \pm 0.7$ & $0.08 \pm 0.01$ & $93 \%$ & $30.4 \pm 7.2$ & $0.23 \pm 0.07$ \\
\hline 2007 & 64 & $72 \%$ & $3.3 \pm 0.5$ & $0.07 \pm 0.01$ & $91 \%$ & $32.6 \pm 5.3$ & $0.30 \pm 0.04$ \\
\hline 2008 & 20 & $65 \%$ & $3.8 \pm 1.2$ & $0.08 \pm 0.03$ & $95 \%$ & $40.8 \pm 11.2$ & $0.23 \pm 0.08$ \\
\hline 2009 & 68 & $46 \%$ & $1.7 \pm 0.5$ & $0.04 \pm 0.01$ & $96 \%$ & $17.6 \pm 3.2$ & $0.18 \pm 0.03$ \\
\hline 2010 & 36 & $58 \%$ & $10.7 \pm 7.7$ & $0.23 \pm 0.17$ & $94 \%$ & $45.7 \pm 12.5$ & $0.23 \pm 0.06$ \\
\hline 2011 & 19 & $63 \%$ & $6.6 \pm 4.1$ & $0.15 \pm 0.10$ & $95 \%$ & $37.0 \pm 10.4$ & $0.27 \pm 0.09$ \\
\hline 2012 & 81 & $59 \%$ & $1.8 \pm 0.3$ & $0.04 \pm 0.01$ & $89 \%$ & $18.8 \pm 3.3$ & $0.26 \pm 0.08$ \\
\hline 2013 & 24 & $63 \%$ & $2.2 \pm 0.6$ & $0.04 \pm 0.01$ & $92 \%$ & $24.6 \pm 7.9$ & $0.14 \pm 0.03$ \\
\hline 2014 & 12 & $75 \%$ & $2.4 \pm 0.8$ & $0.05 \pm 0.01$ & $100 \%$ & $19.0 \pm 3.5$ & $0.31 \pm 0.13$ \\
\hline 2015 & 23 & $43 \%$ & $1.1 \pm 0.4$ & $0.02 \pm 0.01$ & $91 \%$ & $11.0 \pm 2.9$ & $0.23 \pm 0.14$ \\
\hline 2016 & 31 & $48 \%$ & $2.0 \pm 0.7$ & $0.04 \pm 0.01$ & $87 \%$ & $29.7 \pm 12.7$ & $0.25 \pm 0.10$ \\
\hline 2017 & 38 & $32 \%$ & $1.4 \pm 0.7$ & $0.03 \pm 0.01$ & $92 \%$ & $25.5 \pm 13.5$ & $0.21 \pm 0.07$ \\
\hline 2018 & 12 & $50 \%$ & $1.3 \pm 0.5$ & $0.02 \pm 0.01$ & $100 \%$ & $14.5 \pm 7.3$ & $0.09 \pm 0.05$ \\
\hline 2019 & 44 & $41 \%$ & $0.8 \pm 0.2$ & $0.02 \pm 0.01$ & $95 \%$ & $10.6 \pm 2.2$ & $0.08 \pm 0.01$ \\
\hline 2020 & 14 & $64 \%$ & $4.1 \pm 3.1$ & $0.10 \pm 0.07$ & $93 \%$ & $26.8 \pm 15.8$ & $0.32 \pm 0.23$ \\
\hline
\end{tabular}


Table 3. Running averages by 5-year period for plastic abundance in fulmars from the Netherlands. A. all plastic categories combined; B. separate data for industrial and user plastic categories. Sample size is given with the proportion of adult birds in brackets. Frequency of Occurrence $(\% F O)$ represents the proportion of birds with one or more items of that litter present. Average number ( $n \pm s e)$ gives the abundance by number of plastic particles per bird with standard error, and average mass $(g \pm s e)$ the weight of plastic per bird in grams with standard error. Total plastics mass is also shown in terms of medians and geometric mean mass (for comparative purposes reducing the influence of outliers) and as level of performance in relation to the OSPAR ECOQO, now Fulmar-TV, viz. the percentage of birds having more than the threshold of 0.1 gram of plastic in the stomach. Note sample sizes $(n)$ to be very low for particular years implying low reliability of the annual averages for such years, not to be used as separate figures (only years with sample size over 10 birds are printed in bold).

Table 3A.

\begin{tabular}{ccc}
\hline \multicolumn{2}{l}{ Netherlands } & \\
\hline YEAR & $\begin{array}{c}\text { sample } \\
n\end{array}$ & $(\% \mathrm{ad})$ \\
\hline
\end{tabular}

\begin{tabular}{|c|c|c|}
\hline 1979-89 & 70 & $(43 \%)$ \\
\hline 1990_94 & 1 & \\
\hline 1991_95 & 3 & \\
\hline 1992_96 & 10 & \\
\hline 1993_97 & 41 & $(27 \%)$ \\
\hline 1994_98 & 116 & $(38 \%)$ \\
\hline 1995_99 & 223 & $(53 \%)$ \\
\hline 1996_00 & 259 & $(54 \%)$ \\
\hline 1997_01 & 306 & $(51 \%)$ \\
\hline 1998_02 & 331 & $(54 \%)$ \\
\hline 1999_03 & 295 & $(57 \%)$ \\
\hline 2000_04 & 319 & $(62 \%)$ \\
\hline 2001_05 & 332 & $(64 \%)$ \\
\hline 2002_06 & 304 & $(68 \%)$ \\
\hline 2003_07 & 312 & $(66 \%)$ \\
\hline 2004_08 & 293 & $(67 \%)$ \\
\hline 2005_09 & 230 & $(52 \%)$ \\
\hline 2006_10 & 215 & $(47 \%)$ \\
\hline 2007_11 & 207 & $(44 \%)$ \\
\hline 2008_12 & 224 & $(44 \%)$ \\
\hline 2009_13 & 228 & $(43 \%)$ \\
\hline 2010_14 & 172 & $(45 \%)$ \\
\hline 2011_15 & 159 & $(43 \%)$ \\
\hline 2012_16 & 171 & $(39 \%)$ \\
\hline 2013_17 & 128 & $(33 \%)$ \\
\hline 2014_18 & 116 & $(32 \%)$ \\
\hline 2015_19 & 148 & $(30 \%)$ \\
\hline 2016_20 & 139 & $(28 \%)$ \\
\hline
\end{tabular}

\section{Total plastics}

\begin{tabular}{cccccc}
\hline \multirow{2}{*}{ FO } & average number & average mass & median & geometric & EcoQ\% \\
& $\mathbf{n} \pm \mathbf{s e}$ & $\mathrm{g} \pm \mathrm{se}$ & mass & mean mass & (over 0.1g) \\
\hline
\end{tabular}

$0.34 \pm 0.06$

0.162

0.109

$67 \%$

$\begin{array}{llllll}\mathbf{9 8 \%} & \mathbf{3 2 . 6} \pm \mathbf{6 . 1} & \mathbf{0 . 6 1} \pm \mathbf{0 . 1 3} & \mathbf{0 . 2 8 6} & \mathbf{0 . 2 1 7} & \mathbf{7 6 \%} \\ \mathbf{9 6 \%} & \mathbf{3 0 . 0} \pm \mathbf{4 . 0} & \mathbf{0 . 8 2} \pm \mathbf{0 . 2 3} & \mathbf{0 . 2 2 0} & \mathbf{0 . 1 7 6} & \mathbf{7 2 \%} \\ \mathbf{9 7 \%} & \mathbf{3 2 . 5} \pm \mathbf{3 . 6} & \mathbf{0 . 6 4} \pm \mathbf{0 . 1 3} & \mathbf{0 . 1 7 0} & \mathbf{0 . 1 4 8} & \mathbf{6 7 \%} \\ \mathbf{9 7 \%} & \mathbf{3 1 . 2} \pm \mathbf{3 . 2} & \mathbf{0 . 6 0} \pm \mathbf{0 . 1 2} & \mathbf{0 . 1 7 4} & \mathbf{0 . 1 4 6} & \mathbf{6 6 \%} \\ \mathbf{9 7 \%} & \mathbf{2 9 . 8} \pm \mathbf{2 . 8} & \mathbf{0 . 5 4} \pm \mathbf{0 . 1 0} & \mathbf{0 . 1 5 4} & \mathbf{0 . 1 3 5} & \mathbf{6 3 \%} \\ \mathbf{9 7 \%} & \mathbf{3 2 . 9} \pm \mathbf{3 . 3} & \mathbf{0 . 5 2} \pm \mathbf{0 . 1 0} & \mathbf{0 . 1 5 1} & \mathbf{0 . 1 2 8} & \mathbf{6 2 \%} \\ \mathbf{9 8 \%} & \mathbf{3 3 . 5} \pm \mathbf{3 . 6} & \mathbf{0 . 3 7} \pm \mathbf{0 . 0 6} & \mathbf{0 . 1 4 1} & \mathbf{0 . 1 1 2} & \mathbf{5 9 \%} \\ \mathbf{9 5 \%} & \mathbf{2 8 . 7} \pm \mathbf{2 . 9} & \mathbf{0 . 3 0} \pm \mathbf{0 . 0 4} & \mathbf{0 . 1 4 1} & \mathbf{0 . 0 9 5} & \mathbf{5 9 \%} \\ \mathbf{9 5 \%} & \mathbf{2 7 . 8} \pm \mathbf{2 . 7} & \mathbf{0 . 2 9} \pm \mathbf{0 . 0 4} & \mathbf{0 . 1 3 4} & \mathbf{0 . 0 9 1} & \mathbf{5 7 \%} \\ \mathbf{9 4 \%} & \mathbf{2 9 . 3} \pm \mathbf{3 . 0} & \mathbf{0 . 3 0} \pm \mathbf{0 . 0 4} & \mathbf{0 . 1 4 2} & \mathbf{0 . 0 9 4} & \mathbf{6 1 \%} \\ \mathbf{9 3 \%} & \mathbf{2 6 . 6} \pm \mathbf{2 . 1} & \mathbf{0 . 2 8} \pm \mathbf{0 . 0 2} & \mathbf{0 . 1 5 1} & \mathbf{0 . 0 9 3} & \mathbf{6 2 \%} \\ \mathbf{9 3 \%} & \mathbf{2 7 . 6} \pm \mathbf{2 . 2} & \mathbf{0 . 3 0} \pm \mathbf{0 . 0 3} & \mathbf{0 . 1 6 6} & \mathbf{0 . 0 9 8} & \mathbf{6 2 \%} \\ \mathbf{9 5 \%} & \mathbf{2 7 . 5} \pm \mathbf{2 . 5} & \mathbf{0 . 2 9} \pm \mathbf{0 . 0 3} & \mathbf{0 . 1 4 4} & \mathbf{0 . 1 0 4} & \mathbf{5 9 \%} \\ \mathbf{9 4 \%} & \mathbf{3 4 . 6} \pm \mathbf{3 . 8} & \mathbf{0 . 3 2} \pm \mathbf{0 . 0 4} & \mathbf{0 . 1 5 3} & \mathbf{0 . 1 1 0} & \mathbf{6 2 \%} \\ \mathbf{9 5 \%} & \mathbf{3 5 . 6} \pm \mathbf{4 . 0} & \mathbf{0 . 3 4} \pm \mathbf{0 . 0 4} & \mathbf{0 . 1 5 0} & \mathbf{0 . 1 1 2} & \mathbf{6 1 \%} \\ \mathbf{9 4 \%} & \mathbf{3 0 . 0} \pm \mathbf{3 . 6} & \mathbf{0 . 3 1} \pm \mathbf{0 . 0 5} & \mathbf{0 . 1 1 6} & \mathbf{0 . 0 9 2} & \mathbf{5 4 \%} \\ \mathbf{9 4 \%} & \mathbf{2 8 . 4} \pm \mathbf{3 . 4} & \mathbf{0 . 3 0} \pm \mathbf{0 . 0 5} & \mathbf{0 . 1 0 9} & \mathbf{0 . 0 8 8} & \mathbf{5 3 \%} \\ \mathbf{9 3 \%} & \mathbf{3 1 . 5} \pm \mathbf{4 . 3} & \mathbf{0 . 3 4} \pm \mathbf{0 . 0 6} & \mathbf{0 . 1 2 9} & \mathbf{0 . 0 9 4} & \mathbf{5 8 \%} \\ \mathbf{9 3 \%} & \mathbf{2 3 . 1} \pm \mathbf{2 . 8} & \mathbf{0 . 3 0} \pm \mathbf{0 . 0 5} & \mathbf{0 . 1 1 6} & \mathbf{0 . 0 8 5} & \mathbf{5 3 \%} \\ \mathbf{9 1 \%} & \mathbf{2 2 . 4} \pm \mathbf{3 . 1} & \mathbf{0 . 2 8} \pm \mathbf{0 . 0 5} & \mathbf{0 . 1 0 2} & \mathbf{0 . 0 7 3} & \mathbf{5 0 \%} \\ \mathbf{9 2 \%} & \mathbf{2 4 . 9} \pm \mathbf{5 . 5} & \mathbf{0 . 2 6} \pm \mathbf{0 . 0 4} & \mathbf{0 . 0 9 5} & \mathbf{0 . 0 6 8} & \mathbf{4 7 \%} \\ \mathbf{9 3 \%} & \mathbf{2 3 . 5} \pm \mathbf{5 . 9} & \mathbf{0 . 2 6} \pm \mathbf{0 . 0 5} & \mathbf{0 . 0 7 8} & \mathbf{0 . 0 6 6} & \mathbf{4 4 \%} \\ \mathbf{9 3 \%} & \mathbf{2 0 . 1} \pm \mathbf{4 . 6} & \mathbf{0 . 2 0} \pm \mathbf{0 . 0 4} & \mathbf{0 . 0 5 9} & \mathbf{0 . 0 5 1} & \mathbf{3 9 \%} \\ \mathbf{9 3 \%} & \mathbf{2 2 . 5} \pm \mathbf{5 . 2} & \mathbf{0 . 2 1} \pm \mathbf{0 . 0 4} & \mathbf{0 . 0 6 4} & \mathbf{0 . 0 5 2} & \mathbf{3 9 \%}\end{array}$


Table 3B. (for caption see table 3A.)

\begin{tabular}{|c|c|c|c|c|c|c|c|}
\hline \multicolumn{2}{|c|}{ Netherlands } & \multicolumn{3}{|c|}{ Industrial granules } & \multicolumn{3}{|c|}{ User plastics } \\
\hline YEAR & $\begin{array}{c}\text { sample } \\
n\end{array}$ & $\% \mathrm{FO}$ & $\begin{array}{c}\text { avg number } \\
\mathrm{n} \pm \mathrm{se}\end{array}$ & $\begin{array}{c}\text { avg mass } \\
\mathrm{g} \pm \mathrm{se}\end{array}$ & $\% \mathrm{FO}$ & $\begin{array}{c}\text { avg number } \\
n \pm s e\end{array}$ & $\begin{array}{c}\text { avg mass } \\
\mathrm{g} \pm \mathrm{se}\end{array}$ \\
\hline 1979-89 & 70 & $77 \%$ & $6.8 \pm 1.1$ & $0.15 \pm 0.02$ & $84 \%$ & $7.7 \pm 1.2$ & $0.19 \pm 0.05$ \\
\hline 1990_94 & 1 & & & & & & \\
\hline 1991_95 & 3 & & & & & & \\
\hline 1992_96 & 10 & & & & & & \\
\hline 1993_97 & 41 & $76 \%$ & $5.1 \pm 1.5$ & $0.12 \pm 0.03$ & $98 \%$ & $27.5 \pm 5.8$ & $0.49 \pm 0.13$ \\
\hline 1994_98 & 116 & $71 \%$ & $3.8 \pm 0.6$ & $0.08 \pm 0.01$ & $95 \%$ & $26.3 \pm 3.9$ & $0.74 \pm 0.23$ \\
\hline 1995_99 & 223 & $65 \%$ & $3.6 \pm 0.5$ & $0.07 \pm 0.01$ & $96 \%$ & $28.9 \pm 3.4$ & $0.56 \pm 0.13$ \\
\hline 1996_00 & 259 & $64 \%$ & $3.6 \pm 0.5$ & $0.08 \pm 0.01$ & $97 \%$ & $27.6 \pm 3.0$ & $0.53 \pm 0.11$ \\
\hline 1997_01 & 306 & $63 \%$ & $3.4 \pm 0.4$ & $0.07 \pm 0.01$ & $96 \%$ & $26.3 \pm 2.6$ & $0.47 \pm 0.10$ \\
\hline 1998_02 & 331 & $63 \%$ & $3.4 \pm 0.4$ & $0.07 \pm 0.01$ & $96 \%$ & $29.5 \pm 3.1$ & $0.45 \pm 0.09$ \\
\hline 1999_03 & 295 & $60 \%$ & $3.3 \pm 0.4$ & $0.07 \pm 0.01$ & $97 \%$ & $30.1 \pm 3.3$ & $0.30 \pm 0.06$ \\
\hline 2000_04 & 319 & $59 \%$ & $3.0 \pm 0.3$ & $0.06 \pm 0.01$ & $94 \%$ & $25.7 \pm 2.7$ & $0.24 \pm 0.04$ \\
\hline 2001_05 & 332 & $58 \%$ & $2.8 \pm 0.3$ & $0.06 \pm 0.01$ & $94 \%$ & $25.0 \pm 2.6$ & $0.23 \pm 0.04$ \\
\hline 2002_06 & 304 & $58 \%$ & $2.9 \pm 0.3$ & $0.06 \pm 0.01$ & $93 \%$ & $26.4 \pm 2.8$ & $0.24 \pm 0.04$ \\
\hline 2003_07 & 312 & $59 \%$ & $2.7 \pm 0.2$ & $0.06 \pm 0.01$ & $92 \%$ & $23.9 \pm 2.0$ & $0.22 \pm 0.02$ \\
\hline 2004_08 & 293 & $61 \%$ & $2.8 \pm 0.3$ & $0.06 \pm 0.01$ & $92 \%$ & $24.8 \pm 2.1$ & $0.24 \pm 0.02$ \\
\hline 2005_09 & 230 & $60 \%$ & $2.6 \pm 0.3$ & $0.06 \pm 0.01$ & $94 \%$ & $24.9 \pm 2.3$ & $0.23 \pm 0.02$ \\
\hline 2006_10 & 215 & $61 \%$ & $4.1 \pm 1.3$ & $0.09 \pm 0.03$ & $93 \%$ & $30.5 \pm 3.2$ & $0.23 \pm 0.02$ \\
\hline 2007_11 & 207 & $59 \%$ & $4.4 \pm 1.4$ & $0.10 \pm 0.03$ & $94 \%$ & $31.1 \pm 3.3$ & $0.24 \pm 0.02$ \\
\hline 2008_12 & 224 & $56 \%$ & $3.8 \pm 1.3$ & $0.08 \pm 0.03$ & $93 \%$ & $26.2 \pm 2.9$ & $0.23 \pm 0.04$ \\
\hline 2009_13 & 228 & $56 \%$ & $3.6 \pm 1.3$ & $0.08 \pm 0.03$ & $93 \%$ & $24.8 \pm 2.8$ & $0.22 \pm 0.03$ \\
\hline 2010_14 & 172 & $61 \%$ & $4.3 \pm 1.7$ & $0.10 \pm 0.04$ & $92 \%$ & $27.3 \pm 3.5$ & $0.24 \pm 0.04$ \\
\hline 2011_15 & 159 & $59 \%$ & $2.4 \pm 0.5$ & $0.05 \pm 0.01$ & $91 \%$ & $20.7 \pm 2.5$ & $0.24 \pm 0.05$ \\
\hline 2012_16 & 171 & $57 \%$ & $1.8 \pm 0.2$ & $0.04 \pm 0.01$ & $90 \%$ & $20.5 \pm 3.0$ & $0.24 \pm 0.05$ \\
\hline 2013_17 & 128 & $48 \%$ & $1.7 \pm 0.3$ & $0.03 \pm 0.01$ & $91 \%$ & $23.1 \pm 5.3$ & $0.22 \pm 0.04$ \\
\hline 2014_18 & 116 & $45 \%$ & $1.6 \pm 0.3$ & $0.03 \pm 0.01$ & $92 \%$ & $21.9 \pm 5.7$ & $0.22 \pm 0.05$ \\
\hline 2015_19 & 148 & $41 \%$ & $1.3 \pm 0.2$ & $0.03 \pm 0.00$ & $93 \%$ & $18.8 \pm 4.5$ & $0.17 \pm 0.04$ \\
\hline 2016_20 & 139 & $43 \%$ & $1.6 \pm 0.4$ & $0.03 \pm 0.01$ & $93 \%$ & $20.9 \pm 5.0$ & $0.18 \pm 0.04$ \\
\hline
\end{tabular}



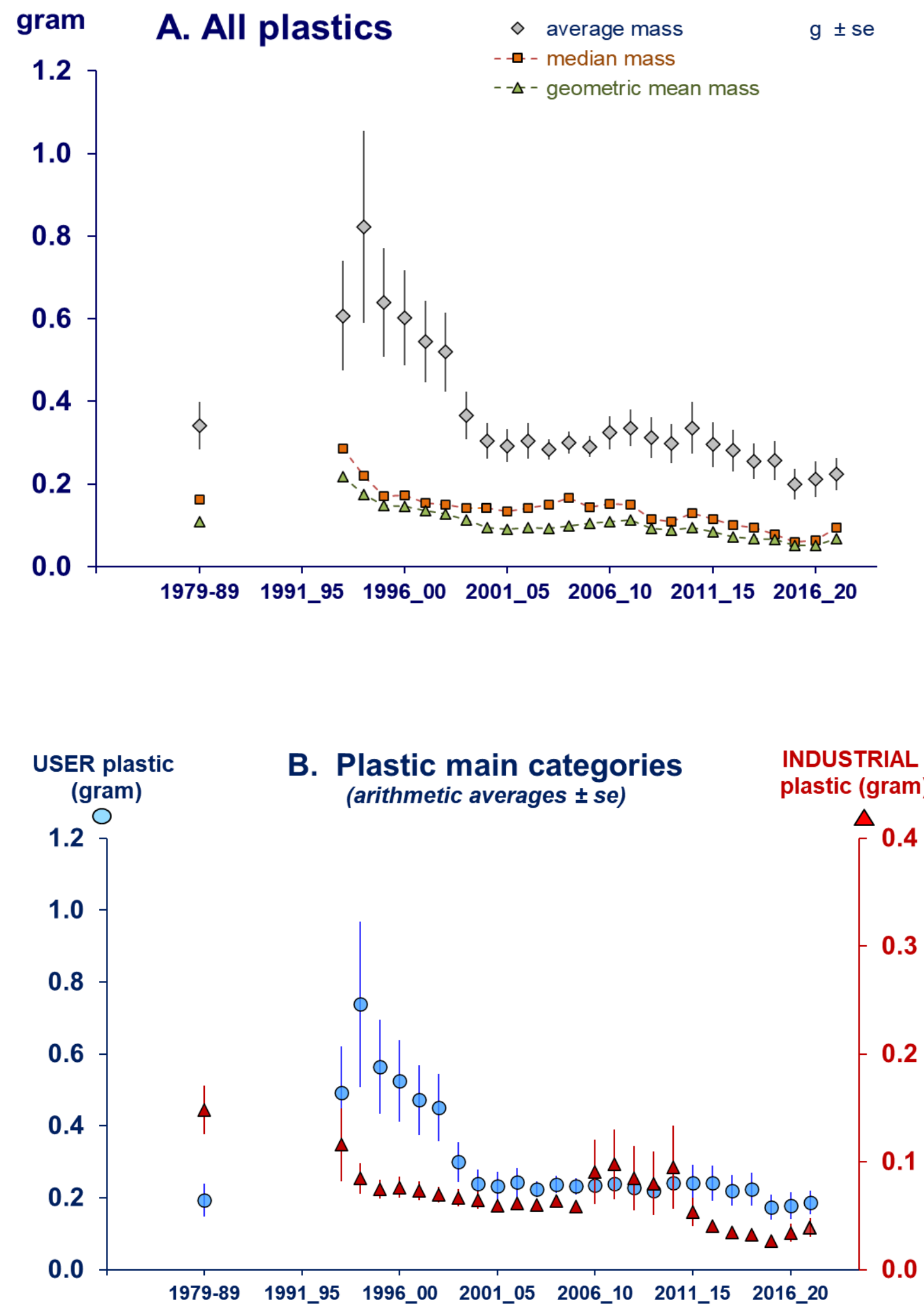

5-year period 


\section{gram}

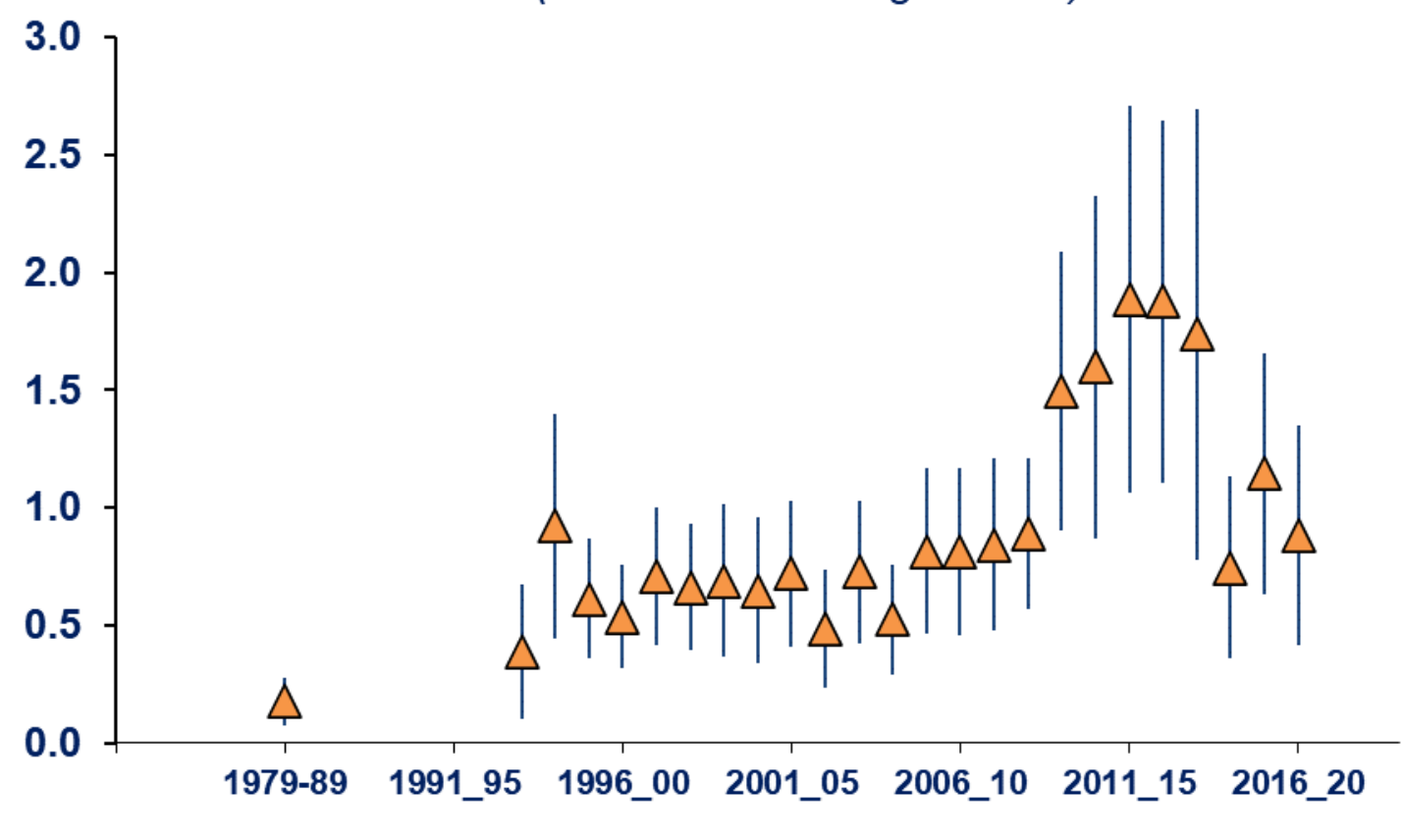

C. Paraffin-like substances

(arithmetic averages \pm se)

\section{5-year period}

Figure 2. Plastic and paraffin-like substance mass in stomachs of fulmars from the

Netherlands 1979-2020. Shown by 5-year running averages, except all data combined for the early period 1979-1989. Data only shown where sample size over 40 stomachs. A: Data for all plastics combined visualising changes in arithmetic average mass \pm se (grey diamonds), median mass (oranges squares) and geometric mean mass (green triangles). B: Arithmetic mass data, split into user plastic (blue circles, left $y$ axis) and industrial plastic (red triangles, right $y$-axis). C: Arithmetic mass \pm se for paraffin-like substances (orange triangles). Data are visualized as running 5-year averages (i.e. data-points shift one year ahead at a time) and do not represent statistical trends.

\subsection{Trends}

In the EcoQO approach, the emphasis in detailed trend analyses is on the mass of plastics in stomachs of beached fulmars rather than on incidence or number of plastic particles. In trend discussions, a distinction is made between:

\subsubsection{Long-term trends}

The 'long-term trend' is defined as the trend over all years in the dataset (now 1979-2020). The current dataset holds records for 1177 fulmars, with 576 adult birds and 567 non-adults, which are juveniles to immatures several years of age. In 34 birds insufficient information was available to assess the age-group.

Long-term trends are influenced by the fact that in initial years, trends for industrial and user plastics were opposite (Fig. 2B, Table 3B, Table 4A). The industrial plastics halved from early 1980 s to mid1990 s while user plastics nearly tripled in mass. Measured over the full period of over 42 years of data for the Netherlands, the initial strong decrease of industrial plastics still contributes strongly to a longterm significant decline in industrial plastic $(p<0.001)$, in spite of the fact that since the early $2000 \mathrm{~s}$ changes have been much less evident (Table 2). The decrease in abundance of industrial plastics in the marine environment has been signalled in different oceanographic regions all over the globe (Van Franeker \& Meijboom 2002, Vlietstra \& Parga 2002, Ryan 2008, Van Franeker et al. 2011; Van Franeker \& Law 2015). For user plastics, the initial increase from the 1980 s to mid-1990s was largely 'compensated' by a rapid decrease from late 1990 s to around 2003, and relatively small changes after 
that. Slopes of regression lines for user plastics over the 1979-2020 period are negative, suggesting declines but are not significant (Table 4A). However, combined for industrial and user plastics the trend is a highly significant decrease $(p<0.001)$. Trends are similar in the different age groups, but due to smaller samples sizes do not always reach the same significance level (adults decrease at $\mathrm{p}=0.02$; the non-adult trend shows a significant reduction at $\mathrm{p}<0.001$ ).

\subsubsection{Recent trends}

The 'recent trend' is defined as the trend in plastic mass in fulmar stomachs over the past 10 years, so in this report: 2011-2020 (Table 4C). After the early 2000s, and up to 2014, recent trends were generally described as stable or as potential slow but non-significant decline (Table 4D). However, the analyses of the period 2006-2015 based on 374 birds for the first time showed significant declines in both industrial plastics $(0.010)$ and user plastics $(p=0.049)$ although their combined trend did not reach significance $(p=0.062)$. The next 10-year analysis over years 2007-2016 $(n=378)$ for the first time demonstrated an overall significant 10 -year decline $(p=0.034)$ mainly based on a similar reduced mass of user plastic debris $(p=0.036)$ and industrial plastics $(p=0.035)$. Over the period 2008-2017 $(n=352)$, and 2009-2018 $(n=344)$ the direction of change was still the same, but did not reach significance (Table 4D) The current 10-year analysis over the 2011-2020 period is based on a smaller sample of 298 birds, but is nevertheless significant for all plastics combined $(p=0.018)$ and for separate industrial $(p=0.006)$ and user plastics $(p=0.049)$. Trends are similar although not always significant for both adults and non-adults (Table 4C).

The new policy relevant addition of FTV Performance, has led to an added wider perspective of the time periods to be considered in analysing trends. This has led to evaluate trends since the start of the international fulmar monitoring in the North Sea. Trends in ingested mass of plastics over the 19-year period (Table 4B) are clearer than over the recent 10 years (Table 4C). Industrial plastics showed a significant decrease over the 2002-2020 period $(p<0.001)$ also for separate age groups. User plastics also showed significant decline $(p=0.014)$, mainly due to the non-adult birds. Combined for all plastics, adults $(p=0.021)$ and non-adults $(p<0.001)$ contributed to a highly significant decline in ingested plastic mass for all ages combined $(p<0.001)$. 
Table 4. Details of linear regression analyses for time related trends in plastic abundance by mass in stomachs of fulmars in the Netherlands. Analysis by linear regression, fitting In-transformed litter mass values for individual birds on the year of collection. Tests were conducted over A. full time period of data, B. the period since start of the Save the North Sea project in 2002, and C. the most recent 10 years of data, which is the recommended period in OSPAR guidelines for testing in the former Fulmar EcoQO, now Fulmar-TV. D significance of sequential decadal trends for 1980 s and 10-year periods starting 1997. The regression line ('trend') is described by $y=$ Constant + estimate $*_{x}$ in which $y$ is the calculated value of the regression-line for year $x$. When the $t$-value of a regression is negative, it indicates a decrease in the tested litter-category; a positive $t$-value indicates increase. A trend is considered significant when the probability $(p)$ of misjudgement of data is less than $5 \%(p<0.05)$. Significant trends in the table are labelled with positive signs in case of increase $(+)$ in plastic mass or negative signs in case of decrease (-). Significance at the $5 \%$ level $(p<0.05)$ is labelled as - or + ; at the $1 \%$ level $(p<0.01)$ as -- or ++ ; and at the $0.1 \%$ level $(p<0.001)$ as --- or +++ . Where test results are not significant (n.s.) but close $(p<0.1)$, upward or downward arrow indicates the potential direction of change.

\begin{tabular}{|c|c|c|c|c|c|c|}
\hline \multirow[t]{2}{*}{ A. } & \multicolumn{6}{|c|}{ LONG TERM TRENDS 1979-2020 } \\
\hline & \multicolumn{6}{|c|}{ for plastics in Fulmar stomachs, the Netherlands } \\
\hline Industrial plastics (InGIND) & $n$ & constant & slope & s.e. & $\mathbf{t}$ & $p$ \\
\hline all ages & 1177 & 98.2 & -0.0512 & 0.0078 & -6.59 & $<0.001 \downarrow--$ \\
\hline adults & 576 & 80.8 & -0.0427 & 0.0128 & -3.33 & $<0.001 \downarrow--$ \\
\hline non adults & 567 & 122.1 & -0.0630 & 0.0100 & -6.30 & $<0.001 \downarrow---$ \\
\hline User plastics (InGUSE) & $n$ & constant & slope & s.e. & $\mathbf{t}$ & $\mathbf{p}$ \\
\hline all ages & 1177 & 19.0 & -0.0108 & 0.0068 & -1.60 & 0.111 n.s. \\
\hline adults & 576 & 31.5 & -0.0172 & 0.0116 & -1.48 & 0.139 n.s. \\
\hline non adults & 567 & 16.3 & -0.0093 & 0.0084 & -1.11 & 0.269 n.s. \\
\hline All plastics combined (InGPLA) & $n$ & constant & slope & s.e. & $\mathbf{t}$ & $\mathbf{p}$ \\
\hline all ages & 1177 & 54.7 & -0.0285 & 0.0066 & -4.30 & $\overline{<0.001} \downarrow-\ldots$ \\
\hline adults & 576 & 50.9 & -0.0267 & 0.0115 & -2.33 & $0.020 \downarrow-$ \\
\hline non adults & 567 & 64.6 & -0.0333 & 0.0080 & -4.16 & $<0.001 \downarrow-\ldots$ \\
\hline
\end{tabular}

\begin{tabular}{|c|c|c|c|c|c|c|}
\hline SUSPECTED CHEMICALS (InGCHE) & $n$ & constant & slope & s.e. & $\mathbf{t}$ & $\mathbf{p}$ \\
\hline all ages & 1177 & -27.5 & 0.0108 & 0.0088 & 1.23 & 0.220 \\
\hline adults & 576 & -5.6 & -0.0001 & 0.0140 & -0.01 & 0.995 \\
\hline non adults & 567 & 42.3 & 0.0182 & 0.0120 & 1.51 & 0.131 \\
\hline
\end{tabular}


B.

TRENDS 2002-2020 since start SNS project for plastics in Fulmar stomachs, the Netherlands

\begin{tabular}{|c|c|c|c|c|c|c|}
\hline Industrial plastics (InGIND) & $n$ & Constant & estimate & s.e. & $\mathbf{t}$ & $\mathbf{p}$ \\
\hline all ages & 790 & 100.1 & -0.0521 & 0.0145 & -3.60 & $<0.001$ \\
\hline adults & 387 & 101.2 & -0.0528 & 0.0228 & -2.32 & 0.021 \\
\hline non adults & 373 & 158.5 & -0.0811 & 0.0207 & -3.91 & $<0.001$ \\
\hline
\end{tabular}

\begin{tabular}{lcrrrrr} 
User plastics (InGUSE) & $\boldsymbol{n}$ & Constant & estimate & s.e. & $\mathbf{t}$ & $\mathbf{p}$ \\
\hline all ages & 790 & 59.7 & -0.0311 & 0.0126 & -2.47 & 0.014 \\
adults & 387 & 75.6 & -0.0392 & 0.0212 & -1.85 & $0.065 \downarrow$ n.s. \\
non adults & 373 & 98.4 & -0.0502 & 0.0166 & -3.03 & $0.003 \downarrow--$
\end{tabular}

\begin{tabular}{|c|c|c|c|c|c|c|}
\hline All plastics combined (InGPLA) & $\boldsymbol{n}$ & Constant & estimate & s.e. & $\mathbf{t}$ & $\mathbf{p}$ \\
\hline all ages & 790 & 76.3 & -0.0392 & 0.0125 & -3.14 & $\overline{0.002} \downarrow--$ \\
\hline adults & 387 & 87.6 & -0.0449 & 0.0210 & -2.14 & $0.033 \downarrow-$ \\
\hline non adults & 373 & 120.4 & -0.0610 & 0.0164 & -3.72 & $<0.001$ \\
\hline
\end{tabular}

\begin{tabular}{|c|c|c|c|c|c|c|}
\hline SUSPECTED CHEMICALS (InGCHE) & $n$ & Constant & estimate & s.e. & $\mathbf{t}$ & $\mathbf{p}$ \\
\hline all ages & 790 & -39.8 & 0.0169 & 0.0166 & 1.02 & 0.310 n.s. \\
\hline adults & 387 & -42.4 & 0.0182 & 0.0237 & 0.77 & 0.444 n.s. \\
\hline non adults & 373 & -27.8 & 0.0110 & 0.0262 & 0.42 & 0.674 n.s. \\
\hline
\end{tabular}

C.

RECENT 10-YEAR TRENDS 2011-2020

for plastics in Fulmar stomachs, the Netherlands

Industrial plastics (InGIND)

all ages

adults

non adults

\begin{tabular}{rrrrrr}
$\boldsymbol{n}$ & constant & slope & s.e. & $\mathbf{t}$ & $\mathbf{p}$ \\
\hline 298 & 223.7 & -0.1134 & 0.0409 & -2.77 & $0.006 \downarrow--$ \\
101 & 211.0 & -0.1075 & 0.0690 & -1.56 & 0.123 n.s. \\
177 & 289.0 & -0.1458 & 0.0540 & -2.70 & $0.008 \downarrow--$
\end{tabular}

\begin{tabular}{lcrrrrr} 
User plastics (InGUSE) & $\boldsymbol{n}$ & constant & slope & s.e. & t & $\mathbf{p}$ \\
\hline all ages & 298 & 147.8 & -0.0748 & 0.0379 & -1.97 & $0.049 \downarrow-$ \\
adults & 101 & 208.0 & -0.1051 & 0.0696 & -1.51 & 0.134 n.s. \\
non adults & 177 & 158.4 & -0.0800 & 0.0483 & -1.66 & $0.099 \downarrow$ n.s.
\end{tabular}

\begin{tabular}{lcrrrrr} 
All plastics combined (InGPLA) & $\boldsymbol{n}$ & constant & slope & s.e. & $\mathbf{t}$ & $\mathbf{p}$ \\
\hline all ages & $\mathbf{2 9 8}$ & $\mathbf{1 7 7 . 0}$ & $\mathbf{- 0 . 0 8 9 2}$ & $\mathbf{0 . 0 3 7 5}$ & $\mathbf{- 2 . 3 8}$ & $\mathbf{0 . 0 1 8} \downarrow-$ \\
adults & 101 & 256.0 & -0.1286 & 0.0679 & -1.89 & $0.061 \downarrow$ n.s. \\
non adults & 177 & 187.7 & -0.0944 & 0.0478 & -1.97 & $0.050 \downarrow-$ \\
\hline
\end{tabular}

\begin{tabular}{|c|c|c|c|c|c|c|}
\hline SUSPECTED CHEMICALS (InGCHE) & $n$ & Constant & estimate & s.e. & $t$ & $p$ \\
\hline all ages & 298 & -24.0 & 0.0092 & 0.0536 & 0.17 & 0.864 \\
\hline adults & 101 & -246.0 & 0.1193 & 0.0863 & 1.38 & 0.170 \\
\hline non adults & 177 & 37.0 & -0.0214 & 0.0725 & -0.29 & 0.768 \\
\hline
\end{tabular}


D.

\begin{tabular}{cc} 
Decade & $n$ \\
\hline $1979-1991$ & $(71)$ \\
& \\
$1995-2004$ & $(542)$ \\
$1996-2005$ & $(591)$ \\
$1997-2006$ & $(610)$ \\
$1998-2007$ & $(643)$ \\
$1999-2008$ & $(588)$ \\
$2000-2009$ & $(549)$ \\
$2001-2010$ & $(547)$ \\
$2002-2011$ & $(511)$ \\
$2003-2012$ & $(455)$ \\
$2004-2013$ & $(521)$ \\
$2005-2014$ & $(402)$ \\
$2006-2015$ & $(374)$ \\
$2007-2016$ & $(378)$ \\
$2008-2017$ & $(352)$ \\
$2009-2018$ & $(344)$ \\
$2010-2019$ & $(320)$ \\
$2011-2020$ & $(298)$ \\
\hline
\end{tabular}

Linear Regression tests over 10-year periods Industrial plastic User plastic

$\frac{\mathbf{p}}{0.028 \downarrow-} \frac{\mathbf{p}}{0.267 \text { n.s. }}$

ALL PLASTICS

$\begin{array}{llll}0.022 & \downarrow- & 0.002 & \downarrow-- \\ 0.007 & \downarrow-- & 0.001 & \downarrow--- \\ 0.087 & \downarrow \text { n.s. } & 0.002 & \downarrow-- \\ 0.819 & \text { n.s. } & 0.289 & \text { n.s. } \\ 0.253 & \text { n.s. } & 0.765 & \text { n.s. } \\ 0.436 & \text { n.s. } & 0.936 & \text { n.s. } \\ 0.537 & \text { n.s. } & 0.395 & \text { n.s. } \\ 0.686 & \text { n.s. } & 0.320 & \text { n.s. } \\ 0.488 & \text { n.s. } & 0.044 & \uparrow+ \\ 0.901 & \text { n.s. } & 0.963 & \text { n.s. } \\ 0.550 & \text { n.s. } & 0.411 & \text { n.s. } \\ 0.010 & \downarrow-- & 0.049 & \downarrow- \\ 0.035 & \downarrow- & 0.036 & \downarrow- \\ 0.050 & \downarrow- & 0.151 & \text { n.s. } \\ 0.104 & \text { n.s. } & 0.121 & \text { n.s. } \\ <0.001 & \downarrow--- & 0.006 & \downarrow-- \\ 0.006 & \downarrow-- & 0.049 & \downarrow-\end{array}$

$\frac{\mathbf{p}}{0.037 \downarrow-}$

$<0.001 \downarrow---$

$<0.001 \downarrow---$

$<0.001 \downarrow---$

0.173 n.s.

0.626 n.s.

0.749 n.s.

0.755 n.s.

0.526 n.s.

$0.079 \uparrow$ n.s.

0.844 n.s.

0.399 n.s.

$0.062 \downarrow$ n.s.

$0.034 \downarrow-$

$0.091 \downarrow$ n.s.

$0.072 \downarrow$ n.s.

$0.002 \downarrow--$

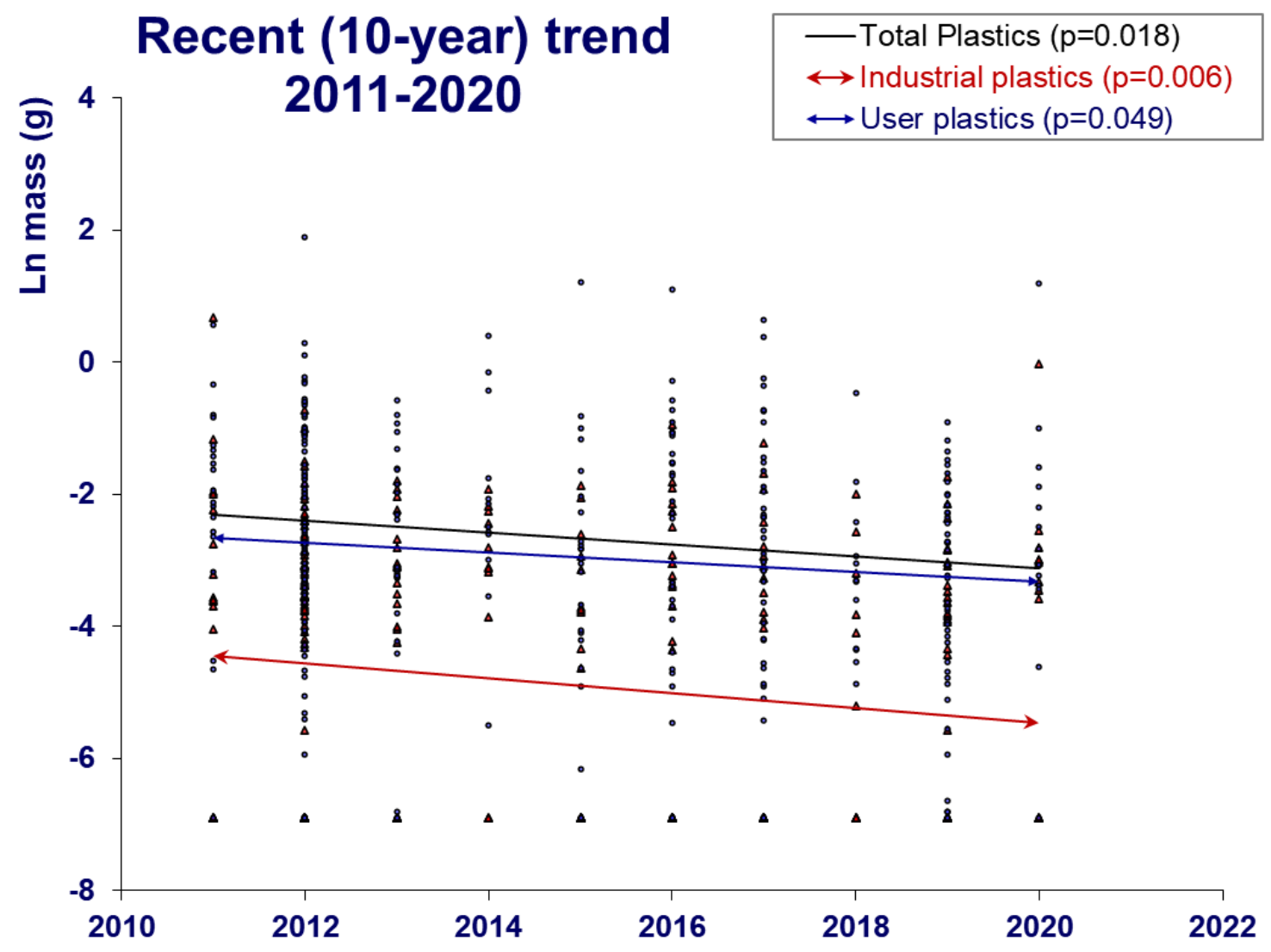

Figure 3. Statistical trend in plastic mass in stomachs of fulmars from the Netherlands 2011-2020. The graph, as an example of the statistical approach, shows plotted In-transformed mass data for industrial plastic and user plastic in stomachs of individual fulmars, plotted against year, and linear trendlines for industrial (lower, red line), user (middle blue line) and total plastics (top black line). Full details for results of statistical tests for trends are available in Table 4. n.s. means that the test result is not significant. Trendlines are shown as solid line when significant, dashed when non-significant. 
Younger fulmars (the 'non-adult' category which includes first year juveniles, second year birds and immatures up to several years of age), have consistently higher levels of ingested plastics than adult birds. Nevertheless, in Fulmar-TV monitoring, all age groups are combined on the assumption that in the long-term, there will be no major directional change in the age-composition of beached birds. Fig. 4 illustrates age related variations in our monitoring data: in geometric means, the persistent difference in plastic loads between adults and non-adults is very clear. However, both age groups follow, at a different level, a very similar pattern, which strengthens the validity of the monitoring approach combining data for all birds. The graph shows similar drop for recent running 5-year averages in both age groups. These changes are not always evidenced in the statistical tests over recent periods, but do support the conclusion of a downward trend in the mass of plastics ingested by fulmars off the Dutch coast.

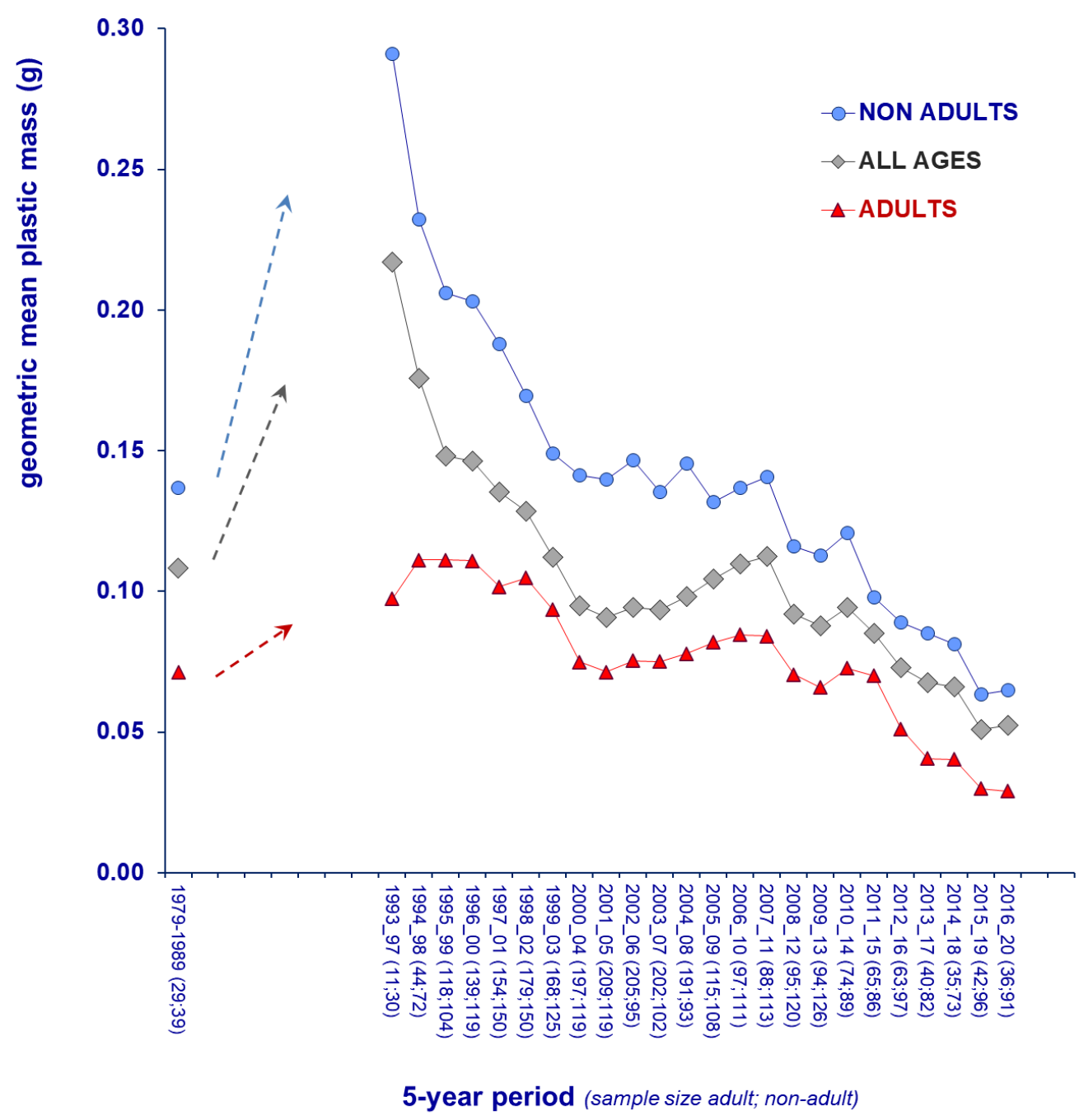

Figure 4. Geometric mean mass of plastics in stomachs of beached fulmars from the

Netherlands 1979-2020 for all age groups combined (grey diamonds; including birds of unknown age), adult birds (red triangles) and non-adults (blue circles), with respective sample sizes in brackets in the $x$ axis labels. Full sample sizes available in e.g. Table 3A. Data illustrate the trends and consistency in agedifferences that allow usage of the all-age trendline in the summary. This graphic visualization does not represent a statistical trend analysis. 


\subsection{Dutch Fulmar-TV Performance}

ICES working groups (e.g. ICES-WGSE 2001, 2003), followed by OSPAR (2008, 2009), have initiated the approach in which the EcoQO metric for marine litter is expressed in terms of a percentage of birds exceeding a threshold value of plastic in the stomach. This approach is now to be replaced by the OSPAR/ EU MSFD Fulmar Threshold Value (Fulmar-TV). At first sight, one might argue that it would be easier to use an Fulmar-TV definition based on for example only the average mass of plastics. However, whether intentional or not, the 'percentage above threshold value' definition represents a simplified procedure to avoid the mathematical problems caused by a few excessive stomach contents that distort comparative analyses and averaged values. In our standard statistical testing procedures and calculations of geometric means, such problems are largely overcome by logarithmic transformation of data. This is a standard statistical procedure. However, it is not always easily conveyed to the general public, and differences between arithmetic averages versus geometric means can be confusing. The Fulmar-TV metric avoids such problems by using a classification of birds in which the exceptional stomach contents lose their influence. The newly proposed Fulmar Threshold Value now states:

"Over a period of at least five consecutive years, no more than $10 \%$ of northern fulmars (Fulmarus glacialis) in samples of at least 100 birds may exceed the level of $0.1 \mathrm{~g}$ of plastic particles in the stomach."

This new Fulmar-TV target will replace the very similar earlier OSPAR EcoQO targets In such a definition, an excessive stomach content of e.g. 10 gram of plastic does not change the metric compared to the situation in which that bird would have had for example only $0.2 \mathrm{~g}$ in its stomach. Using the same data as in earlier sections of this report, Fig. 5 illustrates the time trends in the 5-year average FTV performance of fulmars found in the Netherlands. Although the graph does indicate improvement, it also emphasizes the distance from the 10\% FTV target set by OSPAR. Over the integrated recent 5-year period 2016-2020, 39\% of Dutch fulmars exceed the 0.1 gram critical

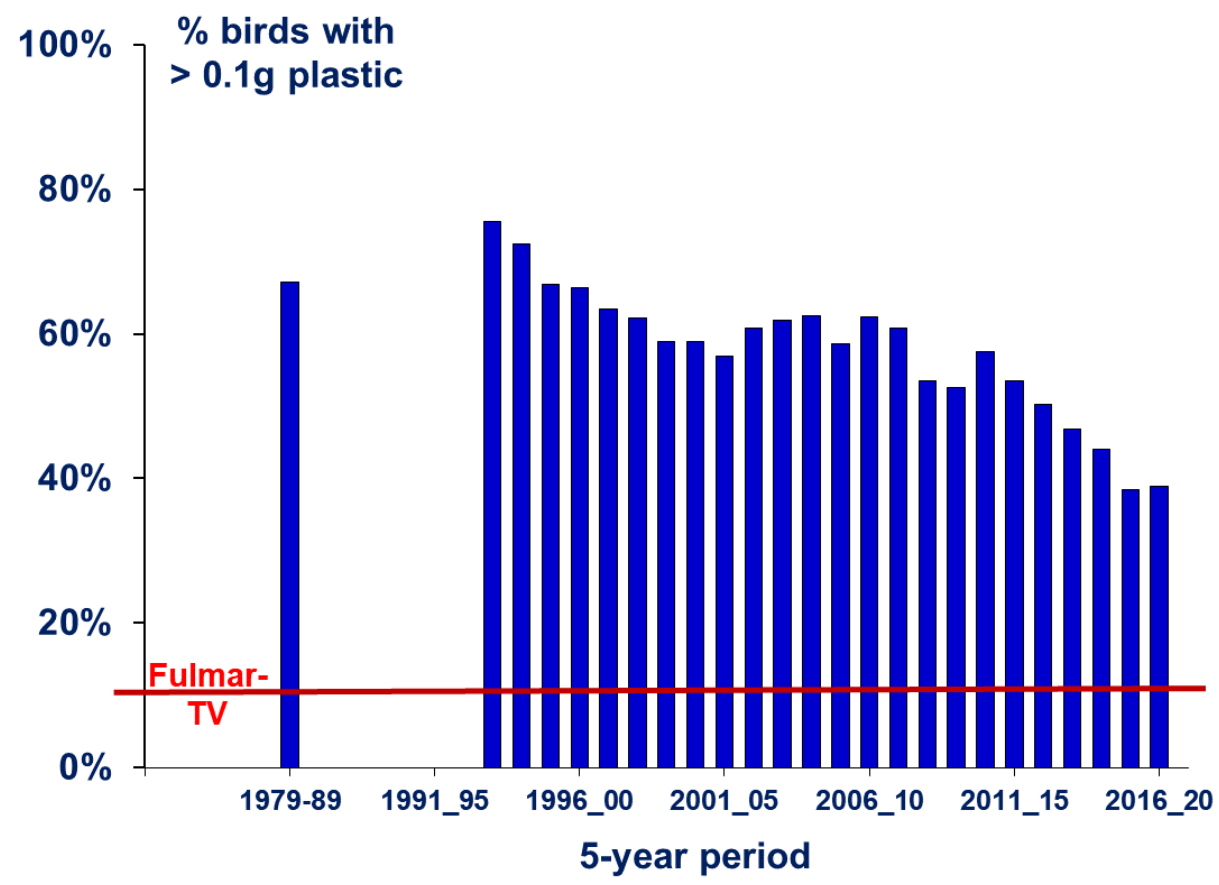

Figure 5. Fulmar-TV performance of fulmars in the Netherlands over running 5-year periods up to 2020. Data for the 1980s were combined due to relatively small sample size. The red line illustrates the OSPAR Fulmar-TV to reduce the percentage of birds with more than $0.1 \mathrm{gram}$ of plastic in the stomach to below $10 \%$. This graphic visualization does not represent a statistical trend analysis.

FTV level of $0.1 \mathrm{~g}$ of plastic in the stomach, which is, together with the previous 5-year period (20152019) the best on record but still substantially above the $10 \%$ target.

As done in Fig. 4 for ingested mass, looking at the EcoQ Performances for separate age groups may provide further confidence in findings. Adult birds and non-adults, in spite of their consistent different level of plastic ingestion, show strongly comparable trends over time and thus support reliability of the trend for all birds combined (Fig.6). 


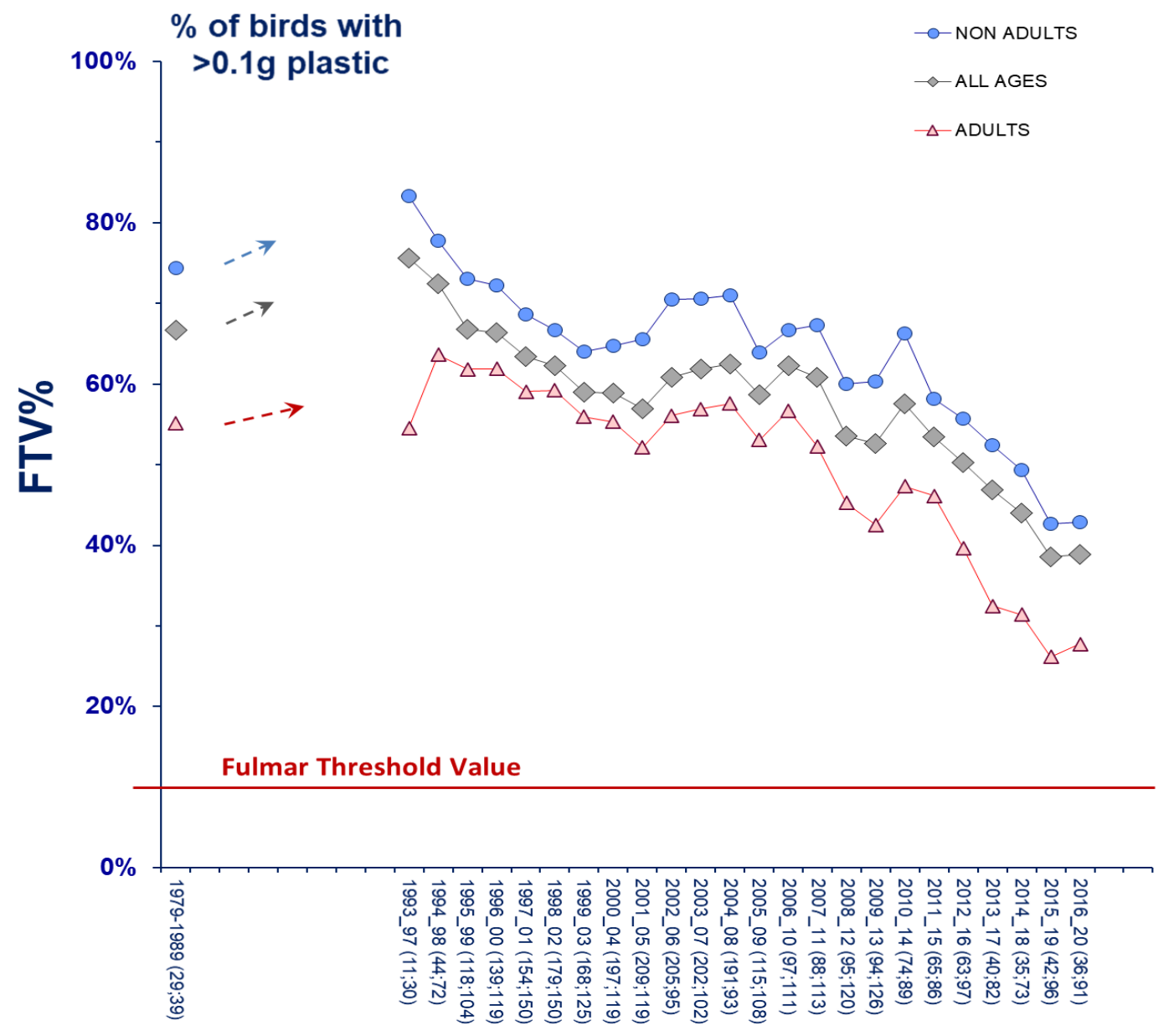

5-year period (sample size adult; non-adult)

Figure 6. Trend in Fulmar-TV Performance of different age classes of beached fulmars from the Netherlands 1979-2020. Trendlines for all birds combined (grey diamonds, including birds of unknown age), for adult birds (red triangles) and for non-adults (blue circles). This graphic visualization is based on a single data-point for the 1980s and overlapping running 5-year averages in later periods. Periods with less than 10 birds in the sample during the late 1980s and early 1990s are not shown in the graph. This visualization in itself does not represent a statistical trend analysis. 


\subsection{Modelling and forecasting future Fulmar-TV Performance}

Policy makers involved in the OSPAR and MSFD process have asked to provide models that might predict plastic ingestion rates by fulmars in future years. Such information could assist in focused planning of actions aiming at reaching policy targets by specific dates.

In our approach of evaluating trends over a period of the most recent ten years, the statistical procedure then has only ten data-points available for statistical tests and modelling. Simple linear regression cannot be applied to this type of data. The data need to be considered in a GLM approach (Generalized Linear Modelling), more specifically in a logistic analysis dedicated for binomial distributions (birds yes or no above threshold) and using logit transformed data.

In principle, significance of the model should be the decision rule to whether or not use the trend for calculating future predicted values. In our analysis of data up to 2017 (Van Franeker \& Kühn 2018), the ten-year binomial regression was not significant, but the same type of analysis over a longer period of data since the start of the SNS project in 2002 was significant $(p=0.003)$. That analysis predicted that the first year of the long-term Fulmar-TV target could be reached between years 2055 to 2060 . In the next data analysis 2002-2018, the trend was highly significant $(p<0.001)$ and predicted reaching the target by year 2049. The significant decline is over the 2002-2019 suggested the target might be reached in year 2048. The current analysis (2002-2020) confirms, that the target could be reached in 2049 (Figure 7A.; Table 5A).

Figure 7B and Table 5B have been added to this report to show the analysis for the full period of Dutch fulmar monitoring since 1979. The long term graph reflects the character of the logistic model applied, which assumes a sigmoid pattern of slow changes near the $0 \%$ minimum and $100 \%$ maximum but potentially more rapid change in the period in between.

The traditional linear regressions of ingested plastic mass support the results of the logistic regressions of annual FTV performance. Possibly the logistic analysis of annual data is somewhat quicker in assigning statistical significance than the linear regression of individual data, and it is advised to continue both types of analyses, with the focus on the recent 10-year period for ingested plastic mass, and a focus on the longer SNS period since 2002 for the binomial data of annual FTV performances. Logistic models for just 10 data years are strongly influenced by individual years which will cause frequent change in statistical significance and thus in variable future predictions.

It has to be emphasized that a predicted trend of reaching target by a specific year does not imply that no further action is needed. The model prediction is not based on a status-quo, but on the current rate of change. We assume the observed change to be the result of increased policy measures and improved awareness and behaviour. This implies that the predicted future change will require further new policy measures and further changes in awareness and behaviour. Without extra effort, it is unlikely that the FTV target could be reached in the predicted time period. 
FTV Performance - Netherlands

Observed 2002-2020 and modelled 2002-2060

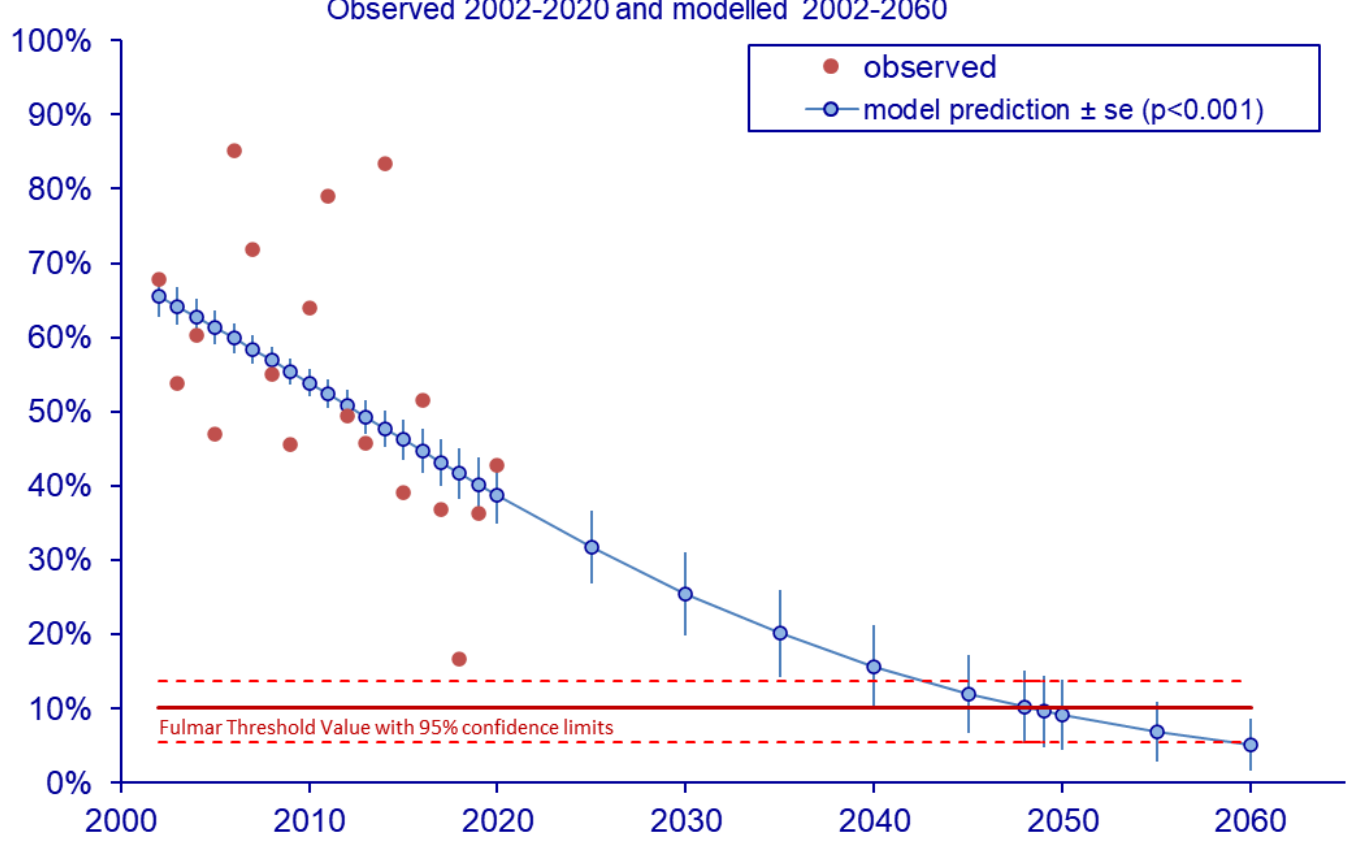

FTV Performance - Netherlands

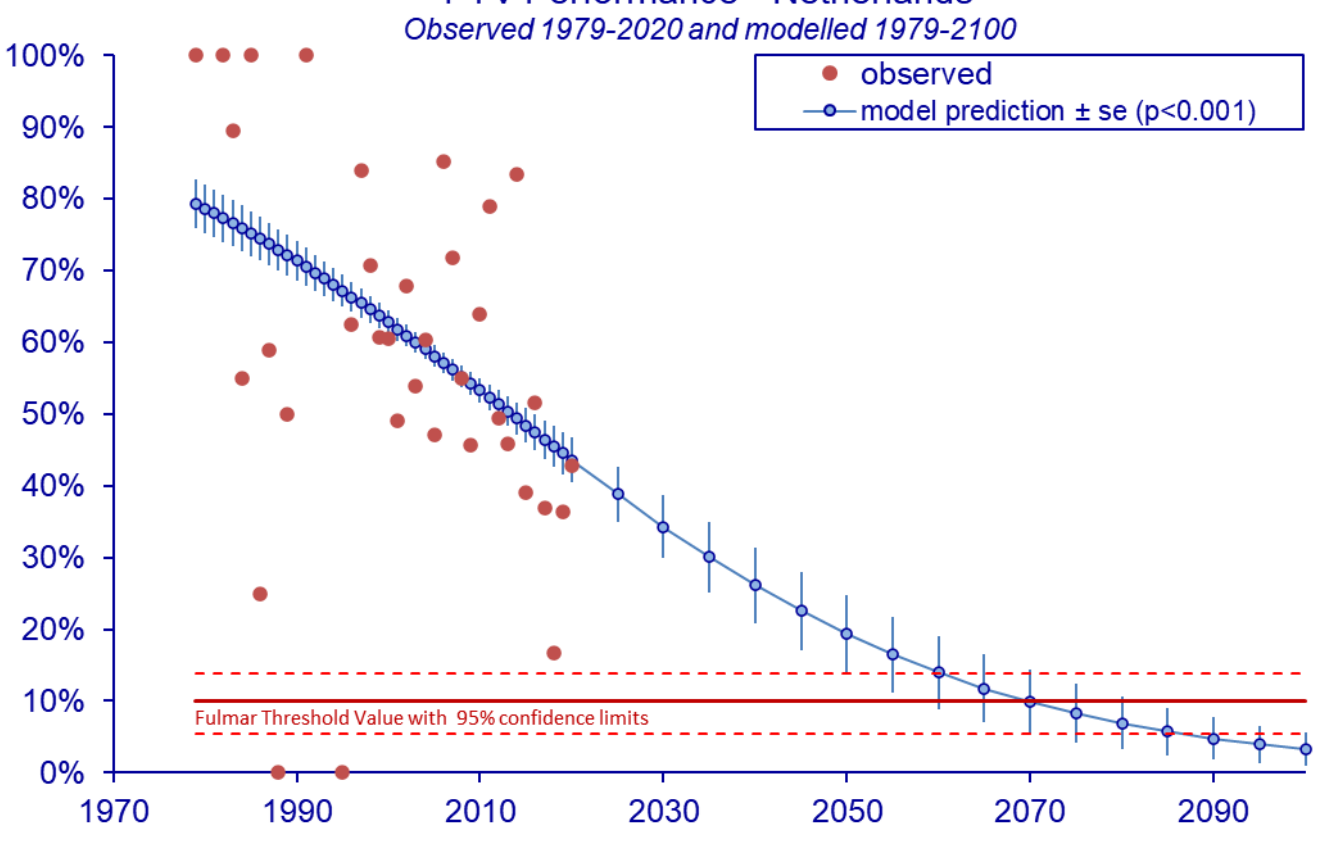

Figure 7. Predicted trajectory to the OSPAR long-term Fulmar-TV target for plastics ingested by Fulmars in Dutch offshore waters, based on a logistic binomial model from annual EcoQ performances. A: model based on observed FTV performance over the 19-year period 2002-2020 $(p<0.001)$. B: model based on observed FTV performance over the 42-year period 1979-2020 $(p<0.001)$. 
Table 5. Observed and modelled data in the logistic binomial models based on annual

Fulmar-TV performances observed over A: the 19-year Save the North Sea period 2002-2020

$(p<0.001)$ and B: the full 42-year period for Dutch data 1979-2020 $(p<0.001)$. These tables are the source for Figure 7.

A.

\section{modelling period from start of the SNS project = year 2002}

\begin{tabular}{|c|c|c|c|c|}
\hline \multicolumn{5}{|c|}{ SOURCE DATA FOR LOGISTIC REGRESSION } \\
\hline Year & $\begin{array}{c}\text { sample } \\
\text { size }\end{array}$ & (\% adult) & $\begin{array}{c}\mathrm{nr} \text { of birds } \\
\text { with }>0.1 \mathrm{~g} \\
\text { plastic }\end{array}$ & $\begin{array}{l}\text { proportion } \\
\text { of birds with } \\
>0.1 \mathrm{~g} \text { plastic }\end{array}$ \\
\hline 2002 & 56 & $(54 \%)$ & 38 & $68 \%$ \\
\hline 2003 & 39 & $(56 \%)$ & 21 & $54 \%$ \\
\hline 2004 & 131 & $(80 \%)$ & 79 & $60 \%$ \\
\hline 2005 & 51 & $(68 \%)$ & 24 & $47 \%$ \\
\hline 2006 & 27 & $(62 \%)$ & 23 & $85 \%$ \\
\hline 2007 & 64 & $(45 \%)$ & 46 & $72 \%$ \\
\hline 2008 & 20 & $(58 \%)$ & 11 & $55 \%$ \\
\hline 2009 & 68 & $(40 \%)$ & 31 & $46 \%$ \\
\hline 2010 & 36 & $(46 \%)$ & 23 & $64 \%$ \\
\hline 2011 & 19 & $(37 \%)$ & 15 & $79 \%$ \\
\hline 2012 & 81 & $(46 \%)$ & 40 & $49 \%$ \\
\hline 2013 & 24 & $(42 \%)$ & 11 & $46 \%$ \\
\hline 2014 & 12 & $(64 \%)$ & 10 & $83 \%$ \\
\hline 2015 & 23 & $(30 \%)$ & 9 & $39 \%$ \\
\hline 2016 & 31 & $(18 \%)$ & 16 & $52 \%$ \\
\hline 2017 & 38 & $(31 \%)$ & 14 & $37 \%$ \\
\hline 2018 & 12 & $(50 \%)$ & 2 & $17 \%$ \\
\hline 2019 & 44 & $(34 \%)$ & 16 & $36 \%$ \\
\hline 2020 & 14 & $(8 \%)$ & 6 & $43 \%$ \\
\hline
\end{tabular}

\begin{tabular}{|c|c|}
\hline \multicolumn{2}{|c|}{ Modelled FTV performance } \\
\hline Year & $\begin{array}{c}\text { model prediction } \pm \text { se } \\
(p<0.001)\end{array}$ \\
\hline 2002 & $0.656 \pm 0.03$ \\
\hline 2003 & $0.642 \pm 0.03$ \\
\hline 2004 & $0.628 \pm 0.02$ \\
\hline 2005 & $0.614 \pm 0.02$ \\
\hline 2006 & $0.599 \pm 0.02$ \\
\hline 2007 & $0.584 \pm 0.02$ \\
\hline 2008 & $0.569 \pm 0.02$ \\
\hline 2009 & $0.554 \pm 0.02$ \\
\hline 2010 & $0.539 \pm 0.02$ \\
\hline 2011 & $0.524 \pm 0.02$ \\
\hline 2012 & $0.508 \pm 0.02$ \\
\hline 2013 & $0.493 \pm 0.02$ \\
\hline 2014 & $0.478 \pm 0.02$ \\
\hline 2015 & $0.462 \pm 0.03$ \\
\hline 2016 & $0.447 \pm 0.03$ \\
\hline 2017 & $0.432 \pm 0.03$ \\
\hline 2018 & $0.417 \pm 0.03$ \\
\hline 2019 & $0.402 \pm 0.04$ \\
\hline 2020 & $0.388 \pm 0.04$ \\
\hline 2025 & $0.318 \pm 0.05$ \\
\hline 2030 & $0.255 \pm 0.06$ \\
\hline 2035 & $0.201 \pm 0.06$ \\
\hline 2040 & $0.157 \pm 0.06$ \\
\hline 2045 & $0.120 \pm 0.05$ \\
\hline 2050 & $0.091 \pm 0.05$ \\
\hline 2055 & $0.069 \pm 0.04$ \\
\hline 2060 & $0.052 \pm 0.03$ \\
\hline 2048 & $0.102 \pm 0.05$ \\
\hline 2049 & $0.097 \pm 0.05$ \\
\hline & \\
\hline & \\
\hline
\end{tabular}


B.

modelling period complete Dutch dataset starting 1979

\begin{tabular}{|c|c|c|c|c|}
\hline \multicolumn{5}{|c|}{ SOURCE DATA FOR LOGISTIC REGRESSION } \\
\hline Year & $\begin{array}{c}\text { sample } \\
\text { size }\end{array}$ & (\% adult) & $\begin{array}{c}\text { nr of birds } \\
\text { with }>0.1 \mathrm{~g} \\
\text { plastic }\end{array}$ & $\begin{array}{l}\text { proportion } \\
\text { of birds with } \\
>0.1 \mathrm{~g} \text { plastic }\end{array}$ \\
\hline 1979 & 1 & $(0 \%)$ & 1 & $100 \%$ \\
\hline 1980 & 0 & & & \\
\hline 1981 & 0 & & & \\
\hline 1982 & 3 & $(0 \%)$ & 3 & $100 \%$ \\
\hline 1983 & 19 & $(41 \%)$ & 17 & $89 \%$ \\
\hline 1984 & 20 & $(40 \%)$ & 11 & $55 \%$ \\
\hline 1985 & 3 & $(33 \%)$ & 3 & $100 \%$ \\
\hline 1986 & 4 & $(25 \%)$ & 1 & $25 \%$ \\
\hline 1987 & 17 & $(59 \%)$ & 10 & $59 \%$ \\
\hline 1988 & 1 & $(0 \%)$ & 0 & $0 \%$ \\
\hline 1989 & 2 & $(100 \%)$ & 1 & $50 \%$ \\
\hline 1990 & 0 & & & \\
\hline 1991 & 1 & $(0 \%)$ & 1 & $100 \%$ \\
\hline 1992 & 0 & & & \\
\hline 1993 & 0 & & & \\
\hline 1994 & 0 & & & \\
\hline 1995 & 2 & $(50 \%)$ & 0 & $0 \%$ \\
\hline 1996 & 8 & $(62 \%)$ & 5 & $63 \%$ \\
\hline 1997 & 31 & $(16 \%)$ & 26 & $84 \%$ \\
\hline 1998 & 75 & $(44 \%)$ & 53 & $71 \%$ \\
\hline 1999 & 107 & $(70 \%)$ & 65 & $61 \%$ \\
\hline 2000 & 38 & $(58 \%)$ & 23 & $61 \%$ \\
\hline 2001 & 55 & $(37 \%)$ & 27 & $49 \%$ \\
\hline 2002 & 56 & $(54 \%)$ & 38 & $68 \%$ \\
\hline 2003 & 39 & $(56 \%)$ & 21 & $54 \%$ \\
\hline 2004 & 131 & $(80 \%)$ & 79 & $60 \%$ \\
\hline 2005 & 51 & $(68 \%)$ & 24 & $47 \%$ \\
\hline 2006 & 27 & $(62 \%)$ & 23 & $85 \%$ \\
\hline 2007 & 64 & $(45 \%)$ & 46 & $72 \%$ \\
\hline 2008 & 20 & $(58 \%)$ & 11 & $55 \%$ \\
\hline 2009 & 68 & $(40 \%)$ & 31 & $46 \%$ \\
\hline 2010 & 36 & $(46 \%)$ & 23 & $64 \%$ \\
\hline 2011 & 19 & $(37 \%)$ & 15 & $79 \%$ \\
\hline 2012 & 81 & $(46 \%)$ & 40 & $49 \%$ \\
\hline 2013 & 24 & $(42 \%)$ & 11 & $46 \%$ \\
\hline 2014 & 12 & $(64 \%)$ & 10 & $83 \%$ \\
\hline 2015 & 23 & $(30 \%)$ & 9 & $39 \%$ \\
\hline 2016 & 31 & $(18 \%)$ & 16 & $52 \%$ \\
\hline 2017 & 38 & $(31 \%)$ & 14 & $37 \%$ \\
\hline 2018 & 12 & $(50 \%)$ & 2 & $17 \%$ \\
\hline 2019 & 44 & $(34 \%)$ & 16 & $36 \%$ \\
\hline 2020 & 14 & $(8 \%)$ & 6 & $43 \%$ \\
\hline
\end{tabular}

\begin{tabular}{|c|c|}
\hline \multicolumn{2}{|c|}{ Modelled FTV performance } \\
\hline Year & $\begin{array}{c}\text { model prediction } \pm \text { se } \\
(p<0.001)\end{array}$ \\
\hline 1979 & $0.793 \pm 0.03$ \\
\hline 1980 & $0.786 \pm 0.03$ \\
\hline 1981 & $0.780 \pm 0.03$ \\
\hline 1982 & $0.773 \pm 0.03$ \\
\hline 1983 & $0.766 \pm 0.03$ \\
\hline 1984 & $0.759 \pm 0.03$ \\
\hline 1985 & $0.752 \pm 0.03$ \\
\hline 1986 & $0.744 \pm 0.03$ \\
\hline 1987 & $0.737 \pm 0.03$ \\
\hline 1988 & $0.729 \pm 0.03$ \\
\hline 1989 & $0.721 \pm 0.03$ \\
\hline 1990 & $0.714 \pm 0.03$ \\
\hline 1991 & $0.705 \pm 0.03$ \\
\hline 1992 & $0.697 \pm 0.03$ \\
\hline 1993 & $0.689 \pm 0.02$ \\
\hline 1994 & $0.681 \pm 0.02$ \\
\hline 1995 & $0.672 \pm 0.02$ \\
\hline 1996 & $0.663 \pm 0.02$ \\
\hline 1997 & $0.655 \pm 0.02$ \\
\hline 1998 & $0.646 \pm 0.02$ \\
\hline 1999 & $0.637 \pm 0.02$ \\
\hline 2000 & $0.628 \pm 0.02$ \\
\hline 2001 & $0.618 \pm 0.02$ \\
\hline 2002 & $0.609 \pm 0.02$ \\
\hline 2003 & $0.600 \pm 0.01$ \\
\hline 2004 & $0.590 \pm 0.01$ \\
\hline 2005 & $0.581 \pm 0.01$ \\
\hline 2006 & $0.571 \pm 0.01$ \\
\hline 2007 & $0.562 \pm 0.02$ \\
\hline 2008 & $0.552 \pm 0.02$ \\
\hline 2009 & $0.543 \pm 0.02$ \\
\hline 2010 & $0.533 \pm 0.02$ \\
\hline 2011 & $0.523 \pm 0.02$ \\
\hline 2012 & $0.513 \pm 0.02$ \\
\hline 2013 & $0.504 \pm 0.02$ \\
\hline 2014 & $0.494 \pm 0.02$ \\
\hline 2015 & $0.484 \pm 0.02$ \\
\hline 2016 & $0.474 \pm 0.03$ \\
\hline 2017 & $0.465 \pm 0.03$ \\
\hline 2018 & $0.455 \pm 0.03$ \\
\hline 2019 & $0.445 \pm 0.03$ \\
\hline 2020 & $0.436 \pm 0.03$ \\
\hline 2025 & $0.388 \pm 0.04$ \\
\hline 2030 & $0.343 \pm 0.04$ \\
\hline 2035 & $0.301 \pm 0.05$ \\
\hline 2040 & $0.261 \pm 0.05$ \\
\hline 2045 & $0.225 \pm 0.05$ \\
\hline 2050 & $0.193 \pm 0.05$ \\
\hline 2055 & $0.165 \pm 0.05$ \\
\hline 2060 & $0.139 \pm 0.05$ \\
\hline 2065 & $0.118 \pm 0.05$ \\
\hline 2070 & $0.099 \pm 0.04$ \\
\hline 2075 & $0.083 \pm 0.04$ \\
\hline 2080 & $0.069 \pm 0.04$ \\
\hline 2085 & $0.058 \pm 0.03$ \\
\hline 2090 & $0.048 \pm 0.03$ \\
\hline 2095 & $0.040 \pm 0.03$ \\
\hline 2100 & $0.033 \pm 0.02$ \\
\hline
\end{tabular}




\section{Concluding remarks}

Following rapid changes in plastic ingestion by fulmars in the North Sea during the 1980s and 1990s, patterns from the early 2000s were not very clear. However, gradually it is becoming evident that plastic abundance in fulmar stomachs is decreasing slowly but at a statistically significant or near significant rate depending on the length of period evaluated and the specific statistics used.

It is difficult to pinpoint specific events that triggered the strong increase in consumer plastics and simultaneous decrease in industrial plastics from the 1980s to the 1990s, nor can we identify a clear background for the subsequent sharp decrease in user plastics during the late 1990 s.

The more gradual change since early 2000s likely reflects media attention and public awareness of the existence of oceanic 'garbage patches' and 'plastic soup' which started with the publication on the North Pacific gyre by Moore et al. (2001). The added element of micro- or nano-sized plastics ingested by marine organisms that could physically or chemically find their way into human food, has certainly led to increased concern and awareness, and has led to a range of dedicated policies and actions by authorities, industry and general public. These appear to gradually take effect.

If current rates of change persist, the first year of reaching the long-term Fulmar Threshold Value target (in which the proportion of fulmars with more than $0.1 \mathrm{~g}$ of plastic in the stomach remains under $10 \%$ ) may be reached in the Netherlands in year 2049. In the current 5-year period (20162020) among 139 stomachs of beached fulmars from the Netherlands, 39\% exceed the $0.1 \mathrm{~g}$ level. Plastics are present in $93 \%$ of fulmars and the average number of plastic particles per individual fulmar is 22.5 with a combined average plastic mass of $0.21 \mathrm{~g}$.

For the shorter-term policy goals, tendency in international discussions is that intermediate assessments should provide evidence of 'significant improvement'. The year 2020 is of major relevance for the GES in the EU MSFD. Our models indicate that continued significant improvement implies that Fulmar-TV Performance by the year 2020 should be at most $38 \%$, and $25 \%$ by the year 2030 (Fig. 7A; Table 5A).

It is important to remain aware that the predicted trend does not imply no further action is needed. The model prediction is not based on a status-quo, but on the current rate of change. We assume that change to be the result of increased policy measures and improved awareness and behaviour. This implies that the predicted future change will require further new policy measures and further improvements in awareness and behaviour. Without extra effort, it is unlikely that the Fulmar-TV target could be reached in the predicted time period.

\section{CONCLUSION}

Stomach contents of fulmars beached in the Netherlands indicate that the marine litter situation off the Dutch coast is gradually improving. Currently (2016-2020), 93\% of the fulmars has some plastic in the stomach. The average number of plastic particles is 22.5 per bird, weighing $0.21 \mathrm{gram}$. Among Dutch fulmars $39 \%$ exceed the $0.1 \mathrm{~g}$ level of plastic whereas the long-term policy target is that this should be below $10 \%$. Trend modelling indicates that observed improvements are slow but statistically significant, and that the OSPAR Fulmar-TV may be reached by the year 2049 if current rates of improvement persist. 


\section{Acknowledgements}

Fulmar monitoring in the Netherlands is supported financially by the Netherlands Ministry of Infrastructure and Waterways (I\&W). The concept an EcoQO based on the abundance of plastics in seabird stomachs was initiated by the ICES Working Group on Seabird Ecology and guided in several workgroups within ICES and OSPAR. The EU Interreg IIIB North Sea program supported the work in the 2002-2004 Save the North Sea project. The work has also been funded by the NYK Group Europe Ltd and Chevron Upstream Europe.

Beached fulmars are mainly collected by volunteers without whom a project such as this is impossible. Below is a list of beach surveyors that contributed to the collection of beached fulmars. If people find that their name or group is listed incorrectly, or worse, not at all, our sincere apologies and please take up contact.

A van der Spoel, A Varkevisser, Ad van den Berge, Albert van den Ende, Alma de Groot, André Meijboom, Annemarie Mewe, Annet de Willigen, Anthony James, Arjen Dijkstra, Arnold Gronert, Arnoud Heikens, Arnout de Vries, Arthur Oosterbaan, Barend Kuiken, Bart Ebbinge, Ben Brugge, Bert Winters, Bezoekerscentrum Nat. Park Schiermonnikoog, BJ Bulsink, Bob Loos, Boogaart, Bram Fey, Buijtelaar, C Boele, Carl Zuhorn, CDI Lelystad, Cees Baart, Cees Swennent, Cees van Hoven, Chris Braat, Chris Winter, Christine Fabricius, CJ de Graaf, Coby Kuiken, Daphna Lavy, De Windbreker Petten, Dick Schermer, Dick Veenendaal, Dierenambulances Den Haag, Velsen, Dirk Bruin, Dirk Kuikent, Dirk Moerbeek, Dook Vlugt, ECOMARE, E-Connection, Eddie Douwma, Edward Soldaatt, Elisa Bravo Rebolledo, Ep van Hijum, Esther de Jong, Faunavisie, Floor Arts DPM, Florian Müller, Folkert Janssens, Frank van den Ende, Frank Willems, Frits-Jan Maas, G Fuchs, GJ Bruin, Guido Keijl, Guus van Duin, H de Groot, H Horn, Hans Schekkerman, Hans Spoelstra, Hans Verdaat, Hauke Flores, Hein Verkade, Henk Brugget, Henk Mellema, Henk Sandee, Huib den Heijer, Ilse Kootkar, Ingrid Tulp, Jasmijn Hulleman, J Alewijn Dijkhuizen, J Appeloo, JT Kuiken, JW Vergeer, Jaap Boersma, Jaap van der Hiele, Jack van Velzen, Jacky Kuiper, Jacob de Vries, Jan den Ouden, Jan F de Jong, Jan Goedbloed, Janne Ouwehand, Jannes Heusinkveld, Jeffrey Huizenga, Jelle van Dijk, Jeroen Reneerkens, Job ten Horn, Johan Krol, Jorg Schagen, Jurgen Rotteveel, $K$ Boele, K Post, Kees Borrius, Kees Camphuysen, Kees de Graaf, Kees Kooiker, Kees Roselaar, Kees Woutersen, Klaas de Jong, Klaas van Dijk, Lars Gaedicke, Laurens Kikkert, Laurens van Kooten, Leon Kelder, LH Kuiken, M Janssen, Maarten Brugge, Maarten Platteeuw, Maarten Sluijter, Marc Kerkhove, Marc Plomp, Marco Bakker, Mardik Leopold, Maria Elisa Hobbelink, Mariëtte Smit, Marijke Barhorst, Marion Mensink, Marjolein Postma, Mark Fonds, Mark van Veen, Martin Baptist, Martin de Jong, Martin Poot, Meinte Engelmoer, Michael Hermse, Natuurmonumenten, Nicole Janinhoff, Nina Dieters, Noordwester Vlieland, P Bison, Peter de Boer, Peter Meininger, Peter Quist, Peter Spannenburg, Peter van Horssen, Pierre Bonnet, Piet Zumkehr, Pieter Duin, Pieter van Klaveren, Pim Lollinga, Pim Wolff, REP Maan, Rob Dekker, Rob Mantel, Rob Strietman, Rob van Bemmelen, Rob Vink, Roel Draijer, Roeland Bom, Romke Kats, Roy de Hey, Rutger Rotscheid, Ruud Costers, Ruud van Halewijn, S Smit, Salko de Wolf. Sander Lagerveld, Sanne van den Berg-Blok, Saskia Kipp, SBB Staatsbosbeheer, SC Kipp, Sharon Lexmond, Simon de Vries, Simon Hart, Sophie Brasseur, St Damland Bergen, Stephan Kühn, Sytske Dijksen, T. Pieters, Teun Talsma, Theo Kiewiet, Theunis Piersma, Tim Oortwijn, Tim van Nus, Tom van Spanje, Tonny van Kooten, van Eck, Vogelasiel Bergen, Vogelasiel de Groot, Vogelasiel De Wulp, Vogelasiel Fugelpits, Vogelasiel Zandvoort, VogelRampenFonds Haarlem, VWG Steenloper, Wandelaar, Wiebe Boomsma, Willem Pompert, Wim de Winter, Wouter Vahl, Y de Jong, Yerko Hankmann, Yvonne Hermes 


\section{References}

Acampora, H., Lyashevska, O., Van Franeker, J.A. \& O'Connor, I. 2016. The use of beached bird surveys for marine plastic litter monitoring in Ireland. Marine Environmental Research 120: 122 129. http://dx.doi.org/10.1016/j.marenvres.2016.08.002

Avery-Gomm, S., O'Hara, P.D., Kleine, L., Bowes, V., Wilson, L.K. \& Barry, K.L. 2012. Northern fulmars as biological monitors of trends of plastic pollution in the eastern North Pacific. Marine Pollution Bulletin 64: 1776-1781. http://dx.doi.org/10.1016/j.marpolbul.2012.04.017

Avery-Gomm, S., Provencher, J.F., Liboiron, M., Poon, F.E. \& Smith, P.A. 2018. Plastic pollution in the Labrador Sea: An assessment using the seabird northern fulmar Fulmarus glacialis as a biological monitoring species. Marine Pollution Bulletin 127: 817-822. https://doi.org/10.1016/j.marpolbul.2017.10.001

Baak, J.E., Provencher, J.F. \& Mallory, M.L., 2020. Plastic ingestion by four seabird species in the Canadian Arctic: Comparisons across species and time. Marine Pollution Bulletin 158: 11386. https://doi.org/10.1016/j.marpolbul.2020.111386

Baltz, D.M. \& Morejohn, G.V. 1976. Evidence from seabirds of plastic pollution off central California. Western Birds 7: 111-112. https://www.westernfieldornithologists.org/archive/V07/7(3)\%20p0111p0112.pdf

Beaman, J., \& Bergeron, C. (Eds.) 2016. State of the Science White Paper - A Summary of Literature on the Chemical Toxicity of Plastics Pollution to Aquatic Life and Aquatic-Dependent Wildlife. EPA822-R-16-009, United States Environmental Protection Agency, Washington DC, 50pp. https://www.epa.gov/sites/production/files/2017-02/documents/tfw-trash free waters plasticsaquatic-life-report-2016-12.pdf

Blight, L.K. \& Burger, A.E. 1997. Occurrence of plastic particles in seabirds from the eastern North Pacific. Marine Pollution Bulletin 34: 232-325. http://web.uvic.ca/ mamu/pdf/Blight\%20\&\%20Burger\%201997\%20plastic\%20MPB.pdf

Bond, A.L., Provencher, J.F., Daoust, P.-Y. \& Lucas, Z.N. 2014. Plastic ingestion by fulmars and shearwaters at Sable Island, Nova Scotia, Canada. Marine Pollution Bulletin 87: 68-75 http://dx.doi.org/10.1016/j.marpolbul.2014.08.010

Booth, A.M., Hansen, B.H., Frenzel, M., Johnsen, H. \& Altin, D. 2016. Uptake and toxicity of methylmethacrylate-based nanoplastic particles in aquatic organisms. Environmental Toxicology and Chemistry 35: 1641-1649. http://dx.doi.org/10.1002/etc.3076

Bourne, W.R.P. 1976. Seabirds and Pollution. in: R. Johnston, (Ed.), Marine Pollution. Academic Press, London. pp 403-502.

Bravo Rebolledo, E.L. 2011. Threshold Levels and Size Dependent Passage of Plastic Litter in Stomachs of Fulmars. MSc thesis. Aquatic Ecology and Water Quality Management group, Wageningen, The Netherlands

Bravo Rebolledo, E.L., Van Franeker, J.A., Jansen, O.E. \& Brasseur, M.J.M. 2013. Plastic ingestion by harbour seals (Phoca vitulina) in The Netherlands. Marine Pollution Bulletin 67: 200-202. http://dx.doi.org/10.1016/j.marpolbul.2012.11.035

Brown, L.D., Cat, T.T. \& DasGupta, A. 2001. Interval Estimation for a proportion. Statistical Science 16:101-133. http://dx.doi.org/10.1214/ss/1009213286

Browne, M.A., Niven, S.J., Galloway, T.S., Rowland, S.J. \& Thompson, R.C. 2013. Microplastic moves pollutants and additives to worms, reducing functions linked to health and biodiversity. Current Biology 23: 2388-2392 http://dx.doi.org/10.1016/j.cub.2013.10.012

Browne, M.A., Underwood, A.J., Chapman, M.G., Williams, R., Thompson, R.C. \& Van Franeker, J.A. 2015. Linking effects of anthropogenic debris to ecological impacts. Proceedings Royal Society B 282: 20142929 (11pp). http://dx.doi.org/10.1098/rspb.2014.2929

Camphuysen C.J. 2019. A decline in oil rates consolidated: Monitoring and assessment of the proportion of oiled Common Guillemots in The Netherlands: winter 2018/19. NIOZ Report, RWS CIV BM 19.29, Dec 2019. Royal Netherlands Institute for Sea Research, Texel. https://www.nioz.nl/application/files/2715/7667/4263/Annual report A decline in oil rates consolida ted FINAL.pdf.

Camphuysen, C.J. 2020. Beached bird surveys in The Netherlands, winter 2019/20. NIOZ, Royal Netherlands Institute for Sea Research, Texel, The Netherlands, pp 7

CBD 2016. Marine debris: understanding, preventing and mitigating the significant adverse impacts on marine and coastal biodiversity. Technical Series No.83. Secretariat of the Convention on Biological Diversity, Montreal, 78 pages. https://www.cbd.int/doc/publications/cbd-ts-83-en.pdf

Cole, M., Lindeque, P., Fileman, E., Halsband, C. \& Galloway, T.S. 2015. The impact of polystyrene microplastics on feeding, function and fecundity in the marine copepod Calanus helgolandicus. Environmental Science and Technology 49: 1130-1137 http://dx.doi.org/10.1021/es504525u.

Danielsen, J., Van Franeker, J.A., Olsen, B. \& Bengtson, S.-A. 2010. Preponderance of mesopelagic fish in the diet of the Northern Fulmar (Fulmarus glacialis) around the Faroe Islands. Seabird 23: 66-75. http://www.seabirdgroup.org.uk/journals/seabird-23/seabird-23-66.pdf 
Day, R.H., Wehle, D.H.S. \& Coleman, F.C. 1985. Ingestion of plastic pollutants by marine birds. pp 344-386 in: R.S. Shomura and H.O. Yoshida (Eds.), Proceedings of the workshop on the fate and impact of Marine debris, 26-29 November 1984, Honolulu, Hawaii. U.S. Dep. Commerce, NOAA Tech. Memo. NMFS, NOAA-TM-NMFS-SWFC-54. http://www.st.nmfs.noaa.gov/tm/swfc/swfc054.pdf

Derraik, J.G.B 2002. The pollution of the marine environment by plastic debris: a review. Marine Pollution Bulletin 44: 842-852. https://doi.org/10.1016/S0025-326X(02)00220-5

Donnelly-Greenan, E.L., Harvey, J.T., Nevins, H.M., Hester, M.M. \& Walker, W.A. 2014. Prey and plastic ingestion of Pacific Northern Fulmars (Fulmarus glacialis rodgersii) from Monterey Bay, California. Marine Pollution Bulletin 85: 214-224. http://dx.doi.org/10.1016/j. marpolbul.2014.05.046.

EC 2000. Directive 2000/59/EC of the European Parliament and of the Council of 27 November 2000 on port reception facilities for ship-generated waste and cargo residues. Official Journal of the European Communities L 332: 81-90 (28 Dec 2000). http://eurlex.europa.eu/resource.html?uri=cellar:15945efb-a7e8-4840-ab4d0535f12692a8.0004.02/DOC 1\&format $=P D F$

EC 2008. Directive 2008/56/EC of the European Parliament and of the Council of 17 June 2008 establishing a framework for community action in the field of marine environmental policy (Marine Strategy Framework Directive). Official Journal of the European Union L 164: 19-40 (25 Jun 2008). http://eur-lex.europa.eu/legal-content/EN/TXT/PDF/?uri=CELEX:32008L0056\&from=EN

EC 2010. Commission Decision of 1 September 2010 on criteria and methodological standards on good environmental status of marine waters (notified under document C(2010) 5956) (Text with EEA Relevance) (2010/477/EU). Official Journal of the European Union L232:14-24. http://eurlex.europa.eu/legal-content/EN/TXT/PDF/?uri=CELEX:32010D0477(01)\&from =EN

EC 2017. Commission Decision (EU) 2017/848 of 17 May 2017 laying down criteria and methodological standards on good environmental status of marine waters and specifications and standardised methods for monitoring and assessment, and repealing Decision 2010/477/EU. Official Journal of the European Union L125: 43-74 (18 May 2017) https://publications.europa.eu/en/publication-detail/-/publication/a7523a58-3b91-11e7-a08e01aa75ed71a1/language-en

Edwards, R. 2005. Litter at sea means a bellyful of plastic. New Scientist 185(2481): 11. http://www.lexisnexis.com.ezproxy.library.wur.nl/hottopics/Inacademic/?verb $=$ sr\&csi $=158275 \& s r=B Y L I$ NE(edwards) $+A N D+H L E A D$ (Litter+at+sea +means $+a+$ bellyful+of +plastic) $+A N D+D A T E+I S+2005$

Endo, S., Takizawa, R., Okuda, K., Takada, H., Chiba, K., Kanehiro, H., Ogi, H., Yamashita, R. \& Date, T. 2005. Concentration of polychlorinated biphenyls (PCBs) in beached resin pellets: Variability among individual particles and regional differences. Marine Pollution Bulletin 50: 1103-1114. http://dx.doi.org/10.1016/j.marpolbul.2005.04.030

Endo, D., Yuyama, M. \& Takada, H. 2013. Desorption kinetics of hydrophobic organic contaminants from marine plastic pellets. Marine Pollution Bulletin 74: 125-131 http://dx.doi.org/10.1016/j.marpolbul.2013.07.018

EU 2019. Directive (EU) 2019/883 of the European Parliament and of the Council of 17 April 2019 on port reception facilities for the delivery of waste from ships, amending Directive 2010/65/EU and repealing Directive 2000/59/EC. Official Journal of the European Union L 151: 116-142 (7.6.2019). https://eur-lex.europa.eu/legal-content/EN/TXT/PDF/?uri=CELEX:32019L0883\&from=EN.

Foekema, E.M., De Gruijter, C., Mergia, M.T., Van Franeker, J.A., Murk, T.J. \& Koelmans, A.A. 2013. Plastic in North Sea fish. Environmental Science \& Technology 47: 8818-8824. http://dx.doi.org/10.1021/es400931b

Furness, R.W. 1985. Plastic particle pollution: accumulation by Procellariiform seabirds at Scottish colonies. Marine Pollution Bulletin 16: 103-106. https://doi.org/10.1016/0025-326X(85)90531-4

Gigault, J., Pedrono, B., Maxit, B. \& Ter Halle, A. 2016. Marine plastic litters: the unanalyzed nanofraction. Environmental Science: Nano 3: 346-350 http://dx.doi.org/10.1039/C6ENO0008H

Guse, N., Fleet, D., van Franeker, J. \& Garthe, S. 2005. Der Eissturmvogel (Fulmarus glacialis)Mülleimer der Nordsee? Seevögel 26(2): 3-12.

Guse, N., Jensen, J.-K., Turner, D.M., Rebolledo, E.B., Kühn, S., van Franeker, J.A., 2020. Detonating cord found in the stomach of a northern fulmar. SULA 28: 1-5 doi https://edepot.wur.nl/534885

Hall, K. 2000. Impacts of marine debris and oil: economic and social costs to coastal communities. KIMO, c/o Shetland Islands Council, Lerwick. 104pp.

Hatch, S.A. \& Nettleship, D.N. 1998. Northern Fulmar (Fulmarus glacialis). No. 361 (31 pp) in: A. Poole and F. Gill, (Eds.), The Birds of North America, Inc. Philadelphia, P.A.

Hauser, R., Skakkebaek, N.E., Hass, U., Toppari, J., Juul, A., Andersson, A.M., Kortenkamp, A., Heindel, J.J. \& Trasande, L. 2015. Male Reproductive Disorders, Diseases, and Costs of Exposure to Endocrine-Disrupting Chemicals in the European Union. Journal of Clinical Endocrinology \& Metabolism 100: 1267-1277. http://dx.doi.org/10.1210/jc.2014-4325

Hermabessiere, L., Dehaut, A., Paul-Pont, I., Lacroix, C., Jezequel, R., Soudant, P. \& Duflos, G. 2017. Occurrence and effects of plastic additives on marine environments and organisms: A review. Chemosphere 182: 781-793. http://dx.doi.org/10.1016/j.chemosphere.2017.05.096

Hunt, P., Sathyanarayana, S., Fowler, P.A. \& Trasande, L. 2016. Female Reproductive Disorders, Diseases, and Costs of Exposure to Endocrine Disrupting Chemicals in the European Union. The 
Journal of Clinical Endocrinology \& Metabolism 101:1562-1570. http://dx.doi.org/10.1210/jc.2015$\underline{2873}$

ICES-WGSE 2001. Report of the Working Group on Seabird Ecology. Ices Headquarters, 16-19 March 2001. ICES CM 2001/C:05. Copenhagen. 68pp http://www.ices.dk/sites/pub/CM\%20Doccuments/2001/C/C0501.pdf

ICES-WGSE 2003. Report of the Working Group on Seabird Ecology. Ices Headquarters, 7-10 March 2003. ICES CM 2003/C:03. Copenhagen. 89pp http://www.ices.dk/sites/pub/CM\%20Doccuments/2003/C/C0303.PDF

Jahnke, A., Arp, H.P.H., Escher, B.I., Gewert, B., Gorokhova, E., Kühnel, D., Ogonowski, M., Potthoff, A., Rummel, C., Schmitt-Jansen, M., Toorman, E. \& MacLeod, M. 2017. Reducing Uncertainty and Confronting Ignorance about the Possible Impacts of Weathering Plastic in the Marine Environment. Environmental Science and Technology Letters 4: 85-90. http://dx.doi.org/10.1021/acs. estlett.7b00008

Koelmans, A.A., Besseling, E., Wegner, A. \& Foekema, E.M. 2013a. Plastic as a carrier of POPs to aquatic organisms: A model analysis. Environmental Science \& Technology 47: 7812-7820 http://dx.doi.org/10.1021/es401169n

Koelmans, A.A., Besseling, E., Wegner, A. \& Foekema, E.M. 2013b. Correction to Plastic As a Carrier of POPs to Aquatic Organisms: A Model Analysis. Environmental Science \& Technology 47: 89928993 http://pubs.acs.org/doi/pdf/10.1021/es403018h

Koelmans, A.A., Besseling, E. \& Foekema, E.M. 2014. Leaching of plastic additives to marine organisms. Environmental Pollution 187: 49-54 http://dx.doi.org/10.1016/j.envpol.2013.12.013

Koelmans, A.A., Besseling, E. \& Shim, W.J. 2015. Nanoplastics in the aquatic environment. Critical review. pp 325-340 Chpt.12 In: Bergmann, M., Gutow, L., and Klages, M. (eds). Marine Anthropogenic Litter. Springer, Berlin. http://link.springer.com/book/10.1007\%2F978-3-319-16510$\underline{3}$

Koelmans, A.A., Bakir, A., Burton, G.A. \& Janssen, C.R. 2016. Microplastic as a vector for chemicals in the aquatic environment: critical review and model-supported reinterpretation of empirical studies. Environmental Science \& Technology 50: 3315-3326. http://dx.doi.org/10.1021/acs. est.5b06069

Kühn, S. 2020. Message in a belly - Plastic pathways in Fulmars. PhD degree. Wageningen Marine Research/Aquatic Ecology and Water Quality Management Wageningen, the Netherlands, pp 232 doi https://doi.org/10.18174/509638

Kühn, S. \& Van Franeker, J.A. 2012. Plastic ingestion by the Northern Fulmar (Fulmarus glacialis) in Iceland. Marine Pollution Bulletin 64: 1252-1254 http://dx.doi.org/10.1016/j.marpolbul.2012.02.027

Kühn, S., Bravo Rebolledo E.L. \& Van Franeker, J.A. 2015. Deleterious effects of litter on marine life. Pp 75-116 in: Bergmann, M., Gutow, L., and Klages, M. (Eds). Marine Anthropogenic Litter. Springer, Berlin (open access). http://dx.doi.org/10.1007/978-3-319-16510-3 4

Kühn, S. \& Van Franeker, J.A. 2020. Quantitative overview of marine debris ingested by marine megafauna. Marine Pollution Bulletin 151: xx-xx (online 110858). https://doi.org/10.1016/j.marpolbul.2019.110858

Kühn, S., Booth, A.M., Sørensen, L., Van Oyen, A. \& Van Franeker, J.A. 2020a. Transfer of additive chemicals from marine plastic debris to the stomach oil of northern fulmars. Frontiers in Environmental Science 8:138 (14pp) https://doi.org/10.3389/fenvs.2020.00138

Kühn, S., van Franeker, J.A., O'Donoghue, A.M., Swiers, A., Starkenburg, M., Van Werven, B., Foekema, E., Hermsen, E., Egelkraut-Holtus, M. \& Lindeboom, H. 2020b. Details of plastic ingestion and fibre contamination in North Sea fishes. Environmental Pollution 257: 113569 https://doi.org/10.1016/i.envpol.2019.113569.

Laist, D.W. 1987. Overview of the biological effects of lost and discarded plastic debris in the marine environment. Marine Pollution Bulletin 18(6B): 319-326. https://doi.org/10.1016/S0025$326 \times(87) 80019-X$

Laist, D.W. 1997. Impacts of marine debris: entanglement of marine life in marine debris including a comprehensive list of species with entanglement and ingestion records. pp 99-140 in: Coe, J.M. and Rogers, D.B. (Eds.). Marine debris sources, impacts and solutions. Springer Series on Environmental Management. Springer Verlag, New York. 432pp. http://plastics.earthmind.net/files/ART Laist 1997.pdf

Liu, L., Fokkink, R. \& Koelmans, A.A. 2016. Sorption of polycyclic aromatic hydrocarbons to polystyrene nanoplastic. Environmental Toxicology and Chemistry 35: 1650-1655. DOI: http://dx.doi.org/10.1002/etc.3311

Lozano, R.L. \& Mouat, J. 2009. Marine litter in the North-East Atlantic Region, Assessment and priorities for response. OSPAR/KIMO/UNEP. Biological Diversity and Ecosystems Nr 386. OSPAR, London, 127 pp. https://qsr2010.ospar.org/media/assessments/p00386 Marine Litter in the NorthEast Atlantic with addendum.pdf

Mallory, M.L., Roberston, G.J. \& Moenting, A. 2006. Marine plastic debris in northern fulmars from Davis Strait, Nunavut, Canada. Marine Pollution Bulletin 52: 813-815. https://doi.org/10.1016/j.marpolbul.2006.04.005

Mallory, M.L. 2008. Marine plastic debris in northern fulmars from the Canadian High Arctic. Marine Pollution Bulletin 56: 1486-1512. https://doi.org/10.1016/j.marpolbul.2008.04.017 
Matiddi, M., Hochsheid, S., Camedda, A., Baini, M., Cocumelli, C., Serena, F., Tomassetti, P., Travaglini, A., Marra, S., Campani, T., Scholl, F., Mancusi, M,, Amato, E., Briguglio, P., Maffucci, F., Fossi, M.C., Bentivegna, F. \& Andrea de Lucia, G. 2017. Loggerhead sea turtles (Caretta caretta): A target species for monitoring litter ingested by marine organisms in the Mediterranean Sea. Environmental Pollution 230: 199-209. http://dx.doi.org/10.1016/j.envpol.2017.06.054

MEPC 2011. Amendments to the Annex of the Protocol of 1978 relating to the International Convention for the Prevention of Pollution from Ships, 1973 (Revised MARPOL Annex V). RESOLUTION MEPC.201(62) IMO, London 12pp. http://www.imo.org/en/OurWork/Environment/PollutionPrevention/Garbage/Documents/2014\%20revisi on/RESOLUTION\%20MEPC.201(62)\%20Revised\%20MARPOL\%20Annex\%20V.pdf

Mintenig, S.M., Bauerlein, P., Koelmans, A.A., Dekker, S.C. \& Van Wezel, A. 2018. Closing the gap between small and smaller: towards a framework to analyse nano-and microplastics in aqueous environmental samples. Environmental Science: Nano 5 1640-1649. http://dx.doi.org/10.1039/C8EN00186C

Moore, C.J., Moore, S.L., Leecaster, M.K. \& Weisberg, S.B. 2001. A comparison of plastic and plankton in the North Pacific Central Gyre. Marine Pollution Bulletin 42: 1297-1300. https://doi.org/10.1016/S0025-326X(01)00114-X

Moser, M.L. \& Lee, D.S. 1992. A fourteen-year survey of plastic ingestion by western North Atlantic seabirds. Colonial Waterbirds 15: 83-94. http://dx.doi.org/10.2307/1521357

Mouat, J., Lozano, R.L. \& Bateson, H. 2010. Economic impacts of marine litter. KIMO Report September 2010. KIMO, Shetland 105pp. https://www.noordzeeloket.nl/images/Economic\%20impacts\%20of\%20marine\%20litter 1290.pdf

MSFD-TSGML 2011. Marine Litter - Technical recommendations for the implementation of MSFD requirements. Joint Research Centre - Institute for Environment and Sustainability Report EU 25009 EN. Publications Office of the EU, Luxembourg, 91pp http://dx.doi.org/10.2788/91406

MSFD-TSGML 2013. Guidance on monitoring of marine litter in European Seas - a guidance document within the Common Implementation Strategy for the Marine Strategy Framework Directive. EUR26113 EN. JRC Scientific and Policy Reports JRC83985. 128pp http://dx.doi.org/10.2788/99475

Nevins, H., Donnelly, E., Hester, M. \& Hyrenbach, D. 2011. Evidence for Increasing Plastic Ingestion in Northern Fulmars (Fulmarus glacialis rodgersii) in the Pacific. Fifth International Marine Debris Conference, Honolulu Hawaii 20-25 Mar 2011. Oral Presentation Extended Abstracts 4.b.3. 140144.

Newman, S., Watkins, E., Farmer, A., Ten Brink, P. \& Schweitzer, J.-P. 2015. The economics of marine litter. pp 367-394 Chpt.14 In: Bergmann, M., Gutow, L., and Klages, M. (Eds). Marine Anthropogenic Litter. Springer, Berlin. http://link.springer.com/book/10.1007\%2F978-3-319-16510$\underline{3}$

North Sea Ministerial Conference 2002. Bergen Declaration. Ministerial declaration of the Fifth International Conference on the Protection of the North Sea. Bergen, Norway, 20-21 March 2002. NSMC Secretariat, Bergen. 50pp. http://www.regjeringen.no/upload/kilde/md/rap/2002/0002/ddd/pdfv/156076-engelsk.pdf

Olsen, K. 2005. Havhesten - en flygende söppelbötte. Var Fuglefauna 28: 28-32.

OSPAR 2005. North Sea Pilot Project on Ecological Quality Objectives: Background Document on the Ecological Quality Objective on Oiled Guillemots. OSPAR Commission Biodiversity Series Publication Number: 2005/252, OSPAR, London 33pp. https://www.ospar.org/documents?d=7011

OSPAR 2008. Background Document for the EcoQO on plastic particles in stomachs of seabirds. OSPAR Commission, Biodiversity Series. ISBN 978-1-905859-94-8 Publication Number: 355/2008. https://www.ospar.org/documents?v=7109

OSPAR 2009. EcoQO Handbook - Handbook for the application of Ecological Quality Objectives in the North Sea. Second Edition - 2009. OSPAR Biodiversity Series Publication 307/2009. OSPAR Commission London, 65pp. https://www.ospar.org/documents? $v=7127$

OSPAR 2010a. Quality Status Report 2010. OSPAR Commission, London. 175pp. http://qsr2010.ospar.org/en/

OSPAR 2010b. The OSPAR system of Ecological Quality Objectives for the North Sea: a contribution to OSPAR's Quality Status Report 2010. OSPAR Publication 404/2009. OSPAR Commission London, en Rijkswaterstaat VenW, Rijswijk. 16pp. (Update 2010). https://qsr2010.ospar.org/media/assessments/EcoQO/EcoQO P01-16 complete.pdf

OSPAR 2015a. Guidelines for Monitoring of plastic particles in stomachs of fulmars in the North Sea area. OSPAR Commission Agreement 2015-03e (Source: EIHA 15/5/12 Add.1). 26pp. http://www.ospar.org/convention/agreements?q=fulmar.

OSPAR 2015b. Explanatory note for the data reporting format for the OSPAR common indicator on plastic particles in fulmars' stomachs. OSPAR Commission Agreement 2015-09ef 2pp. http://www.ospar.org/convention/agreements?q=fulmar.

OSPAR 2017. OSPAR Intermediate Assessment 2017. Plastic Particles in Fulmar Stomachs in the North Sea. OSPAR Assessment Portal OAP online document: https://oap.ospar.org/en/osparassessments/intermediate-assessment-2017/pressures-human-activities-v2/marine-litter/plasticparticles-fulmar-stomachs-north-sea/

OSPAR, 2019. OSPAR Committee Assessment: Plastic particles in fulmar stomachs in the North Sea. OSPAR Assessment Portal (OAP) Online Document. https://oap.ospar.org/en/ospar- 
assessments/committee-assessments/eiha-thematic-assessments/marine-litter/plastic-particles-infulmar-stomachs-north-sea/

OSPAR, 2020. Summary record of the meeting of the OSPAR Commission, videoconference 8-9 December 2020. OSPAR Convention for the Protection of the Marine Environment of the NorthEast Atlantic, London, UK, pp 23. https://www.ospar.org/meetings/archive/ospar-commission-17

Peda, C., Caccamo, L., Fossi, M.C., Cai, F., Andaloro, F., Genovese, L., Perdichizzi, A., Romeo, T. \& Maricchiolo, G. 2016. Intestinal alterations in European sea bass Dicentrarchus labrax (Linnaeus, 1758) exposed to microplastics: Preliminary results. Environmental pollution 212: 251-256. http://dx.doi.org/10.1016/j.envpol.2016.01.083.

Poon, F.E., Provencher, J.F., Mallory, M.L., Braune, B.M. \& Smith, P.A. 2017. Levels of ingested debris vary across species in Canadian Arctic seabirds. Marine Pollution Bulletin 116: 517-520. http://dx.doi.org/10.1016/j.marpolbul.2016.11.051

Provencher, J.F., Gaston, A.J. \& Mallory, M.L. 2009. Evidence for increased ingestion of plastics by northern fulmars (Fulmarus glacialis) in the Canadian Arctic. Marine Pollution Bulletin 58: 10921095. https://doi.org/10.1016/j.marpolbul.2009.04.002

Provencher, J.F., Bond, A.L., Avery-Gomm, S., Borrelle, S.B., Bravo Rebolledo, E.L., Hammer, S., Kühn, S., Lavers, J.L., Mallory, M.L., Trevail, A. \& Van Franeker, J.A. 2017. Quantifying ingested debris in marine megafauna: a review and recommendations for standardization. Analytical Methods 9: 1454-1469. http://dx.doi.org/10.1039/C6AY02419J

Ribeiro, F., Garcia, A.R., Pereira, B.P., Fonseca, M., Mestre, M.C., Fonseca, T.G., Ilharco, L.M. \& João Bebianno, M.J. 2017. Microplastics effects in Scrobicularia plana. Marine Pollution Bulletin 122: 379-391. https://doi.org/10.1016/j.marpolbul.2017.06.078

Robards, M.D., Piatt, J.F. \& Wohl, K.D. 1995. Increasing frequency of plastic particles ingested by seabirds in the subarctic North Pacific. Marine Pollution Bulletin 30: 151-157.

Rochman, C.M., Hoh, E., Kurobe, T. \& Teh, S.J. 2013. Ingested plastic transfers hazardous chemicals to fish and induces hepatic stress. Scientific Reports 3, 3263. 7pp http://dx.doi.org/10.1038/srep03263

Rochman, C.M., Kurobe, T., Flores, I. \& Teh, S.J. 2014a. Early warning signs of endocrine disruption in adult fish from the ingestion of polyethylene with and without sorbed chemical pollutants from the marine environment. Science of the Total Environment 493: 656-661 http://dx.doi.org/10.1016/j.scitotenv.2014.06.051.

Rochman, C.M., Lewison, R.L., Eriksen, M., Allen. H., Cook, A.-M. \& Teh, S.J. 2014b. Polybrominated diphenyl ethers (PBDEs) in fish tissue may be an indicator of plastic contamination in marine habitats. Science of The Total Environment, Volumes 476-477: 622-633 http://dx.doi.org/10.1016/j.scitotenv.2014.01.058

Rochman, C.M., Browne, M.A., Underwood, A.J., Van Franeker, J.A., Thompson, R.C. Amaral-Zettler, L. 2016. The ecological impacts of marine debris: unraveling the demonstrated evidence from what is perceived. Ecology 97: 302-312. http://www.esajournals.org/doi/pdf/10.1890/14-2070.1.

Ryan, P.G. 2008. Seabirds indicate changes in the composition of plastic litter in the Atlantic and south-western Indian Oceans. Marine Pollution Bulletin 56: 1406-1409. https://doi.org/10.1016/j.marpolbul.2008.05.004

Ryan, P.G., Moore, C.J., Van Franeker, J.A. \& Moloney, C.L. 2009. Monitoring the abundance of plastic debris in the marine environment. Philosophical Transactions of the Royal Society B 364: 19992012. http://dx.doi.org/10.1098/rstb.2008.0207.

Save the North Sea, 2004. Reduce marine litter: 'Save the North Sea' project results. Keep Sweden Tidy Foundation, Stockholm, 17pp. https://www.researchgate.net/publication/343080543 Reduce Marine Litter Save the North Sea Pro ject Results

Sergeant, E.S.G., 2019. Epitools epidemiological calculators. Ausvet Pty Ltd. http://epitools.ausvet.com.au

Snaethorsson, A.Ö. 2018. Plast í meltingarvegi fýla við Ísland árið 2018. Náttúrustofa Vestfjarða Report NNA-1808, Husavik, Iceland, pp 9 https://ust.is/library/Skrar/1808\%20Plast\%20\%C3\%AD\%20meltingarvegi\%20f\%C3\%BDla\%20vi \%C3\%B0\%20\%C3\%8Dsland\%20\%C3\%A1ri\%C3\%B0\%202018.pdf

Snaethorsson, A.Ö. 2019. Plast í meltingarvegi fýla við Ísland árið 2019. Náttúrustofa Vestfjarða Report NNA-1904, Húsavík, Iceland, pp 11 https://www.ust.is/library/Skrar/Atvinnulif/Haf-ogvatn/Plast $\% 20 \%$ C3\%AD\%20meltingarvegi\%20f\%C3\%BDla\%20vi\%C3\%B0\%20\%C3\%8Dsland\%2 0\%C3\%A1ri\%C3\%B0\%202019.pdf

Snaethorsson, A.Ö. 2021. Plast í meltingarvegi fýla við Ísland árið 2020. Náttúrustofa Norðausturlands Report NNA-2101, Húsavík, Iceland, pp 9. https://nna.is/wp-content/uploads/2021/03/NNA-2101Plast-i-meltingarvegi-fyla-vid-Island-arid-2020.pdf

Tanaka, K., Takada, H., Yamashita, R., Mizukawa, K., Fukuwaka, M. \& Watanuki, Y. 2013. Accumulation of plastic-derived chemicals in tissues of seabirds ingesting marine plastics. Marine Pollution Bulletin 69: 219-222. http://dx.doi.org/10.1016/j.marpolbul.2012.12.010

Tanaka, K., Takada, H., Yamashita, R., Mizukawa, K., Fukuwaka, M.-A. \& Watanuki, Y. 2015. Facilitated leaching of additive-derived PBDEs from plastic by seabirds' stomach oil and 
accumulation in tissues. Environmental Science and Technology 49: 11799-11807. http://dx.doi.org/10.1021/acs. est.5b01376

Tanaka, K., Van Franeker, J.A., Deguchi, T. \& Takada, H. 2019. Piece-by-piece analysis of additives and manufacturing byproducts in plastics ingested by seabirds: implication for risk of exposure to seabirds. Marine Pollution Bulletin 145: 36-41.https://doi.org/10.1016/j.marpolbul.2019.05.028

Tanaka, K., Watanuki, Y., Takada, H., Ishizuka, M., Yamashita, R., Kazama, M., Hiki, N., Kashiwada, F., Mizukawa, K., Mizukawa, H., Hyrenbach, D., Hester, M., Ikenaka, Y., Nakayama, S.M.M. 2020. Accumulation of plastic-derived chemicals into seabird tissues. Current Biology 30: 723-728 https://doi.org/10.1016/j.cub.2019.12.037

Terepocki, A.K., Brush, A.T., Kleine, L.U., Shugart, G.W. \& Hodum, P. 2017. Size and dynamics of microplastic in gastrointestinal tracts of Northern Fulmars (Fulmarus glacialis) and Sooty Shearwaters (Ardenna grisea). Marine Pollution Bulletin 116: 143-150. https://doi.org/10.1016/j.marpolbul.2016.12.064

Teuten, E.L., Rowland, S.J., Galloway, T.S. \& Thompson, R.C. 2007. Potential for Plastics to Transport Hydrophobic Contaminants. Environmental Science and Technology 41: 7759-7764 http://dx.doi.org/10.1021/es071737s

Teuten, E. L., Saquing, J.M., Knappe, D.R.U., Barlaz, M.A., Jonsson, S., Björn, A., Rowland, S.J., Thompson, R.C., Galloway, T.S., Yamashita, R., Ochi, D., Watanuki, Y., Moore, C., Viet, P.H., Tana, T.S., Prudente, M., Boonyatumanond, R., Zakaria, M.P., Akkhavong, K., Ogata, Y., Hirai, H., Iwasa, S., Mizukawa, K., Hagino, U., Imamura, A., Saha, M. \& Takada, H. 2009. Transport and release of chemicals from plastics to the environment and to wildlife. Philosophical Transactions of the Royal Society B 364: 2027-2045 http://dx.doi.org/10.1098/rstb.2008.0284

Thompson, R.C., Moore, C.J., vom Saal, F.S. \& Swan, S.H. (Eds.) 2009. Plastics, the environment and human health. Philosophical Transactions of the Royal Society B 364 (nr 1526 Theme Issue) pages 1969-2166. http://rstb.royalsocietypublishing.org/content/364/1526

Thompson, R.C., Olsen, Y., Mitchell, R.P., Davis, A., Rowland, S.J., John, A.W.G., McGonigle. D. \& Russell, A.E. 2004. Lost at sea: Where is all the plastic?. Science 304 (5672): 838-838. http://dx.doi.org/10.1126/science.1094559

Trevail, A.M., Gabrielsen, G.W., Kühn, S. \& Van Franeker, J.A. 2015. Elevated levels of ingested plastic in a high Arctic seabird, the northern fulmar (Fulmarus glacialis). Polar Biology 38: 975-981. (open access) http://dx.doi.org/10.1007/s00300-015-1657-4

Van Franeker, J.A. 1985. Plastic ingestion in the North Atlantic Fulmar. Marine Pollution Bulletin 16: 367-369. https://doi.org/10.1016/0025-326X(85)90090-6

Van Franeker, J.A. \& Bell, P.J. 1988. Plastic ingestion by petrels breeding in Antarctica. Marine Pollution Bulletin 19: 672-674. https://doi.org/10.1016/0025-326X(88)90388-8

Van Franeker, J.A. \& Meijboom, A. 2002. Litter NSV - Marine litter monitoring by Northern Fulmars: a pilot study. ALTERRA-Rapport 401. Alterra, Wageningen, 72pp. http://edepot.wur.nl/45695

Van Franeker, J.A. 2004. Save the North Sea - Fulmar Study Manual 1: Collection and dissection procedures. Alterra Rapport 672. Alterra, Wageningen. 38pp. http://edepot.wur.nl/40451

Van Franeker, J.A. 2005. Schoon strand Texel 2005: onderzoeksresultaten van de schoonmaakactie van het Texelse strand op 20 april 2005. Alterra speciale uitgave 2005/09. Alterra, Texel. 23pp. http://edepot.wur.nl/19515

Van Franeker, J.A., Blaize, C., Danielsen, J., Fairclough, K., Gollan, J., Guse, N., Hansen, P.L., Heubeck, M., Jensen, J.-K., Le Guillou, G., Olsen, B., Olsen, K.O., Pedersen, J., Stienen, E.W.M. \& Turner, D.M. 2011. Monitoring plastic ingestion by the northern fulmar Fulmarus glacialis in the North Sea. Environmental Pollution 159: 2609-2615. http://dx.doi.org/10.1016/j.envpol.2011.06.008

Van Franeker, J.A. 2012. Plastic ingestion by fulmars at the Faroe Islands (Plastic i færoske mallemukkers fodeindtagelse). pp 82-85 in: Jensen, J.-K., Mallemukken på Færoerne / The Fulmar on the Faroe Islands. Prenta, Torshavn. http://www.wur.nl/upload mm/e/9/f/c7466bbdd617-4a01-943f-f6e7dfa3c7ba 2012 Faroe.pdf

Van Franeker, J.A. \& the SNS Fulmar Study Group 2013. Fulmar Litter EcoQO monitoring along Dutch and North Sea coasts - Update 2010 and 2011. IMARES Report C076/13. IMARES, Texel. 61pp.

Van Franeker, J.A. \& Law, K.L. 2015. Seabirds, gyres and global trends in plastic pollution. Environmental Pollution 203: 89-96. http://dx.doi.org/10.1016/j.envpol.2015.02.034

Van Franeker, J.A. \& Kühn, S. 2018. Fulmar Litter EcoQO monitoring in the Netherlands - Update 2017. Wageningen Marine Research Report C060/18 \& RWS Centrale Informatievoorziening BM 18.20. Den Helder, 60pp. https://doi.org/10.18174/458857

Van Franeker, J.A., Bravo Rebolledo, E.L., Hesse, E., IJsseldijk, L.L., Kühn, S., Leopold, M. \& Mielke, L. 2018. Plastic ingestion by harbour porpoises Phocoena phocoena in the Netherlands: establishing a standardized method. Ambio 47: 387-397. https://doi.org/10.1007/s13280-017-1002-y

Van Franeker, J.A., Kühn, S., Kotterman, M. Kwadijk, C. 2019 Monitoring van paraffine-achtige stoffen op Nederlandse stranden en in magen van Noordse Stormvogels. Wageningen University and Research Report C001/19. Wageningen Marine Research, Den Helder, 33pp. https://doi.org/10.18174/467759.

Van Franeker, J.A. \& Kühn, S., 2019. Fulmar Litter EcoQO monitoring in the Netherlands - Update 2018. Wageningen Marine Research Report C077/19 \& RWS Centrale Informatievoorziening BM 19.16. Den Helder, 60pp. https://doi.org/10.18174/486799 
Van Franeker, J.A., Kühn, S., Anker-Nilssen, T., Edwards, E.W.J., Gallien, F., Guse, N., Kakkonen, J.E., Mallory, M.L., Miles, W., Olsen, K.O., Pedersen, J., Provencher, J., Roos, M., Stienen, E., Turner, D.M., van Loon, W.M.G.M. 2021. New tools to evaluate plastic ingestion by northern fulmars applied to North Sea monitoring data 2002-2018. Marine Pollution Bulletin 166: 112246 doi https://doi.org/10.1016/j.marpolbul.2021.112246

Venables, V.N. \& Ripley, B.D. 2002. Modern applied statistics with S, fourth ed. Springer, New York, 503pp. http://www. bagualu.net/wordpress/wpcontent/uploads/2015/10/Modern Applied Statistics With S.pdf

Vlietstra, L.S. \& Parga, J.A. 2002. Long-term changes in the type, but not the amount, of ingested plastic particles in Shor1t-tailed Shearwaters in the southeastern Bering Sea. Marine Pollution Bulletin 44: 945-955. https://doi.org/10.1016/S0025-326X(02)00130-3

Werner, S., Budziak, A., Van Franeker, J., Galgani, F., Maes, T., Matiddi, M., Nilsson, P., Oosterbaan, L., Priestland, E., Thompson, R., Veiga, J. \& Vlachogianni, T. 2016. Harm caused by marine litter. MSFD GES TG Marine Litter - Thematic Report. JRC Technical Report EUR 28317, Publications Office of the European Union, Luxembourg, 89pp. http://dx.doi.org/10.2788/19937

Yamashita, R., Tanaka, K., Yeo, B.G., Takada, H., Van Franeker, J.A., Dalton, M. \& Dale, E. 2018. Hazardous chemicals in plastics in marine environments: International Pellet Watch. The Handbook of Environmental Chemistry Springer, Berlin, Heidelberg. (Book chapter 21pp). https://doi.org/10.1007/698 2018299.

\title{
Relevant website
}

\author{
www.wur.eu/plastics-fulmars
}

(in Dutch: www.wur.nl/plastics-stormvogels)

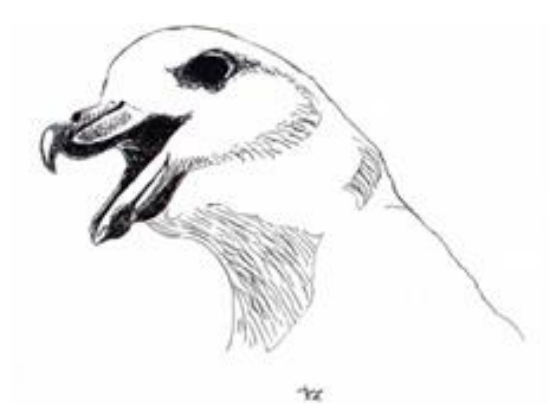




\section{Main acronyms - abbreviations}

OSPAR = Oslo/Paris convention for the Protection of the Marine Environment of the North-East Atlantic. OSPAR is the mechanism by which 15 Governments \& the EU cooperate to protect the marine environment of the North-East Atlantic. OSPAR started in 1972 with the Oslo Convention against dumping and was broadened to cover land-based sources of marine pollution and the offshore industry by the Paris Convention of 1974. These two conventions were unified, up-dated and extended by the 1992 OSPAR Convention.

OSPAR ECOQO = Ecological Quality Objective.

At the request of ministers of North Sea border states in 2002, OSPAR developed a system of measurable targets for environmental/ecological quality in the North Sea and the OSPAR area in general. There is a broad range of EcoQO's for various types of pollution (oil, fouling paints, mercury, organochlorines, litter), euthrophication, biodiversity, bycatch, fishstocks, seabird populations etc. Ingestion of plastic particles by northern fulmars is one of these.

OSPAR ICG-ML = Intersessional Correspondence Group on Marine Litter, advises higher levels in OSPAR on issues related to marine litter

EcoQ\% or EcoQ Performance = the percentage of fulmars in a sample that exceed the level of 0.1 gram of plastic in the stomach. The long term OSPAR target is that this percentage should be reduced to under $10 \%$. The EcoQO will be replaced by the 'Fulmar-TV' (see below for definition) that has now been accepted by OSPAR.

\section{EU MSFD = European Marine Strategy Framework Directive}

The aim of the European Union's MSFD is to protect more effectively the marine environment across Europe. It was adopted on 17 June 2008. In 2010 the Commission also produced a set of detailed criteria and methodological standards to help Member States implement the Marine Strategy Framework Directive. These were revised in 2017 leading to the new Commission Decision on Good Environmental Status.

\section{EU-MSFD GES = Good Environmental Status}

GES represents the MSFD concept in which a broad combination of indicators with objectives (similar to EcoQO's) indicates a healthy state of the marine environment.

MSFD-TGML = MSFD Technical Group on Marine Litter advises higher levels in EU on issues related to marine litter

\section{FTV performance $($ FTV\% $)=$ Fulmar Threshold Value Performance}

MSFD requires a data-derived threshold value (Fulmar-TV) representing 'Good Environmental Status'. Such Fulmar-TV was calculated from near-pristine Canadian Arctic data where $10.06 \%$ of fulmars exceeded the level of $0.1 \mathrm{~g}$ ingested plastic. This Fulmar-TV is almost identical to the earlier OSPAR EcoQO, arbitrarily set at $10 \%$.

\section{ICES = International Council for the Exploration of the Sea.}

ICES is a leading multidisciplinary scientific forum for the exchange of information and ideas on all aspects of marine sciences pertaining to the North Atlantic, including the adjacent Baltic Sea and North Sea, and for the promotion and coordination of marine research by scientists within its member nations. It has many workgroups, for example ICES WGSE (= Working Group on Seabird Ecology), which stood the basis of several of the OSPAR EcoQO's.

\section{KIMO = 'Kommunenes Internasjonale Miljøorganisasjon'}

$\mathrm{KIMO}$ is a local authorities international environmental organisation in the northeast Atlantic, designed to give municipalities a political voice at regional, national and international level. KIMO joins forces for healthy seas, cleaner beaches, and thriving coastal communities. KIMO was an extremely important motivator for the SNS project.

MARPOL = International Convention for the Prevention of Marine Pollution from Ships (MARPOL 73/78). This is a global convention under the International Maritime Organization (IMO). The convention has several annexes focusing at specific ship environmental issues such as e.g. oil pollution (ANNEX I) or ships garbage (ANNEX V). Most MARPOL issues are dealt with in IMO's Marine Environment Protection Committee (MEPC). 


\section{SNS $=$ Save the North Sea}

The SNS campaign ran from 2002 to 2004. It was a regional EU project which aimed at a reduction of marine litter in the North Sea through increases awareness. One of the SNS projects was to implement the fulmar plastic particle monitoring system in all countries around the North Sea. The SNS fulmar study group continued its work in an informal cooperation after the end of the formal SNS project. The SNS project was co-funded by the EU INTERREG program for cross-border cooperation, and was led by the Keep Sweden Tidy Foundation. 


\section{Quality Assurance}

Wageningen Marine Research utilises an ISO 9001:2015 certified quality management system. This certificate is valid until 15 December 2021. The organisation has been certified since 27 February 2001. The certification was issued by DNV GL. 


\section{Justification}

Report Wageningen Marine Research C068/21

Project Number: WMR project 4315100164
RWS Centrale Informatievoorziening BM 21.17

Fulmar-EcoQO-NL2020-26

The scientific quality of this report has been peer reviewed by a colleague scientist and a member of the Management Team of Wageningen Marine Research

Approved: $\quad$ Dr R.H. Jongbloed

Scientist Wageningen Marine Research

Signature:

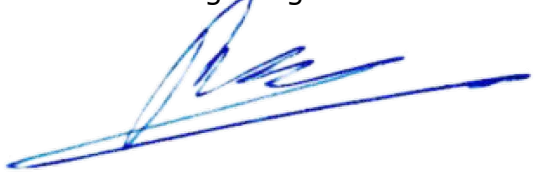

Date:

October $19^{\text {th }}, 2021$

Approved: Dr. J. Asjes

Manager Integration

Signature:

Date:

October $19^{\text {th }}, 2021$ 
Wageningen Marine Research

T +31 (0)317480900

E: marine-research@wur.nl

www.wur.eu/marine-research

Visitors' address

- Ankerpark 27, 1781 AG Den Helder

- Korringaweg 7, 4401 NT Yerseke

- Haringkade 1, 1976 CP IJmuiden
With knowledge, independent scientific research and advice, Wageningen Marine Research substantially contributes to more sustainable and more careful management, use and protection of natural riches in marine, coastal and freshwater areas.

Wageningen Marine Research is part of Wageningen University \& Research. Wageningen University \& Research is the collaboration between Wageningen University and the Wageningen Research Foundation and its mission is: 'To explore the potential for improving the quality of life' 